\author{
UNIVERSIDADE DO PoRTO \\ FACUldade DE Engenharia
}

\title{
Analysis of morphing, multi-stable structures actuated by piezoelectric patches
}

\author{
Pedro Miguel dos Santos Carvalho Portela \\ Licenciado em Engenharia Mecânica \\ pela Universidade do Porto, Faculdade de Engenharia
}

Dissertação submetida para satisfação parcial dos requisitos do grau de Mestre em Engenharia Mecânica

Dissertação realizada sob a orientação de

Professor Doutor Pedro M. P. R. C. Camanho

do Departamento de Engenharia Mecânica e Gestão Industrial

Professor Doutor Ian Paul Bond

do Departamento de Engenharia Aeroespacial da Universidade de Bristol

Porto, Julho de 2005 


\title{
Análise de estruturas de geometria variável, multi-estáveis
}

\author{
accionadas por actuadores piezoeléctricos
}

por

\author{
Pedro Miguel Portela
}

Submetido ao Departamento de Engenharia Mecânica e Gestão Industrial em Julho de 2005, para satisfação parcial dos requisitos na obtenção do grau de

Mestre em Engenharia Mecânica

na Universidade do Porto, Faculdade de Engenharia

\section{Resumo}

As estruturas de geometria variável, estruturas mórficas, adaptam activamente a sua forma reagindo a solicitações exteriores ou simplesmente por forma a aumentar o seu rendimento. As superfícies de controlo existentes actualmente em aeronaves comerciais são necessárias para manter o seu controlo e estabilidade mas não podem ser consideradas estruturas mórficas. Alguns exemplos de estruturas mórficas consistem em asas com variações de ângulo de varrimento, incidência e dihedro. Estas aplicações muito específicas e, essencialmente, do domínio da aviação militar combinam estruturas articuladas rígidas com actuadores "clássicos" do tipo hidráulico, pneumático ou electromagnético para efectivar as mudanças de forma. A pesquisa e investigação actual está a focar a sua atenção em combinações de actuadores feitos com materiais activos, do estilo piezoeléctricos, magnetoestrictivos e ligas de memória de forma, com estuturas e mecanismos complacentes. Esta combinação, quando bem conseguida, permite aumentar a fiabilidade e diminuir o consumo energético dos actuadores ao mesmo tempo que reduz drasticamente o seu tamanho. O ponto fraco reside nas estruturas subjacentes que normalmente têm uma capacidade de carga muito reduzida.

Este trabalho explora a possibilidade de criar estruturas mórficas combinando estruturas multi-estáveis com um tipo especial de actuador piezoeléctrico. Este conceito foi estudado no passado por investigadores da Virginia Polytechnic Institute and State University. Foi efectuado um esforço adicional para produzir um modelo de elementos finitos que permitisse perceber melhor os fenómenos associados. A flexibilidade do Método dos Elementos Finitos permitiu também testar uma grande variedade de configurações e assim escolher a mais eficiente. Os resultados obtidos foram verificados experimentalmente através da produção de um laminado compósito assimétrico bi-estável accionado por um actuador piezoeléctrico.

Orientadores:

Dr. Pedro P. Camanho

Universidade do Porto

Dr. Ian Paul Bond

University of Bristol 


\title{
Analysis of morphing, multi-stable structures
}

\author{
actuated by piezoelectric patches
}

\author{
by
}

\author{
Pedro Miguel Portela
}

Submitted to the Department of Mechanical Engineering
and Industrial Management

in July 2005, as partial fulfillment of the requirements for the degree of

Master in Mechanical Engineering

at the University of Porto, Faculty of Engineering

\section{Abstract}

Morphing or shape changing structures can actively modify its geometry in order to better adapt to exterior loading or to increase performance. Control surfaces in today's aircrafts are necessary for a controlled flight and cannot be considered as morphing structures. Previous designs of morphing aircraft structures include wings with variable sweep, incidence and dihedral angle. These designs combined stiff structures with mechanisms and powerful actuators to perform the desired shape change. Current research is focusing on combinations of active materials such as piezoelectric materials, magnetostrictive materials and shape memory alloys with compliant structures and mechanisms to achieve macro scale geometric changes. These combinations, when successful, allow for an increase e reliability, a reduction in power consumption as well as in actuator size. The problem areas are usually the underlying compliant structures that have a reduced load carrying capability.

This work explores the possibilities of creating a morphing structure using multi-stable structures combined with a piezoelectric actuator. This concept has been tested in the past by researchers in Virginia Polytechnic Institute and State University. Considerable effort was put here on the accurate Finite Element Modelling of such structures in order to better understand the underlying physics and to be able to design such structures. Experimental measurements and tests were performed on both the bi-stable laminates and on the morphing plate that was manufactured.

Supervisors:

Dr. Pedro P. Camanho

University of Porto

Dr. Ian Paul Bond

University of Bristol 
Analyse de structures de géométrie variable, multi stables activées

par des actuateurs piézoélectriques

\author{
par \\ Pedro Miguel Portela \\ Présentée au Département de Genie Mechanique et Gestion Industrielle en \\ julliet 2005, comme accomplissement partiel des exigences pour le degré de \\ Maître en Inginerie Mécanique
}

\title{
Resumé
}

Les structures de géométrie variable, structures morphiques, adaptent activement sa forme en réagissant aux sollicitations extérieurs ou, plus simplement, de façon à augmenter sa performance. Les surfaces de contrôle qu'on trouve actuellement dans les avions commerciaux sont nécessaires pour maintenir son contrôle et stabilité, mais ne peuvent pas être considérés structures morphiques. Quelques exemples d'estructures morphiques sont les aigles avec des variations d'angle de balayage, incidence et diédre. Ces applications très spécifiques et essentiellement du domaine de l'aviation militaire combinent des structures articulées rigides avec des actuateurs « classiques » de type hydraulique, pneumatique ou électromagnétique pour réaliser les changements de forme. L'investigation actuelle fait attention aux combinassions de actuateurs fait a partir des matériaux actifs, comme des matériaux piézoélectriques, magnétostrictifs et avec mémoire de forme, avec des structures et mécanismes accommodantes. Cette combinaison, si bien accompli, permet de augment la fiabilité et diminuer la consumation énergique des actuateurs au même temps que réduit sa taille drastiquement. Les problèmes se trouvent au niveau des structures subjacentes que ont normalement une capacité de charge très réduite. Ce travail explore la possibilité de développer des structures morphiques en combinant des structures multi stables avec un type spécial d'actuateur piézoélectrique. Ce concept a été étudié par des investigateurs de la « Virginia Polytechnic Institute and State University $\gg$. Un effort supplémentaire a été fait pour produire un model de Eléments Finits que permettait de mieux comprendre les phénomènes associés. La flexibilité de la méthode des Eléments finits a permit de essayer une grande variété de configurations et choisir la plus efficiente. Les résultats obtenus ont été vérifiés expérimentalement a travers de la production d'un laminé composite asymétrique bistable activé par un actuateur piézoélectrique.

Superviseurs:

Dr. Pedro P. Camanho

University of Porto

Dr. Ian Paul Bond

University of Bristol 


\section{Acknowledgments}

I would first like to express my gratitude to my supervisors, Dr. Pedro Camanho from the Universiy of Porto, Dr. Ian Bond and Dr. Paul Weaver from the University of Bristol for their encouragement, support and for giving me all the conditions both at the University of Bristol, where most of the experimental work was performed and at the University of Porto, where most of the analysis part of the project was done.

I would also like to thank Dr. Kevin Potter from the University of Bristol for introducing me to the world of asymmetrical laminates and for helping me in the manufacturing and testing of some specimens. A special thanks to the staff and post-graduate students of the Aerospace Engineering Department of the University of Bristol for making me feel at home away from home. I also wish to thank my fellow coworkers and friends at the Department of Mechanical Engineering of the University of Porto and at INEGI, Porto for their honest friendship and for being excellent team players.

To my parents, to whom I dedicate this work, I wish to acknowledge all that they did for me to get this far. To Carolina, for believing in me and for her constant support.

Finally, the financial support of the Portuguese Science Foundation (FCT) through the grant $\mathrm{SFRH} \backslash \mathrm{BM} \backslash 16199 \backslash 2004$ is gratefully acknowledged. 


\section{Contents}

Resumo ............................. iii

Abstract .............................. iv

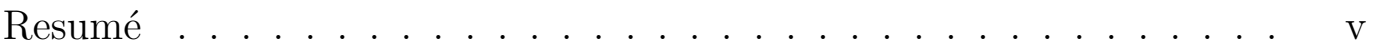

Acknowledgments ......................... vi

1 Introduction and objectives 1

1.1 Motivation . . . . . . . . . . . . . . . . . 1

1.2 Bibliographical survey . . . . . . . . . . . . . . . 4

1.3 Multistable laminates . . . . . . . . . . . . . . . . . . . 13

1.3.1 Classical lamination theory at a glance . . . . . . . . . 13

1.3.2 Laminate thermal stresses . . . . . . . . . . . . . 18

1.4 Macro-Fibre composite actuators . . . . . . . . . . . . . 21

1.4.1 Piezoelectric effect and materials . . . . . . . . . . 21

1.4.2 Macro Fibre Composite . . . . . . . . . . . . . . 23

2 Initial Exploratory Investigation $\quad 27$

3 Finite Element Simulations $\quad 33$

3.1 Introduction and scope . . . . . . . . . . . . . 33

3.2 Modelling the curvature development . . . . . . . . . . . . . 34

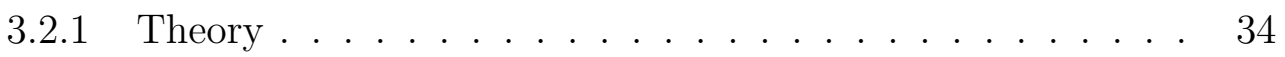

3.2 .2 Model description . . . . . . . . . . . . . . . . 36

3.2.3 Moisture effects and stress relaxation. . . . . . . . . . . 42

3.2.4 Discussion of results . . . . . . . . . . . . . . . 45

ix 
3.3 Modelling the snap-through event . . . . . . . . . . . . . . . 46

3.3 .1 Theory ...................... 46

3.3.2 Model description . . . . . . . . . . . . . . . . . . . . 48

3.3.3 Discussion of results . . . . . . . . . . . . . 52

3.4 Modelling the piezoelectric actuator . . . . . . . . . . 54

3.4.1 Theory........................... 54

3.4.2 Model description . . . . . . . . . . . . . . 57

3.4.3 Modelling the actuation effect . . . . . . . . . . . 58

3.4.4 Discussion of results . . . . . . . . . . . . . 60

3.5 Additional FE Models . . . . . . . . . . . . . . . . . . . 66

3.5.1 Rectangular $\left[0^{\circ} / 90^{\circ}\right]$ slab . . . . . . . . . . . . 66

3.5.2 Combined $\left[0^{\circ} / 90^{\circ}\right]+\left[0^{\circ} / 45^{\circ}\right]$ laminate . . . . . . . . 67

3.5.3 Chess board laminate . . . . . . . . . . . . . 68

3.5.4 Laminate with two MFC's . . . . . . . . . . . . . 71

3.6 Conclusions . . . . . . . . . . . . . . . . . 71

$\begin{array}{lll}4 & \text { Experimental results } & 73\end{array}$

$\begin{array}{llr}5 & \text { Conclusions } & 77\end{array}$

$\begin{array}{llr}6 & \text { Future Work } & 81\end{array}$

$\begin{array}{llr}7 & \text { Bibliography } & 82\end{array}$ 


\section{List of Figures}

1-1 Depiction of how birds adapt their wing geometry for different flight regimes. . . . . . . . . . . . . . . . . 2

$1-2$ The F14- Tomcat . . . . . . . . . . . . . . . . . 3

1-3 Flight profile, adapted from $[1] \ldots \ldots$

1-4 Rockwell B-1B Lancer with variable sweep wings . . . . . . . . 6

1-5 Valkyre XB-70 with rotating wingtips . . . . . . . . . . 7

1-6 Classification of morphing aircraft technology, adapted from [2] . 8

1-7 Schematics of the Active Fibre Composite actuator . . . . . . . 11

1-8 The MFC patch actuator . . . . . . . . . . . . . . . . 12

1-9 Schematics of a hollow piezoelectric fibre [3] . . . . . . . . . . . . 12

1-10 Laminate coupling relationships . . . . . . . . . . . . . . . . 18

1-11 Shapes obtained with CLT and with non-linear FEA. . . . . . . 20

1-12 Example of extreme shape change accomplished with an asymmetrical laminate. . . . . . . . . . . . . . . . . . 20

1-13 Polarization of piezoelectric crystals. . . . . . . . . . . . . . 22

1-14 Piezoelectric strains. . . . . . . . . . . . . . . . . . . 22

1-15 Layers of an MFC actuator [4] . . . . . . . . . . . . . . . 24

1-16 MFC voltage versus strain characteristics. . . . . . . . . . . 25

2-1 Manufacturing of the plates. . . . . . . . . . . . . 27

2-2 Direction in which the MFC should be bonded. . . . . . . . . 28

2-3 Preparing the laminate's surface. . . . . . . . . . . . . . . . . 28 
2-4 The bi-stable laminate, the MFC patches and the adhesive before bonding. . . . . . . . . . . . . . . . . . . . . 29

2-5 Vacuum bag used to cure the adhesive. . . . . . . . . . . . . 29

2-6 MFC patch bonded to the CFRP laminate. . . . . . . . . . . 30

2-7 Spring effect. . . . . . . . . . . . . . 30

2-8 Two MFCs bonded to the laminate. . . . . . . . . . . . . . . 31

3-1 FE model boundary conditions . . . . . . . . . . . . . . 35

3-2 Representation of the analysis steps used . . . . . . . . . . . . 37

3-3 FE plot of the deformed plate at the beginning of the snap-through step. Scale factor $=1 \ldots \ldots \ldots$. . . . . . . . . . . 37

3-4 Definition of parameters used to calculate the curvature . . . . . 38

3-5 Definition of principal curvatures directions . . . . . . . . . . . 38

3-6 FE contour plots of the three principle curvatures for the three different lay-ups . . . . . . . . . . . . . . . . . . . . . . . . 39

3-7 Comparison between FE shapes and those of the manufactured laminates. . . . . . . . . . . . . . . . 40

3-8 Boundary conditions used on the $\left[45^{\circ} /-45^{\circ}\right]_{T}$ laminate models . 41

3-9 Solution failure if load maximum is reached . . . . . . . . . . 47

3-10 The arc length method implemented in Abaqus . . . . . . . . . . 47

3-11 FE plots of the two stables states for the three different laminates 49

3-12 Evolution of the applied load with the step increment . . . . . . . 49

3-13 Measured force versus displacement. Taken from [5] . . . . . . . 50

3-14 Measured force [5] versus displacement. . . . . . . . . . . . . 51

3-15 Maximum force versus plate length plot. Polynomial fit allows to extrapolate for shorter or longer plates . . . . . . . . . . . 52

3-16 Schematics of the solution proposed by Schultz . . . . . . . . . . 55

3-17 Variation of the MFC's elastic properties with temperature . . . . 55

3-18 Development of curvature during cool down. . . . . . . . . . . 56

3-19 FE mesh of the laminate and the active area of MFC patch . . . . 58 
3-20 FE mesh of the laminate and the active area of MFC patch after the curing step . . . . . . . . . . . . . . . . . . . 59

3-21 Schematics of the insufficient actuation power . . . . . . . . 60

3-22 Design tree of the FE models analyzed . . . . . . . . . . . . 60

3-23 Typical LPF plot for a successful snap-through . . . . . . . . 62

3-24 LPF curve for the T800 fibre with M8557 actuator . . . . . . . 62

3-25 Design curve of MFC actuated bi-stables plates . . . . . . . . . 63

3-26 LPF plot for the moistened AS4 fibre laminate with an M8557 actuator .............................. 64

3-27 Contour plots of the strain field caused by the MFC . . . . . . . 65

3-28 Rectangular asymmetrical laminate. Pictures of the two stable states and the FE model. . . . . . . . . . . . . . . . . . 66

3-29 Schematics of the two stable states. . . . . . . . . . . 67

3-30 The mixed laminate before and after snap-through. . . . . . . . 68

3-31 Rectangular asymmetrical laminate. Pictures of the two stable states and the FE model. . . . . . . . . . . . . . . . . . . 69

3-32 Chess board laminate curvatures. . . . . . . . . . . . . . . 70

3-33 Laminate with two MFC bonded to each side. . . . . . . . . . . 71

4-1 Measurement of the critical loads. . . . . . . . . . . . . . . . 74

4-2 Morphing plate in both states . . . . . . . . . . . . 75 


\section{List of Tables}

1.1 Comparison of typical performance of smart materials . . . . . . . 10

1.2 MFC engineering properties . . . . . . . . . . . . . . . . . 24

3.1 Mechanical properties of the AS4-8552 and the T800-977-2 prepregs used in the FE models . . . . . . . . . . . . . . 36

3.2 Comparison between measured curvature and curvature obtained with FE . . . . . . . . . . . . . . . . . . . 40

3.3 Typical values for $a$ and $b$ parameters . . . . . . . . . . . 44

3.4 Typical values for $c$ and $d$ parameters . . . . . . . . . . . . 44

3.5 Maximum moisture content and time to reach it for three different materials . . . . . . . . . . . . . . . . . 44

3.6 Effect of moisture content on the curvature. . . . . . . . . . . . 45

3.7 Comparison of measured versus FE calculated critical loads . . . . 51

3.8 Effect of moisture content of the critical force . . . . . . . . . 52

3.9 Mechanical properties of the MFC . . . . . . . . . . 57

3.10 Artificial mechanical properties of the MFC . . . . . . . . 57

4.1 Summary of the plates manufactured in the second experimental campaign. . . . . . . . . . . . . . . . 73

4.2 Summary of the measured critical loads. . . . . . . . . . . . . . 74 


\section{List of Acronyms}

AFC

Active Fibre Composite

CFRP

Carbon Fibre Reinforced Plastics

CTE Coefficient of Thermal Expansion

FE Finite Element

IBC Individual Blade Control

IDE . Interigitated Electrode

LPF Load Proportionality Factor

MFC Macro Fibre Composite

MFCX Microfabrication by Coextrusion

PFC Piezoelectric Fibre Composite PVDF Polyvinyllidene Fluoride

PZT Lead Zirconate Titanate SMA Shape Memory Alloy Segmented Piezoelectric Fibre Composite 


\section{List of Symbols}

$A_{i j} \ldots \ldots \ldots \ldots \ldots \ldots \ldots$ Components of the extensional stiffness matrix.

$B_{i j} \quad \ldots \ldots \ldots \ldots \ldots$ Components of the membrane coupling stiffness matrix.

$D_{i j} \ldots \ldots \ldots \ldots \ldots \ldots \ldots \ldots \ldots$ Components of the bending stiffness matrix.

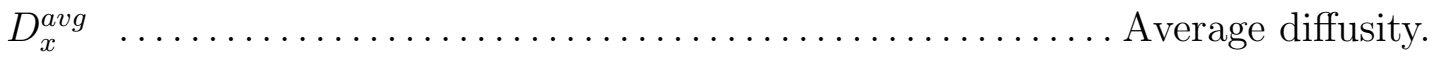

$d_{33}, d_{31} \quad \ldots \ldots \ldots \ldots \ldots \ldots \ldots \ldots \ldots \ldots \ldots \ldots \ldots \ldots \ldots$ Piezoelectric constants.

$E_{1} \ldots \ldots \ldots \ldots \ldots \ldots \ldots \ldots \ldots$ Young's modulus in the fibre direction.

$E_{2} \quad \ldots \ldots \ldots \ldots \ldots \ldots$ Young's modulus in the transverse fibre direction.

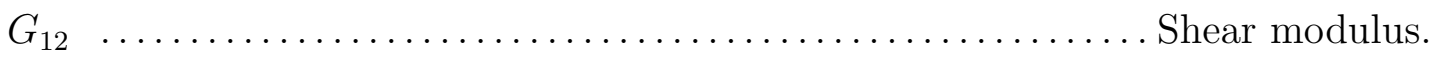

$N^{T} \ldots \ldots \ldots \ldots \ldots \ldots \ldots \ldots \ldots \ldots \ldots \ldots \ldots \ldots \ldots \ldots \ldots \ldots \ldots$ Resulting thermal tractions.

$M^{T} \ldots \ldots \ldots \ldots \ldots \ldots \ldots \ldots \ldots \ldots \ldots$ Resulting thermal bending moments.

$N_{x}, N_{y}, N_{x y} \quad \ldots \ldots \ldots \ldots \ldots \ldots \ldots \ldots \ldots \ldots$ Inplane traction components.

$M_{x}, M_{y}, M_{x y} \ldots \ldots \ldots \ldots \ldots \ldots \ldots \ldots \ldots \ldots$ Bending moment components.

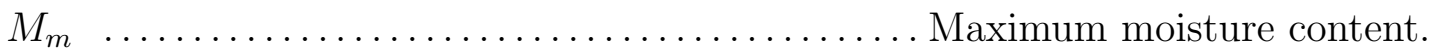

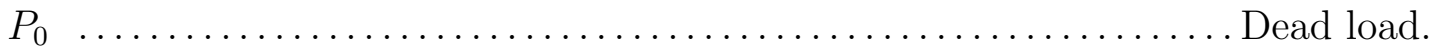

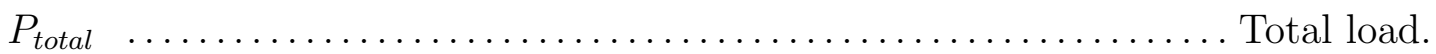

$\bar{Q}_{i j} \ldots \ldots \ldots \ldots \ldots \ldots \ldots \ldots \ldots \ldots \ldots \ldots$ Transformed reduced stiffness matrix. 
$Q_{i j}$ Reduced stiffness matrix.

$u, v$ Displacement field. $u_{0}, v_{0}, w_{0}$ Midplane displacement field.

$\alpha_{i}^{k}$... Component of the coefficients of thermal expansion in the ply coordinate system.

$\alpha_{i}^{*} \quad \ldots \ldots \ldots \ldots \ldots$ Equivalent coefficient of thermal and moisture expansion. $\beta_{i}^{k} \quad \ldots \ldots \ldots \ldots$. Moisture expansion coefficient in the ply coordinate system. $\Delta M$ Percent weight gain through moisture absorption. $\Delta T$ Temperature difference.

$\varepsilon_{i}$ . Mechanical strain components. $\phi$ Relative humidity. 
"It is difficult to say what is impossible, for the dream of yesterday is the hope of today and the reality of tomorrow" 1927, Robert Goddard 


\section{Chapter 1}

\section{Introduction and objectives}

\subsection{Motivation}

Smart technologies, including sensors, actuators, support hardware and electronics have given rise to a large field of research in Aerospace Engineering. These technologies promise to provide large improvements in aircraft system safety, affordability and environmental compatibility [1]. A smart device senses and reacts to its local environment to achieve an overall system benefit, such as to increase performance and maintain operational worthiness in the event of failure. These so called smart technologies are currently being implemented as vibration sensing and suppression devices, as well as in health monitoring systems. The existing sensing and actuation technologies are mostly based on piezoelectric materials, shape memory alloys and magnetostrictive materials. When subjected to mechanical loading, piezoelectric materials respond by generating an electric field and they strain conversely when an electric field is applied to them. They respond very quickly although the strains and blocking forces generated are very small. On the other hand, shape memory alloys (SMA) when activated respond slower but provide a higher blocking force. Piezoelectric materials are therefore frequently used when small strains and high frequency response are necessary.

Birds and insects served as an inspiration to the aviation's pioneers that mimicked the wing shapes and their flapping movement, hoping it would produce 
enough lift to get them of the ground. One of the most remarkable characteristics of birds is their ability to adapt their wing geometry in order to maximize lift according to the different flight conditions and to use the wings to produce both lift and propulsion. Figure 1-1 depicts how birds adjust the their wing geometry for different flight regimes and speeds.

\section{Pigeon}
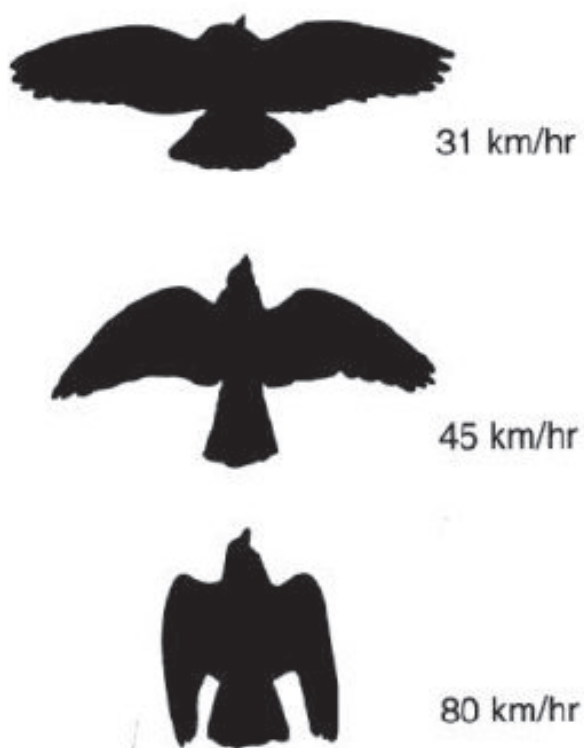

Falcon
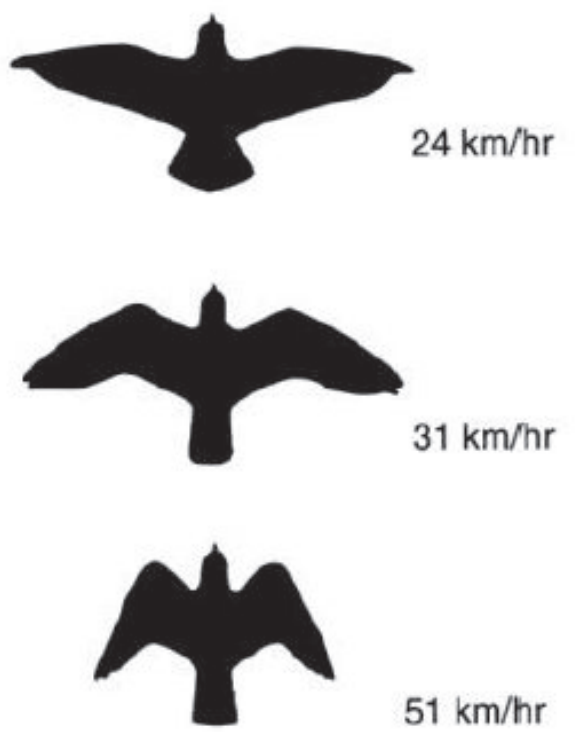

$51 \mathrm{~km} / \mathrm{hr}$

Figure 1-1: Depiction of how birds adapt their wing geometry for different flight regimes.

Technology abandoned the flapping wings concept immediately after realizing the potential of fixed wings. Nowadays, aircrafts have fixed wings that produce lift and engines that produce propulsion separately.

The idea of a configurable structure, one that can change its shape and geometry to better respond to a particular load case, has always been on the engineers' minds. The same way a bird can sweep its wings back and forward and configure them for high lift or low drag, engineers always wished to be able to design a wing that can be reconfigured depending on the flight regime. Airplanes today 
are a design compromise. They have a fixed-wing structure that is not ideal for any part of a typical flight. Some military aircraft, like the 1970's Grumman's F14-Tomcat, have sweeping wings that provide some extent of morphing and adaptability.

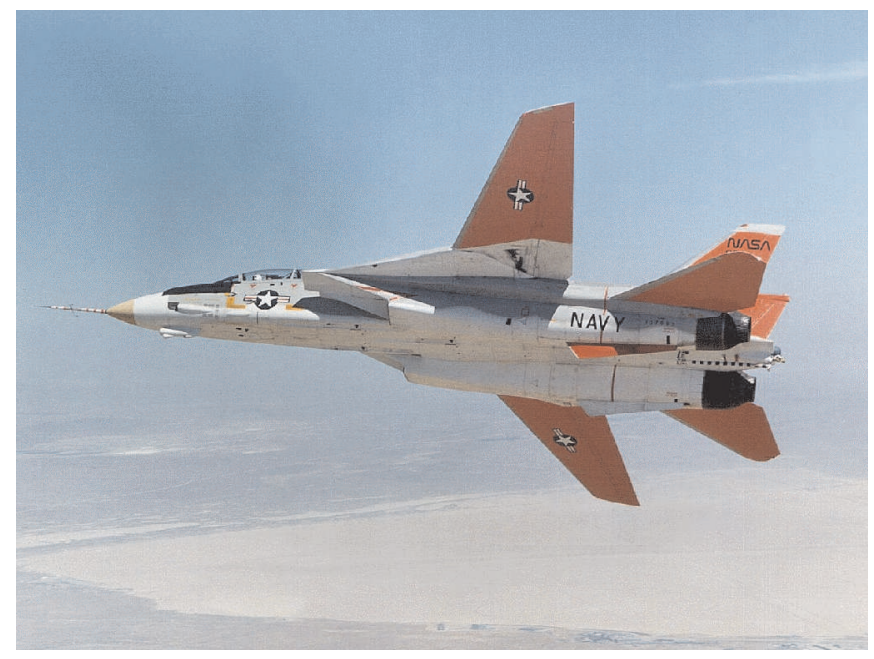

Figure 1-2: The F14- Tomcat

Ideally, aircraft designers would like to be able to optimize their designs for every flight regimes depicted in Figure 1-3.

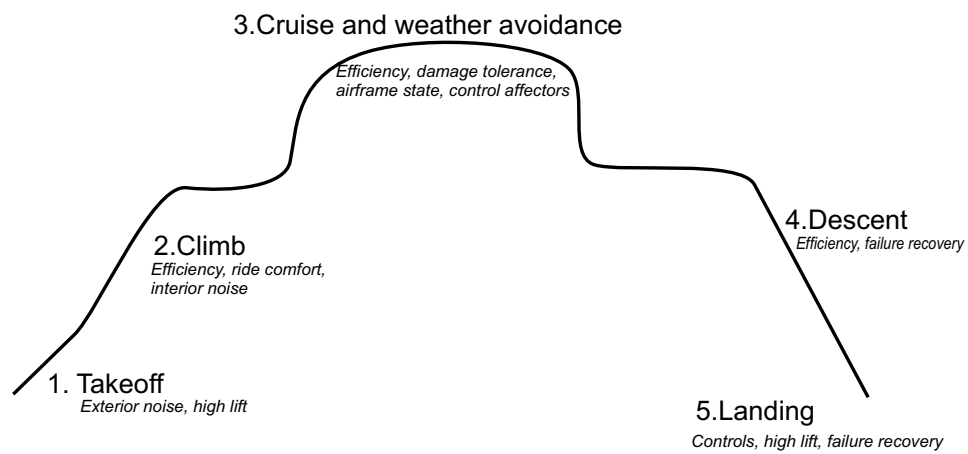

Figure 1-3: Flight profile, adapted from [1]

This requires a quantum leap in the areas of material science, actuation and sensing technologies as well as control engineering. The main objective of the 
work presented herein is to provide a better understanding of possible shape changing, active structures. Piezoelectric actuators based on piezoelectric fibres are used to produce structural snap-through of asymmetrical carbon fibre reinforced plastic (CFRP) laminates. Depending on the lay-up, composite laminates can, after cure, exhibit two structural and energetically stable shapes. Structures like these are called bi-stable structures. Transition from one stable shape to another can be achieved by applying an external load. When this load reaches a critical level, determined by the residual stress field and its geometry, the structure will snap-through to the other stable shape through a buckling mechanism. Piezoelectric patches bonded to the surface of asymmetrical laminated carbon fibre reinforced plastics plates are used to trigger the snap-through event. In the remainder of this chapter a bibliographical survey will be made on the topics of morphing structures and state of the art actuation technologies. Next, a special section on multistable composite structures followed by another one on the Macro-Fibre Composite (MFC) actuator will give some theoretical background on the working principles of the two components of the morphing concept under study. Chapter two will report on the procedures and results of a first set of experiments. These initial experiments revealed some unexpected difficulties that were the motivation for the work reported in chapter three. Chapter three describes in detail the Finite Element (FE) Models developed to design a working morphing plate. Special care was given to the simulation of the snap-through phenomenon, long term behaviour of asymmetrical laminates and the effect of the MFC actuator in the laminate. Based on the results from the FE models, a new set of experiments is described in chapter four, followed by a set of conclusions and recommendations for further work.

\subsection{Bibliographical survey}

The initial objectives of this project were to study the possibility of using embedded technologies to trigger snap-through of asymmetrical laminates. These 
were then to be adapted to a morphing structure concept. The bibliographical survey was dispersed into different fields: morphing structures in general, asymmetrical laminates, snap-through of asymmetrical laminates and recent actuator technologies (embedded piezo-fibres, SMA, MFC's, etc).

The expression "Morphing Structures" is very undefined. In this text a morphing structure will be defined as one capable of macroscopic geometric changes in order to better adapt to environmental circumstances. Because of the resources available in aerospace industry and due to the clear advantages that these technologies can bring, morphing structures applications are currently under study for airplanes wing geometry changes, replacement of mechanically driven control surfaces, helicopter blade control, reliable actuators for space mission, etc. If a morphing aircraft is defined merely as an aircraft that changes its configuration in-flight, it can be seen that morphing aircraft is not a new concept. Extending flaps, elevators, ailerons and wing twisting can be considered geometric changes and can be technically termed as morphing. However these changes are either necessary enablers for a controlled flight or contributors to the improved aerodynamic performances of an aircraft. As a result, these technologies do not necessarily allow an aircraft to perform different types of mission tasks. Historically the first efforts into morphing aircrafts was to design a wing that would allow the aircraft to fly in at least two speed regimes. The first design appeared in the 1920's and was based on a wing with variable incidence. The variable sweep wing design was introduced in 1944 by German Messerschmidt and is still the most popular morphing design. It encountered many technical challenges but most were corrected and several high performance sweep wing airplanes such as Mig-23 (USSR, 1967), Grumman F-14 Tomcat (1970), and Rockwell B-1B Lancer (1983), Figure 1-4 still fly today. 


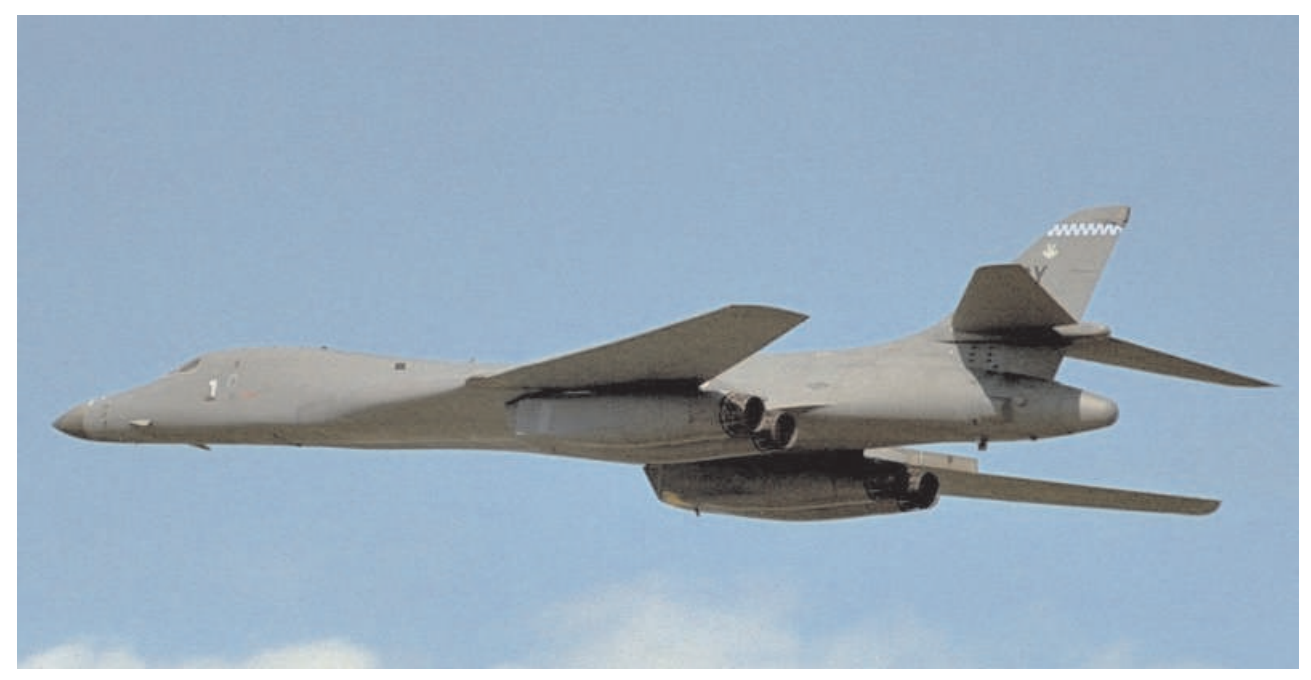

Figure 1-4: Rockwell B-1B Lancer with variable sweep wings

Morphing concepts based on small wing planform changes work mainly as a replacement or enhancement of control surfaces. Rotating wingtips were used in North American's Valkyre XB-70 (1964) to replace ailerons and elevators.

The pivoted wingtips acted both as elevators and ailerons to control the pitch (rotated together) and roll (rotated opposite). Camber control of wings using control surfaces has been extensively utilized in the aircraft industry. Most of these designs use discrete and rotating leading and trailing edge controls. Out of the two, the leading edge control surfaces are much less popular. The F16 Fighting Falcon, developed by General Dynamics and first flown in 1974, uses leading edge flaps to change the camber of its wings. The wing has also a set of "flaperons" that combines the roles of flaps and ailerons. Recently, NASA's Active Aeroelastic Wing (AAW) programme tested the idea of using wing twist for primary maneuvering roll control at transonic and supersonic speeds. NASA-Ames Mission Adaptive Wing Research program focus was to produce a smooth camber change avoiding the discontinuous curvature. The wing developed during this programme had an internal mechanism to flex the outer wing skin and produce a high camber section for subsonic speeds, a supercritical section for transonic speeds, and symmetrical section for supersonic speeds. Due to 


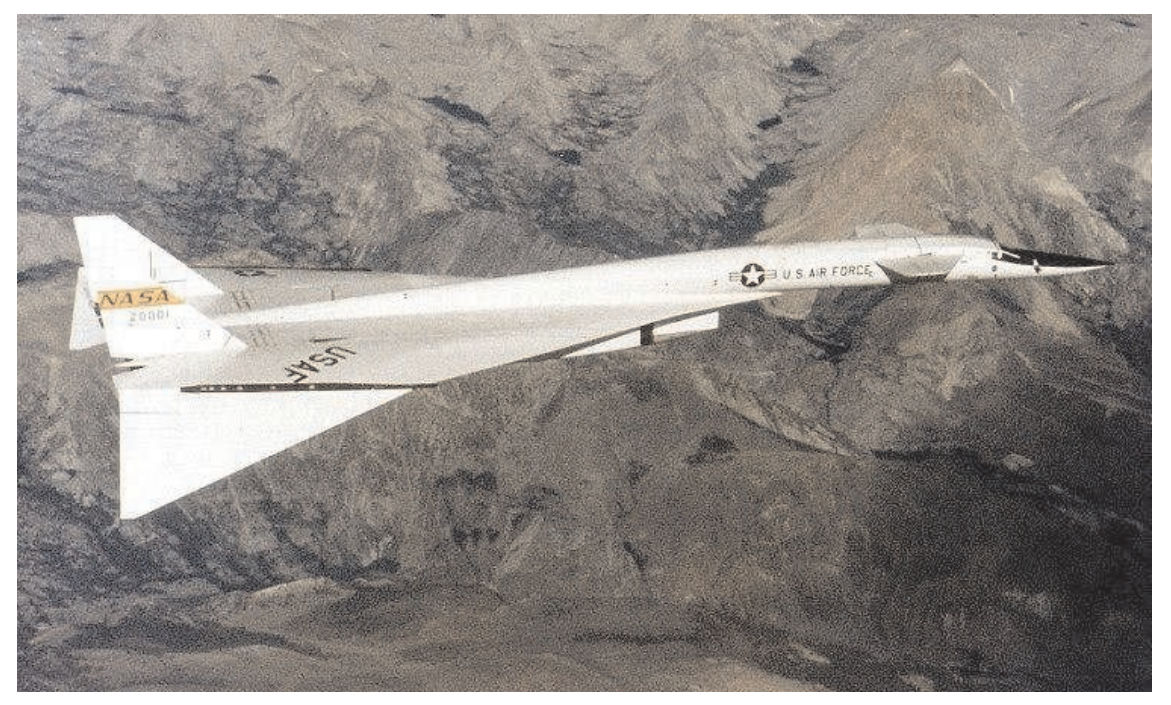

Figure 1-5: Valkyre XB-70 with rotating wingtips

smoothness of the resulting wing surface, the drag was found to decrease by around 7 percent at the wing design cruise point to over 20 percent at an offdesign condition, [2].

Several research groups have proposed solutions for achieving macroscopic wing morphing by using compliant mechanisms, [6]-[7]. A compliant mechanism is a single piece flexible structure that delivers the desired motion by undergoing elastic deformation as opposed by a rigid body motion in conventional mechanisms. It is designed to accomplish with one piece what conventional mechanisms can do with multiple pieces. It must be designed to be flexible enough to transmit motions, yet stiff enough to withstand the external loads, [6]. These mechanisms can have dramatic applications in aircraft systems as is demonstrated by Flexsys, Inc in their website (http://www.flxsys.com/).

Using innovative piezoelectric actuators, Straub et. al. [8], [9], have demonstrated a morphing concept for individual blade control of rotorcraft blades. Because of the combination of forward movement with rotation that helicopter blades have, the lift produced by each blade varies during one cycle. To solve this problem and to keep the aircraft balanced helicopter blades have trailing edge flaps that are extended and retracted in each cycle and their pitch angle 
is changed accordingly. This is accomplished by a very complex mechanism at the root of the blade. Replacing this mechanism by a piezoelectric based device would increase reliability an significantly reduce weight. A classification of current aircraft morphing technologies is shown in Figure 1-6.

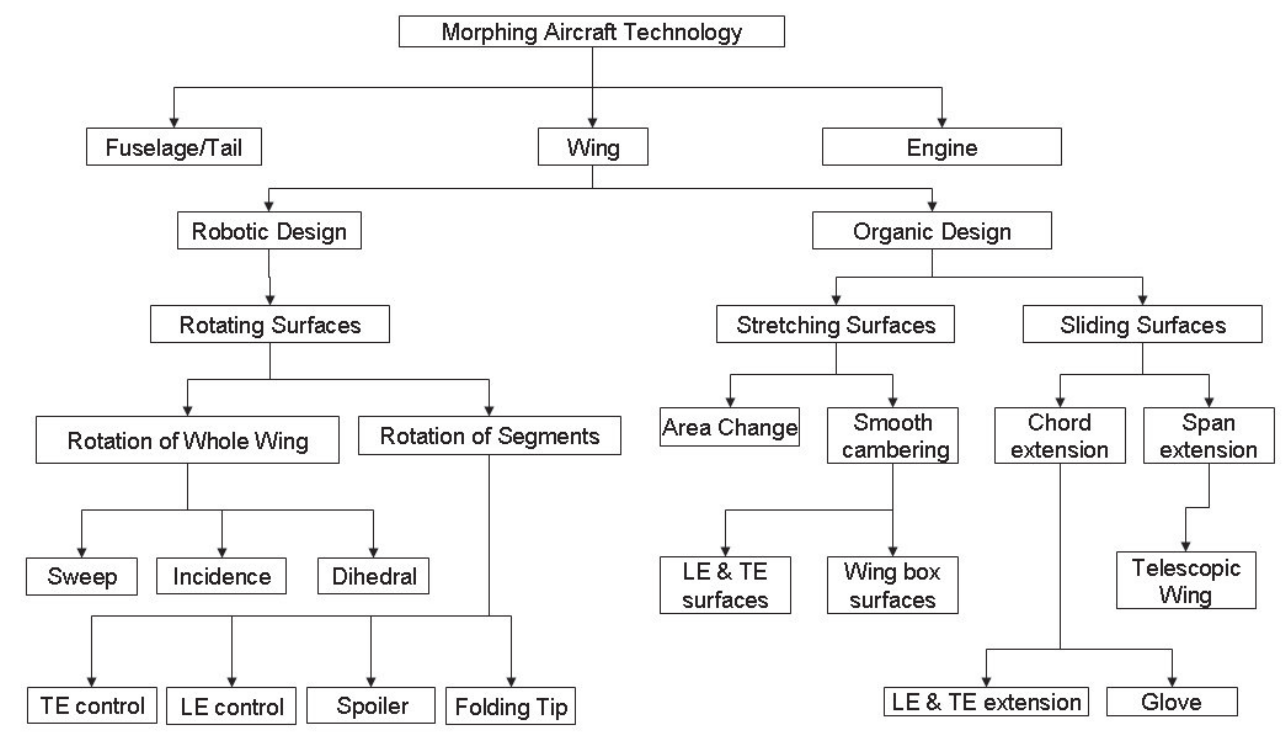

Figure 1-6: Classification of morphing aircraft technology, adapted from [2]

Jha and Kudva, [2] identified the several technical challenges that face a morphing aircraft design. From the structures' perspective, new and efficient ways of changing structural shape and size are demanded. A compliant skin in a sliding wing, for example, needs to be flexible to accommodate the change in the internal structures. This in turn makes it a non-load-carrying part and degrades the overall structural stiffness. For the flexible skin design, high strain materials with good structural properties and requiring less actuation force needs to be developed. In parallel, the configuration change of aircraft in-flight will require the actuators to work against aerodynamic and friction forces. It is imperative to find new ways of actuation by using aerodynamic forces, for example, for supplemental actuation, so as to minimize the space, weight, and power requirements. 
Recently, Schutlz [10] proposed a novel morphing concept based on asymmetrical CFRP laminates. If a composite laminate does not have a symmetrical stacking sequence, thermally induced stresses that develop during the curing process will cause an out of plane curvature. This curvature can be tailored by adjusting the stacking sequence and pre-preg thickness. Depending on the plate's geometry these thermally induced stresses may cause the laminate to have more than one stable configuration or shape. Morphing can be obtained by a snapthrough mechanism triggered by an external force. The main advantage of using these structures is that they will hold one of the stable shapes without the need of a constant applied load. Hence they can carry loads in both states as long the critical snap-through load is not reached. Schultz [11]- [10] used piezoelectric patches bonded to the surface of the laminate to induce snap-through with a shear force. He successfully produced a morphing laminate based on MFC actuators and was able to make good predictions of the snap-through loads for a patch bonded in the middle of the plate. Dano [12] used SMA wires that, when heated, applied a bending moment to the plate. Hufenbach et. al [13], [14] developed optimization algorithms to dimension such laminates as well as produced a SMA based morphing, bi-stable laminates. Both Schultz and Dano were concerned with a semi-analytical approach to predict the two stable shapes of such laminates as well as the required snap-through loads. There is a significant amount of work done in the prediction of room temperature shapes of asymmetrical laminates, [15],[16]. Most of this work is based on semi-analytical Rayleigh-Ritz methods although non linear FE analysis has also been successfully used, [17], [18].

To effectively produce a morphing structure, a way must be found to activate the shape changes in the bi-stable laminate. Ideally, the actuator would be powerful enough to provide the necessary loads but small and light enough to minimize its effect on the assembly. Embedding the actuator into the structure would protect it from accidental damage and is preferred to surface mounted actuation technologies. The speed at which the actuators respond can also be critical depending on the application. The following table presents a comparison 
of the actuation strain that current state of the art smart materials can deliver, together with the maximum frequency at which they can operate.

\begin{tabular}{lll}
\hline State of the Art "Smart" Material & Max Strain & Freq. of Max Power \\
\hline Polycrystalline Piezoelectric & $30 \mu \varepsilon$ & $30 \mathrm{MHz}$ \\
Single Crystal Piezoelectric & $200 \mu \varepsilon$ & $20 \mathrm{MHz}$ \\
Piezoelectric Polymer & $1000 \mu \varepsilon$ & $10 \mathrm{MHz}$ \\
Magnetostrictor & $2000 \mu \varepsilon$ & $30 \mathrm{MHz}$ \\
Shape Memory Alloy & $80000 \mu \varepsilon$ & $1 \mathrm{~Hz}$ \\
\hline
\end{tabular}

Table 1.1: Comparison of typical performance of smart materials

Piezoelectric materials are typically used for vibration suppression where high bandwidth response is desirable. On the contrary, shape memory alloys deliver significantly more force but at a quasi-static rate. Recently there has been a significant amount of effort made to increase the strain output of piezoelectric materials and embed them into a substrate. Most of these new devices are based on fibrous piezoelectric materials. Just as advanced composites offer many benefits over traditional engineering materials for structural design, actuators that utilize the active properties of piezoelectric fibres can improve upon many limitations encountered in monolithic piezoceramic devices used to control structural dynamics. The idea of a composite material consisting of an active piezoceramic fibrous phase embedded in a polymeric matrix phase remedies many of the restrictions imposed by monolithic wafers (brittleness, large add-on mass, limited ability to conform to curved surfaces). Typically, crystalline materials have much higher strengths in the fiber form, where the decrease in volume fraction of flaws leads to an increase in specific strength. Also, in addition to protecting the fibers, the flexible nature of the polymer matrix allows the material to more easily conform to the curved surfaces found in more realistic industrial applications. Presently, there is an ever-increasing number of research grade and commercially available composites containing piezoelectric fibers. However, there exist four industry leading types of promising actuators for intelligent structure:

1. The 1-3 Composites has round or square piezoelectric fibres embedded in a polymer matrix and aligned through the thickness of the device. These 
devices are typically used for ultrasound and acoustic control applications

2. The Active Fibre Composite was developed by the Active Materials and Structures Lab at MIT and are another type of piezoceramic fibre composite. The device uses uniaxially aligned piezoceramic fibres surrounded by a polymer matrix and can include inactive glass fibres for increased structural strength.

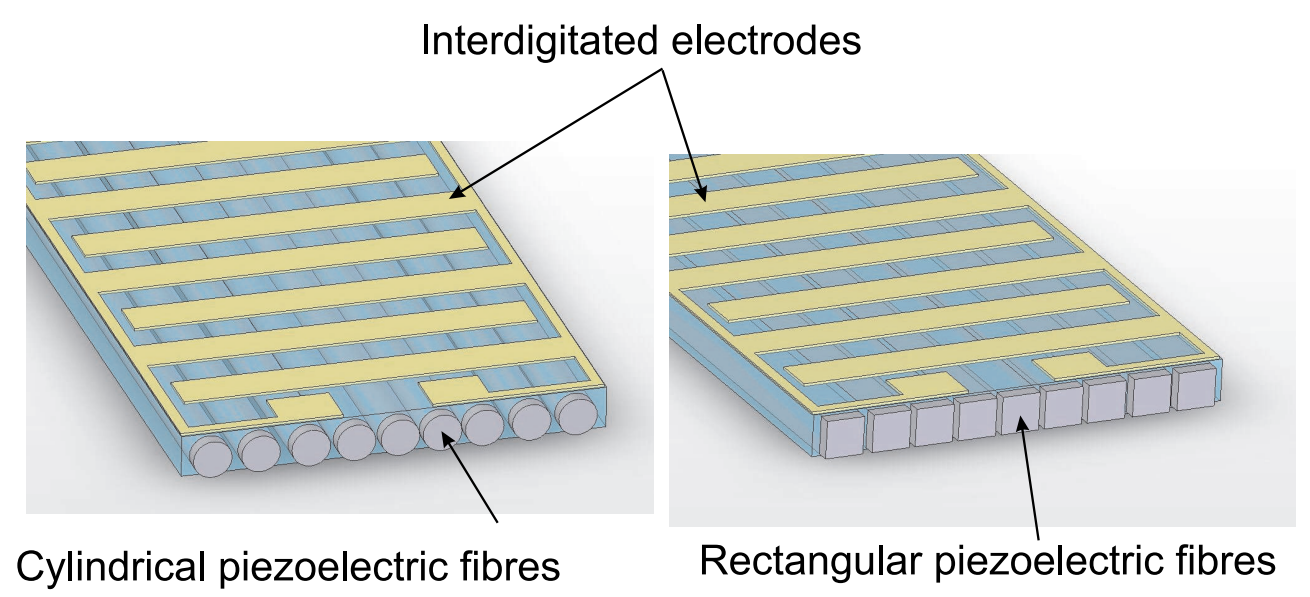

Figure 1-7: Schematics of the Active Fibre Composite actuator

3. Finally, the Macro Fibre Composite actuator was developed at NASA Langley Research Center. The design principle is the same as the AFC's but the piezoelectric fibers used have a rectangular cross-section. This way, a larger area of piezoelectric material is in contact with the electrodes thus increasing the overall performance. Rectangular fibres can be easily obtained by cutting from traditional ceramic wafers.

One last class of fibre based piezoelectric actuators still under research are those consisting of hollow piezoelectric fibres. The major drawback to the AFC approach described above is the requirement of the electric field to pass through the polymeric resin serving as matrix to the fibres. Due to the placement of the electrode on the matrix surface, electric field losses are significant, requiring high voltages for actuation. Furthermore, this approach limits the matrix to electri- 


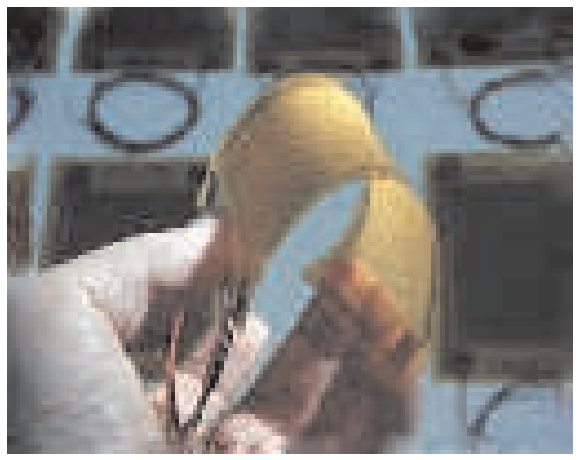

Figure 1-8: The MFC patch actuator

cally nonconductive materials which is particularly a problem in large structure and air vehicle applications where metals and carbon fibers are almost exclusively utilized in construction. Hollow fibers, individually electroded on both the inside and outside surfaces are activated by an electric field applied directly across the fibre, generating longitudinal strain due to the piezoelectric $d_{31}$ mode. The piezoelectric modes are defined in Section 1.4.1

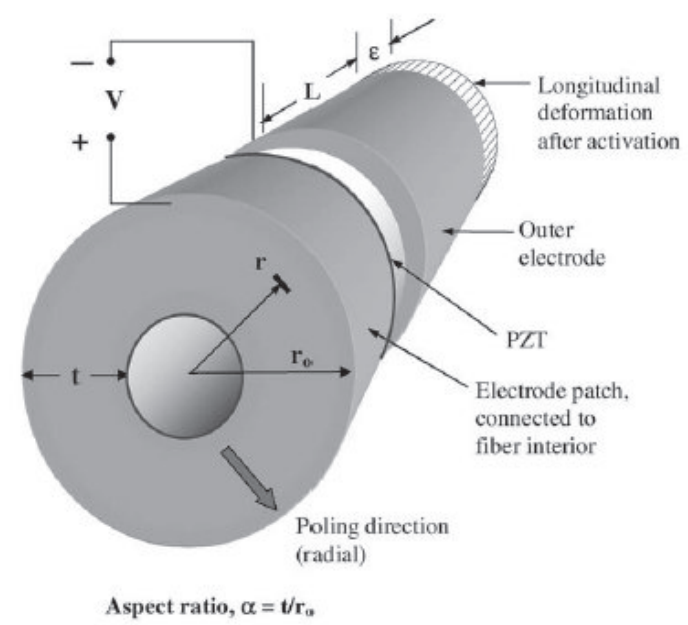

Figure 1-9: Schematics of a hollow piezoelectric fibre [3]

Even though the longitudinal strain is decreased by half by using the $d_{31}$ mode instead of the $d_{33}$ mode in conventional AFC's, it is possible to reduce the activation voltage by a factor of ten or more because the field is applied 
only through the fibre's thickness. The electric field losses in the matrix are also reduced. Another benefit of the hollow fibre topology is that the inner electrode is isolated from the matrix enabling the fibre to be embedded in electrically conductive matrices. Published studies [3] suggest that design parameters such as fibre aspect ratio, volume fraction and matrix/fibre modulus ratio play a role in the performance characteristics. Hollow piezoelectric active fibre composites are not yet commercially available, as is the case of the MFC actuators. They are, however, considered likely candidates to provide actuation for small morphing structures.

\subsection{Multistable laminates}

In order to understand why certain laminates assume two stable geometries it is necessary to briefly review the fundamentals of classical lamination theory.

\subsubsection{Classical lamination theory at a glance}

Knowledge of the variation of stress and strain through the laminate thickness is essential for the definition of the extensional and bending stiffness of a laminate. The following assumptions are considered

1. The laminate is assumed to be a series of perfectly bonded plies. Moreover, the bonds are presumed to be infinesimally small as well as non-sheardeformable. That is, the displacements are continuous across ply boundaries so that no relative slippage can occur relative to another.

2. The laminate is assumed to be "thin". That is to say, that a line originally straight and perpendicular to the middle surface is assumed to remain straight and perpendicular to the middle surface after deformation. The consequence of this is that the shearing strains in planes perpendicular to the middle surface are ignored, i.e. $\gamma_{x z}=\gamma_{y z}=0$. 
3. Finally, the normals are presumed to have constant length so that the strain perpendicular to the middle surface is ignored as well, i.e. $\varepsilon_{z z}=0$

The displacement field resulting from these assumptions is given by:

$$
\begin{aligned}
& u=u_{0}-z \frac{\partial w_{0}}{\partial x} \\
& v=v_{0}-z \frac{\partial w_{0}}{\partial y}
\end{aligned}
$$

The laminate strains have been reduced to $\varepsilon_{x}, \varepsilon_{y}$ and $\gamma_{x y}$ by virtue of the Kirchhoff hypothesis. For small strains (linear elasticity), these are defined in terms of of displacements as:

$$
\begin{aligned}
\varepsilon_{x} & =\frac{\partial u}{\partial x} \\
\varepsilon_{y} & =\frac{\partial v}{\partial y} \\
\gamma_{x y} & =\frac{\partial u}{\partial y}+\frac{\partial v}{\partial x}
\end{aligned}
$$

Thus, introducing the derived displacements from equations (1.1) into equation (1.2):

$$
\begin{aligned}
\varepsilon_{x} & =\frac{\partial u_{0}}{\partial x}-z \frac{\partial^{2} w_{0}}{\partial x^{2}} \\
\varepsilon_{y} & =\frac{\partial v_{0}}{\partial y}-z \frac{\partial^{2} w_{0}}{\partial y^{2}} \\
\gamma_{x y} & =\frac{\partial u_{0}}{\partial y}+\frac{\partial v_{0}}{\partial x}-2 z \frac{\partial^{2} w_{0}}{\partial x \partial y}
\end{aligned}
$$

or:

$$
\left\{\begin{array}{c}
\varepsilon_{x} \\
\varepsilon_{y} \\
\gamma_{x y}
\end{array}\right\}=\left\{\begin{array}{c}
\varepsilon_{x}^{0} \\
\varepsilon_{y}^{0} \\
\gamma_{x y}^{0}
\end{array}\right\}+z\left\{\begin{array}{c}
\kappa_{x} \\
\kappa_{y} \\
\kappa_{x y}
\end{array}\right\}
$$

where: 


$$
\left\{\begin{array}{c}
\varepsilon_{x}^{0} \\
\varepsilon_{y}^{0} \\
\gamma_{x y}^{0}
\end{array}\right\}=\left\{\begin{array}{c}
\frac{\partial u_{0}}{\partial x} \\
\frac{\partial v_{0}}{\partial y} \\
\frac{\partial u_{0}}{\partial y}+\frac{\partial v_{0}}{\partial x}
\end{array}\right\}
$$

and:

$$
\left\{\begin{array}{c}
\kappa_{x} \\
\kappa_{y} \\
\kappa_{x y}
\end{array}\right\}=-\left\{\begin{array}{c}
\frac{\partial^{2} w_{0}}{\partial x^{2}} \\
\frac{\partial^{2} w_{0}}{\partial y^{2}} \\
2 \frac{\partial^{2} w_{0}}{\partial x \partial y}
\end{array}\right\}
$$

By substitution of the strain variation through the thickness (equation 1.3) in a stress-strain relation, the stresses in the $\mathrm{k}^{\text {th }}$ layer can be expressed in terms of the laminate middle-surface strains and curvatures as

$$
\left\{\begin{array}{c}
\sigma_{x} \\
\sigma_{y} \\
\tau_{x y}
\end{array}\right\}=\left[\begin{array}{lll}
\bar{Q}_{11} & \bar{Q}_{12} & \bar{Q}_{16} \\
\bar{Q}_{12} & \bar{Q}_{22} & \bar{Q}_{26} \\
\bar{Q}_{16} & \bar{Q}_{26} & \bar{Q}_{66}
\end{array}\right]\left[\left\{\begin{array}{c}
\varepsilon_{x}^{0} \\
\varepsilon_{y}^{0} \\
\gamma_{x y}^{0}
\end{array}\right\}+z\left\{\begin{array}{c}
\kappa_{x} \\
\kappa_{y} \\
\kappa_{x y}
\end{array}\right\}\right]
$$

The terms $\bar{Q}_{i j}$ are the transformed reduced stiffnesses, i.e. stiffness given in the global coordinate system. The terms $\bar{Q}_{i j}$ are related to the reduced stiffnesses in the local coordinate system by equations 1.8 .

$$
\begin{aligned}
& \bar{Q}_{11}=Q_{11} \cos ^{4} \theta+2\left(Q_{12}+2 Q_{66}\right) \sin ^{2} \theta \cos ^{2} \theta+Q_{22} \sin ^{4} \theta \\
& \bar{Q}_{12}=\left(Q_{11}+Q_{22}-4 Q_{66}\right) \sin ^{2} \theta \cos ^{2} \theta+Q_{12}\left(\sin ^{4} \theta+\cos ^{4} \theta\right) \\
& \bar{Q}_{22}=Q_{11} \sin ^{4} \theta+2\left(Q_{12}+Q_{66}\right) \sin ^{2} \theta \cos ^{2} \theta+Q_{22} \cos ^{4} \theta \\
& \bar{Q}_{16}=\left(Q_{11}-Q_{12}-2 Q_{66}\right) \sin \theta \cos ^{3} \theta+\left(Q_{12}-Q_{22}+2 Q_{66}\right) \sin ^{3} \theta \cos \theta \\
& \bar{Q}_{26}=\left(Q_{11}-Q_{12}-2 Q_{66}\right) \sin ^{3} \theta \cos \theta+\left(Q_{12}-Q_{22}+2 Q_{66}\right) \sin \theta \cos ^{3} \theta \\
& \bar{Q}_{66}=\left(Q_{11}+Q_{22}-2 Q_{12}-2 Q_{66}\right) \sin ^{2} \theta \cos ^{2} \theta+Q_{66}\left(\sin ^{4} \theta+\cos ^{4} \theta\right)
\end{aligned}
$$

The terms $Q_{i j}$ are the reduced stiffness in the ply coordinate system and are related to the engineering constants by equations 


$$
\begin{aligned}
Q_{11} & =\frac{E_{1}}{1-\nu_{12} \nu_{21}} \\
Q_{12} & =\frac{\nu_{12} E_{2}}{1-\nu_{12} \nu_{21}}=\frac{\nu_{21} E_{1}}{1-\nu_{12} \nu_{21}} \\
Q_{22} & =\frac{E_{2}}{1-\nu_{12} \nu_{21}} \\
Q_{66} & =G_{12}
\end{aligned}
$$

The resultant membrane forces and bending moments acting on a laminate are obtained by integration of the stresses in each layer or ply through the laminate thickness

$$
\left\{\begin{array}{c}
N_{x} \\
N_{y} \\
N_{x y}
\end{array}\right\}=\int_{-t / 2}^{t / 2}\left\{\begin{array}{c}
\sigma_{x} \\
\sigma_{y} \\
\tau_{x y}
\end{array}\right\} d z=\sum_{k=1}^{N} \int_{z_{k-1}}^{z_{k}}\left\{\begin{array}{c}
\sigma_{x} \\
\sigma_{y} \\
\tau_{x y}
\end{array}\right\} d z
$$

and

$$
\left\{\begin{array}{c}
M_{x} \\
M_{y} \\
M_{x y}
\end{array}\right\}=\int_{-t / 2}^{t / 2}\left\{\begin{array}{c}
\sigma_{x} \\
\sigma_{y} \\
\tau_{x y}
\end{array}\right\} z d z=\sum_{k=1}^{N} \int_{z_{k-1}}^{z_{k}}\left\{\begin{array}{c}
\sigma_{x} \\
\sigma_{y} \\
\tau_{x y}
\end{array}\right\}_{k} z d z
$$

Substitution of equation 1.7 into equations 1.10 and 1.11 yields

$$
\left\{\begin{array}{c}
N_{x} \\
N_{y} \\
N_{x y}
\end{array}\right\}=\sum_{k=1}^{N}\left[\begin{array}{lll}
\bar{Q}_{11} & \bar{Q}_{12} & \bar{Q}_{16} \\
\bar{Q}_{12} & \bar{Q}_{22} & \bar{Q}_{26} \\
\bar{Q}_{16} & \bar{Q}_{26} & \bar{Q}_{66}
\end{array}\right]_{k}\left[\int_{z_{k-1}}^{z_{k}}\left\{\begin{array}{c}
\varepsilon_{x}^{0} \\
\varepsilon_{y}^{0} \\
\gamma_{x y}^{0}
\end{array}\right\}_{k} d z+\int_{z_{k-1}}^{z_{k}}\left\{\begin{array}{c}
\kappa_{x} \\
\kappa_{y} \\
\kappa_{x y}
\end{array}\right\}_{k} z d z\right]
$$


and

$$
\left\{\begin{array}{c}
M_{x} \\
M_{y} \\
M_{x y}
\end{array}\right\}=\sum_{k=1}^{N}\left[\begin{array}{ccc}
\bar{Q}_{11} & \bar{Q}_{12} & \bar{Q}_{16} \\
\bar{Q}_{12} & \bar{Q}_{22} & \bar{Q}_{26} \\
\bar{Q}_{16} & \bar{Q}_{26} & \bar{Q}_{66}
\end{array}\right]_{k}\left[\int_{z_{k-1}}^{z_{k}}\left\{\begin{array}{c}
\varepsilon_{x}^{0} \\
\varepsilon_{y}^{0} \\
\gamma_{x y}^{0}
\end{array}\right\}_{k} z d z+\int_{z_{k-1}}^{z_{k}}\left\{\begin{array}{c}
\kappa_{x} \\
\kappa_{y} \\
\kappa_{x y}
\end{array}\right\} z^{2} d z\right]
$$

These equations can be rearranged in terms of the midplane strains and curvatures as

$$
\left\{\begin{array}{l}
N_{x} \\
N_{y} \\
N_{x y}
\end{array}\right\}=\left[\begin{array}{ccc}
A_{11} & A_{12} & A_{16} \\
A_{12} & A_{22} & A_{26} \\
A_{16} & A_{26} & A_{66}
\end{array}\right]\left\{\begin{array}{c}
\varepsilon_{x}^{0} \\
\varepsilon_{y}^{0} \\
\gamma_{x y}^{0}
\end{array}\right\}+\left[\begin{array}{ccc}
B_{11} & B_{12} & B_{16} \\
B_{12} & B_{22} & B_{26} \\
B_{16} & B_{26} & B_{66}
\end{array}\right]\left\{\begin{array}{c}
\kappa_{x} \\
\kappa_{y} \\
\kappa_{x y}
\end{array}\right\}
$$

and

$$
\left\{\begin{array}{l}
M_{x} \\
M_{y} \\
M_{x y}
\end{array}\right\}=\left[\begin{array}{lll}
B_{11} & B_{12} & B_{16} \\
B_{12} & B_{22} & B_{26} \\
B_{16} & B_{26} & B_{66}
\end{array}\right]\left\{\begin{array}{c}
\varepsilon_{x}^{0} \\
\varepsilon_{y}^{0} \\
\gamma_{x y}^{0}
\end{array}\right\}+\left[\begin{array}{ccc}
D_{11} & D_{12} & D_{16} \\
D_{12} & D_{22} & D_{26} \\
D_{16} & D_{26} & D_{66}
\end{array}\right]\left\{\begin{array}{c}
\kappa_{x} \\
\kappa_{y} \\
\kappa_{x y}
\end{array}\right\}
$$

where

$$
\begin{aligned}
A_{i j} & =\sum_{k=1}^{N}\left(\bar{Q}_{i j}\right)\left(z_{k}-z_{k-1}\right) \\
B_{i j} & =\frac{1}{2} \sum_{k=1}^{N}\left(\bar{Q}_{i j}\right)\left(z_{k}^{2}-z_{k-1}^{2}\right) \\
D_{i j} & =\frac{1}{3} \sum_{k=1}^{N}\left(\bar{Q}_{i j}\right)\left(z_{k}^{3}-z_{k-1}^{3}\right)
\end{aligned}
$$

In equations 1.18 the $A_{i j}$ are the extensional stiffness, the $B_{i j}$ are the bendingextension or membrane coupling stiffness and the $D_{i j}$ are bending stiffness. When a laminate stacking sequence is symmetrical about the midplane, the $B_{i j}$ components are all zero. This means that a membrane force will cause in-plane strains 
only and no curvature, the same way that bending moments will cause curvature and no in-plane strains. In unsymmetrical laminates however the coupling terms are nonzero and thus, membrane forces will cause out of plane curvatures. The different effects of the coupling terms can be seen in Figure 1-10.

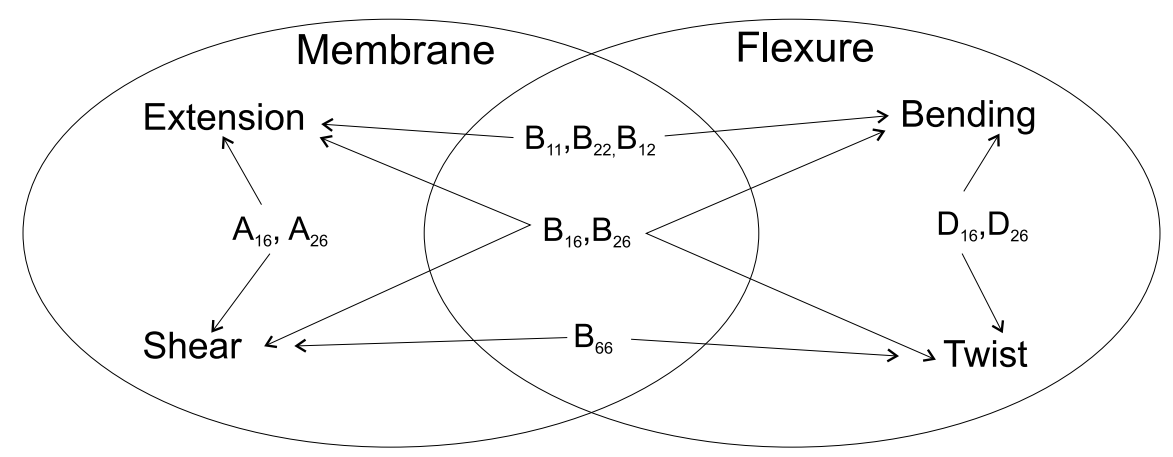

Figure 1-10: Laminate coupling relationships

\subsubsection{Laminate thermal stresses}

The equations of lamination theory for thermal stress analysis can be derived following essentially the same procedure as used for mechanical loading, but with the use of thermo-elastic lamina constitutive equations. It is assumed that the total strains are the superposition of mechanical strains.

$$
\{\varepsilon\}=\left\{\varepsilon^{0}\right\}+z\{\kappa\}+\left\{\varepsilon^{t}\right\}=\left\{\varepsilon^{\sigma}\right\}+\left\{\varepsilon^{t}\right\}
$$

The final form of the thermo-elastic laminate analysis is:

$$
\left\{\begin{array}{c}
N+N^{t} \\
M+M^{t}
\end{array}\right\}=\left[\begin{array}{ll}
A & B \\
B & D
\end{array}\right]\left\{\begin{array}{l}
\varepsilon^{0} \\
\kappa
\end{array}\right\}
$$

The equivalent thermal force per unit length and thermal moment per unit length are given respectively by:

$$
\left\{N^{t}\right\}=\int_{-H}^{H}[\bar{Q}]^{k}\left\{\varepsilon^{t}\right\}^{k} d z
$$




$$
\left\{M^{t}\right\}=\int_{-H}^{H}[\bar{Q}]^{k}\left\{\varepsilon^{t}\right\}^{k} z d z
$$

When a temperature change $\triangle T$ is applied to the laminate, in-plane strains appear and are a function of the materials coefficients of thermal expansion (CTE).

$$
\varepsilon=\alpha \triangle T
$$

From the expressions above, it would be safe to assume that, given that the Kirchhoff hypothesis are valid and that the material engineering constants and CTE are know, a closed form solution for the curvature development of laminates during the curing cycle could be obtained. In fact, some commercially available design softwares use CLT to predict laminate stresses due to temperature changes do processing. According to the results provided also by linear FEA, square asymmetrical $\left[0^{\circ} / 90^{\circ}\right]$ laminates have only one stable configuration with equal curvature in both its principal axes. This defines a saddle. Experiments and geometrically non-linear FEA show that this is not true. In fact, the laminates assume a cylindrical shape with large curvature in one principal direction and a negligible curvature in the perpendicular direction. Additionally, the laminate is bi-stable, meaning that it can be snapped to another configuration where the axis of the cylinder shape rotates by $90^{\circ}$, Figure 1-11. 


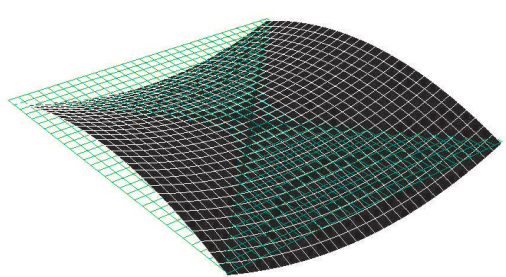

Saddle shape obtained with linear FEA or classical lamination theory

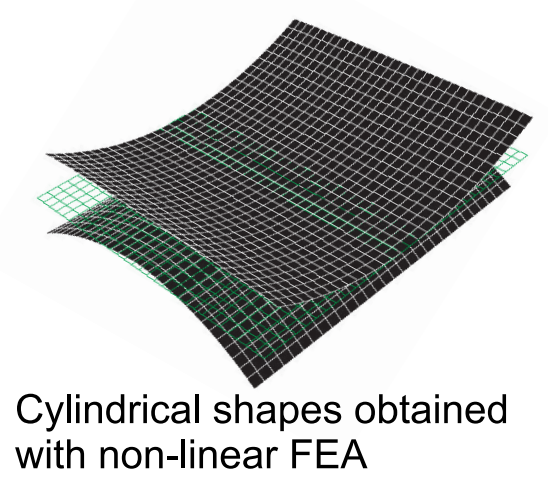

Cylindrical shapes obtained with non-linear FEA

Figure 1-11: Shapes obtained with CLT and with non-linear FEA.

Clearly, the curvature development is a geometrically non-linear phenomenon. The combination of asymmetrical stacking sequences is limitless. Varying the geometric parameters and number of plies, interesting shapes and functional structures can be created, outperforming the traditional "black aluminum" concept. Figure 1-12 shows the two stable shapes of a long $\left[0^{\circ} / 90^{\circ}\right]$ rectangular slab.
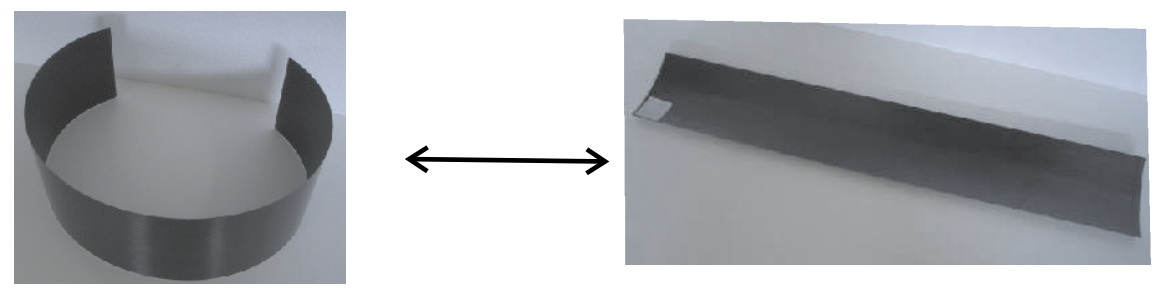

Figure 1-12: Example of extreme shape change accomplished with an asymmetrical laminate.

There is a pending issue that needs to be resolved before these structures take their places in the designers' drawing boards. There is no closed form method to develop a multi-stable, asymmetrical laminate based on derived requirements except for those particular cases which have already been extensively studied (square plates with simple cross ply stacking sequences). It is foreseeable that multi-stable laminates will be part of a structural system built of traditional 
materials. Integrating these laminates into traditional, symmetrical ones or even into metallic structures has not yet been tried or tested.

\subsection{Macro-Fibre composite actuators}

\subsubsection{Piezoelectric effect and materials}

The piezoelectric effect was discovered by Pierre and Jacques Curie when they were 21 and 24 years old in 1880. The word piezo is Greek for "push". The piezoelectric effect is demonstrated by crystals that become electrically polarized when subjected to a mechanical strain. Owing to its asymmetric crystalline structure, piezoelectric materials generate an electric field across the materials when a mechanical strain in applied to them (direct piezoelectric effect). This relationship is reversible, so the application of an electric field to a piezoelectric material will induce a mechanical strain (converse piezoelectric effect). Some natural materials such as quartz and tourmaline display piezoelectric properties, but the effects are relatively small. Improvements in piezoelectric performance have been achieved with the development of polycrystalline ferroelectric materials such as Barium Titanate $\left(\mathrm{BaTiO}_{3}\right)$ and Lead Zirconate Titanate $\left(\mathrm{Pb}(\mathrm{Zr}, \mathrm{Ti}) \mathrm{O}_{3}\right)$. PZT is the most widely used material in actuator applications. It is available in a variety of forms to account for different performance demands. Crystals in raw PZT fibres are randomly orientated, as they have not been exposed to an electric field. In this state they are ferroelectric isotropic materials, displaying poor piezoelectric performance. To demonstrate useful piezoelectric properties, the PZT must be permanently polarized, providing an anisotropic material. Remnant polarisation is achieved by applying a sufficiently large electric field to the material, aligning crystals in the required direction. A ferroelectric crystal that is spontaneously polarized will try to minimize its electrostatic energy by forming Weiss domains. Weiss domains are regions in which aligned cells are parallel to one another. The application of a suitable electric field will generate a homogenous region in the PZT material, orientated in the desired direction. To achieve remnant polariza- 
tion, an electric field of sufficient strength must be applied for a prolonged time period and at an elevated temperature. Ideal poling conditions for the Type 5H2 PZT material are an electric field strength of $2 \mathrm{kV} / \mathrm{mm}$, for a time of 20 minutes at a temperature between $50-60^{\circ} \mathrm{C}$. When the electric field is removed there is some relaxation and crystals deviate from their position, Figure 1-13. This reorientation of crystals is small and the anisotropic material properties remain [19].
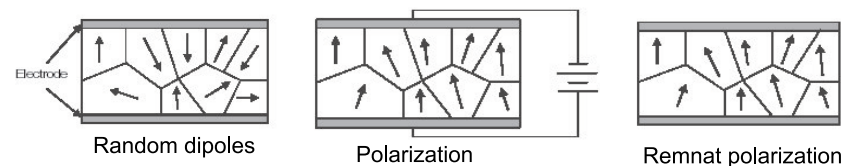

Figure 1-13: Polarization of piezoelectric crystals.

Once the PZT is polarized, only a small fraction of the polarizing field is needed to activate it. An electric field applied in the polarization direction will result in a longitudinal strain $x_{3}$ and a transverse strain $x_{1}=x_{2}$, Figure 1-14.

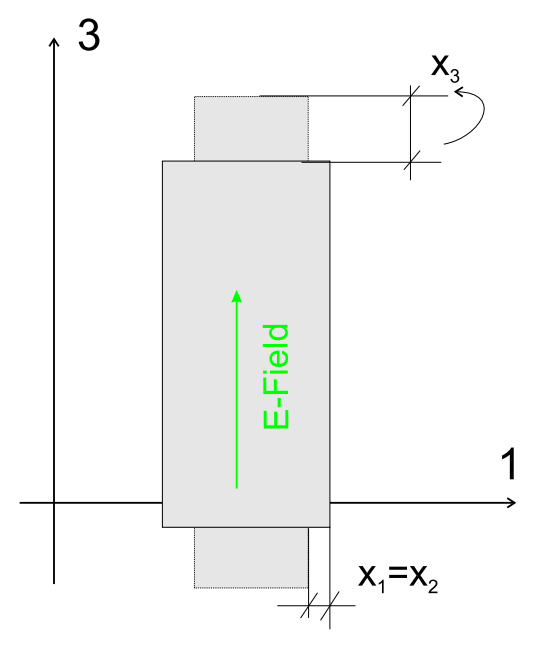

Figure 1-14: Piezoelectric strains.

The relations between the applied field and the strains are given by equations (1.24) and (1.25). 


$$
\begin{aligned}
& x_{3}=d_{33} E_{3} \\
& x_{1}=d_{31} E_{3}
\end{aligned}
$$

The first equation is known as the $d_{33}$ mode of activation while the second governs the $d_{31}$ mode. The longitudinal piezoelectric constant is two times larger than the transverse constant. A number of actuators combine the piezoceramic with a displacement amplification mechanism to tackle the inherent limited stroke of the piezoceramics. Architectures such as stacks, bender actuators, unimorph actuators and building block actuators are only a few examples of how this limitation can be surpassed. The simplest form of amplification, the stacks, consists of thin piezoceramic patches stacked to linearly increase their overall deflection while maintaining a low voltage requirement. The bender actuator architecture uses the internal piezoelectric strain to indirectly induce actuator motion. Benders consist of two or more layers of piezoelectric material that are poled and activated such that layers on opposite sides of the neutral axis have opposing strains. A special case of the bender actuator architecture is a unimorph. A unimorph is a composite beam, plate, or disk with one active layer and one inactive layer, or substrate. RAINBOW, ceramic biased oxide wafer (CERAMBOW), Crescent, and THUNDER actuators are typically referred to as unimorph benders [20].

\subsubsection{Macro Fibre Composite}

The Macro Fibre Composite (MFC) actuator is part of an emerging technology that strives to improve the current state of the art for structural actuation, which currently relies heavily upon monolithic piezoceramic materials. The MFC is a layered, planar actuation device that employs rectangular cross section, unidirectional piezoceramic fibers embedded in a thermosetting polymer matrix. This active, fiber-reinforced layer is then sandwiched between copper-clad Kapton film layers that have an etched interdigitated electrode pattern. During manufactur- 
ing, these layers are laid-up by hand and then cured in a vacuum hot-press. After the epoxy matrix that bonds the package together is fully cured, a high DC voltage $(1500 \mathrm{~V})$ is applied to the electrodes, thereby poling the piezoceramic material in the plane of the actuator and establishing the poling direction parallel to the PZT fibers. This in-plane poling and subsequent in-plane voltage actuation allows the MFC to utilize the $d_{33}$ piezoelectric effect, which is much stronger than the $d_{31}$ effect used by traditional PZT actuators with through-the-thickness poling.

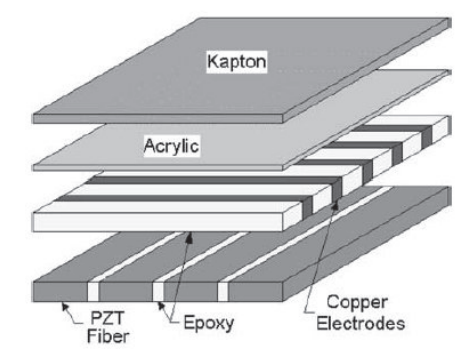

Figure 1-15: Layers of an MFC actuator [4]

A summary of the most important MFC engineering properties are listed in Table 1.2 .

\begin{tabular}{ll}
\hline Property & Value \\
\hline$d_{33}$ & $4.6 \mathrm{E}+02 \mathrm{pC} / \mathrm{N}$ \\
$d_{31}$ & $-2.1 \mathrm{E}+02 \mathrm{pC} / \mathrm{N}$ \\
Free strain per volt & $0.75-0.9 \mu \varepsilon / V$ \\
Tensile Modulus $E_{1}$ & $30.336 \mathrm{GPa}$ \\
Tensile Modulus $E_{2}$ & $15.857 \mathrm{GPa}$ \\
Poissons ratio, $\nu_{12}$ & 0.31 \\
Poissons ratio, $\nu_{21}$ & 0.16 \\
Shear modulus, $G_{12}$ & $5.515 \mathrm{GPa}$ \\
Maximum operational positive voltage, Vmax for $d_{33} \mathrm{MFC}$ & $+1500 \mathrm{~V}$ \\
Maximum operational negative voltage, Vmin for $d_{33} \mathrm{MFC}$ & $-500 \mathrm{~V}$ \\
Linear-elastic tensile strain limit & $1000 \mu \varepsilon$ \\
Maximum operational tensile strain & $<4500 \mu \varepsilon$ \\
Maximum operating temperature & $<80 C$ \\
Operational bandwidth & $0 \mathrm{~Hz}$ up to $10 \mathrm{kHz}$ \\
\hline
\end{tabular}

Table 1.2: MFC engineering properties 
The performance indicator of this actuator is its free strain per applied voltage value. The voltage versus strain characteristics is nonlinear and shows hysteresis, Figure 1-16.

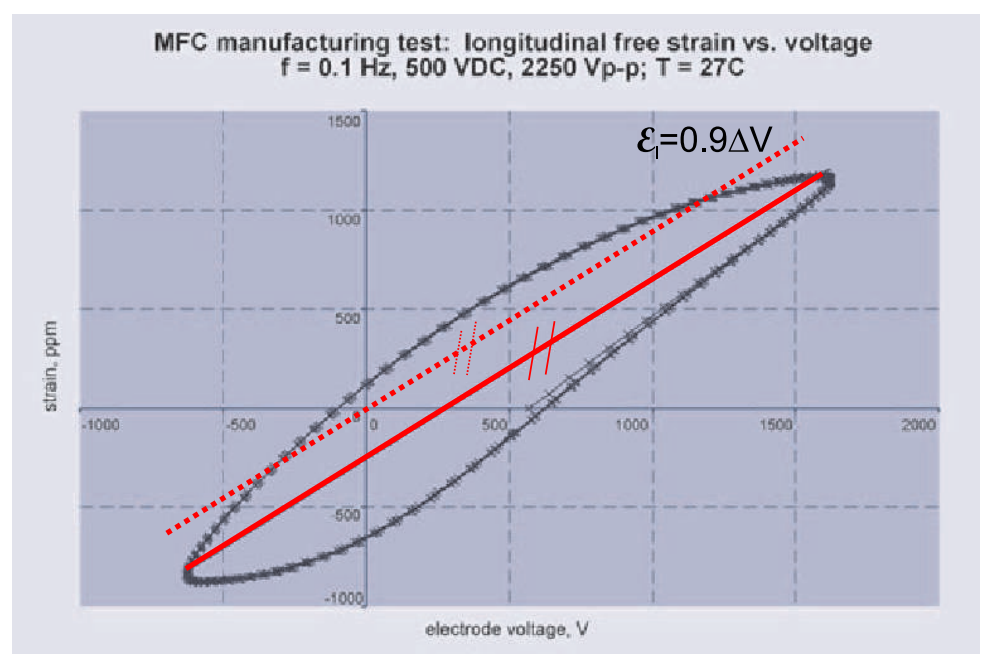

Figure 1-16: MFC voltage versus strain characteristics.

The free-strain per volt value is an approximate linear proportionality factor obtained from the line shown in solid red. In this work, the MFC actuation will be recreated by an equivalent thermal expansion coefficient. Thermal expansion is considered a linear effect represented by a single value and it is difficult to represent the nonlinear behaviour as well as the hysteresis. In fact, the true simulated behaviour is the one shown in dashed red line in Figure 1-16. 
1. INTRODUCTION AND OBJECTIVES 


\section{Chapter 2}

\section{Initial Exploratory Investigation}

Supported by published results, a first set of experiments was prepared early in the project. The objective of these first experiments was to use available rectangular MFC patches measuring $85 \mathrm{~mm}$ by $28 \mathrm{~mm}$ in square $\left[0^{\circ} / 90^{\circ}\right]$ laminates. The pre-preg used was the AS4/8552 carbon fibre/epoxy combination and the standard procedure to manufacture the plates was used (Figure 2-1).

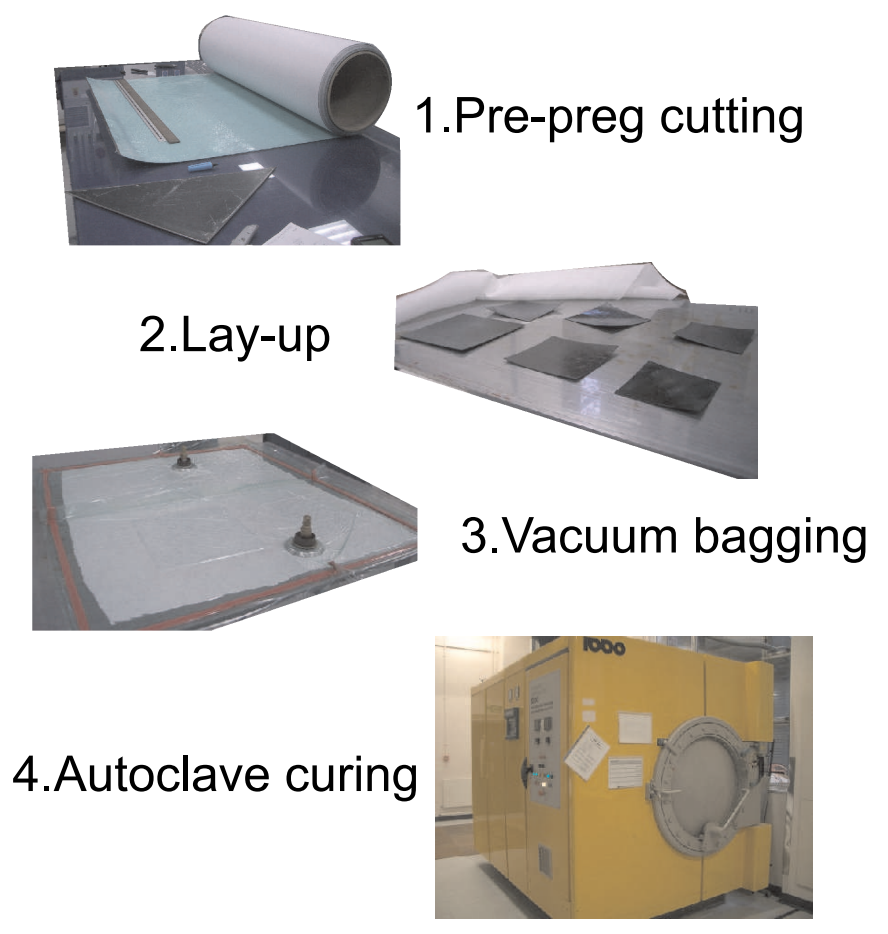

Figure 2-1: Manufacturing of the plates. 
Five curved, bi-stable, $150 \mathrm{~mm}$ by $150 \mathrm{~mm}$ plates were manufactured. The next step was the bonding of the MFC on the plate's surface. The direction and alignment of the MFC's is critical and it should be bonded in a way that when activated the actuator "flattens" the plate, Figure 2-2.

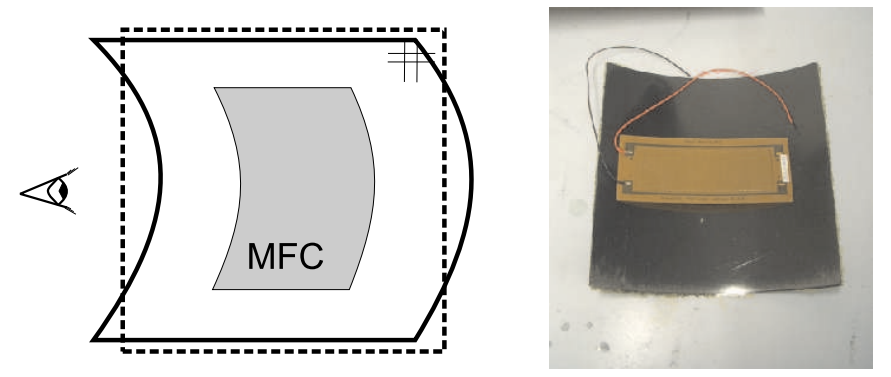

Figure 2-2: Direction in which the MFC should be bonded.

The bonding surface needs to be prepared with sandpaper first. The surface is considered ready to receive the adhesive when water wets it and sticks to it, instead of forming bubbles (wet-out test).

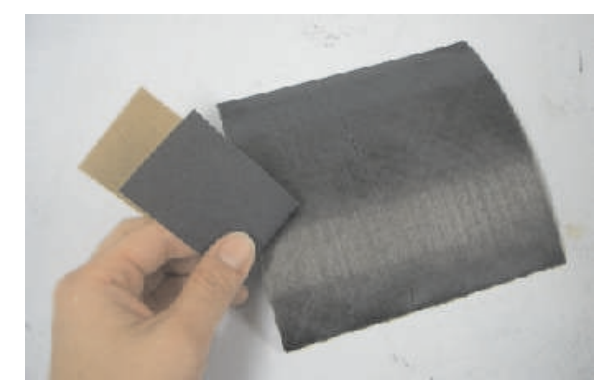

Figure 2-3: Preparing the laminate's surface.

Both the MFC and the laminate are cleaned with acetone and kept in closed bags to avoid contamination. 


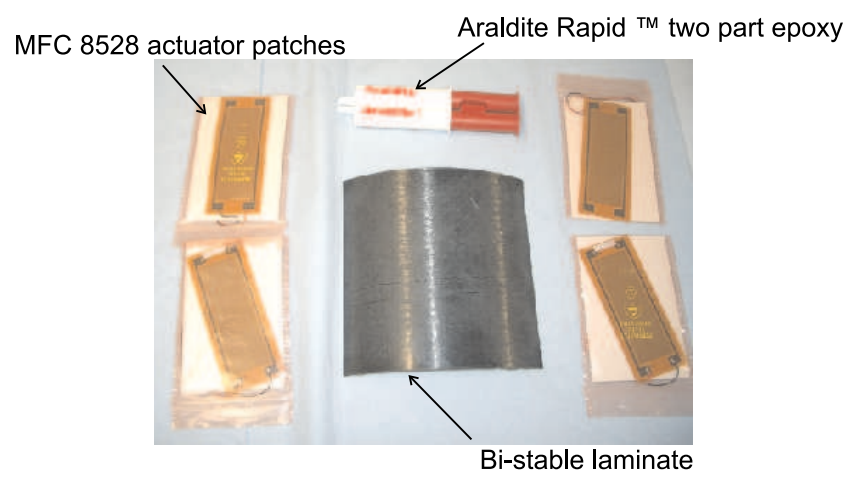

Figure 2-4: The bi-stable laminate, the MFC patches and the adhesive before bonding.

Araldite Rapid epoxy adhesive was chosen for the preliminary tests because it was readily available. This adhesive cures at room temperature and has a high viscosity. A layer of adhesive was applied to the laminate's bonding surface with a spatula and the patch was placed and kept in place with the help of tape. A vacuum bag was used to ensure that a uniform pressure was applied as well as any air bubbles trapped in the epoxy layer would disappear during the cure.

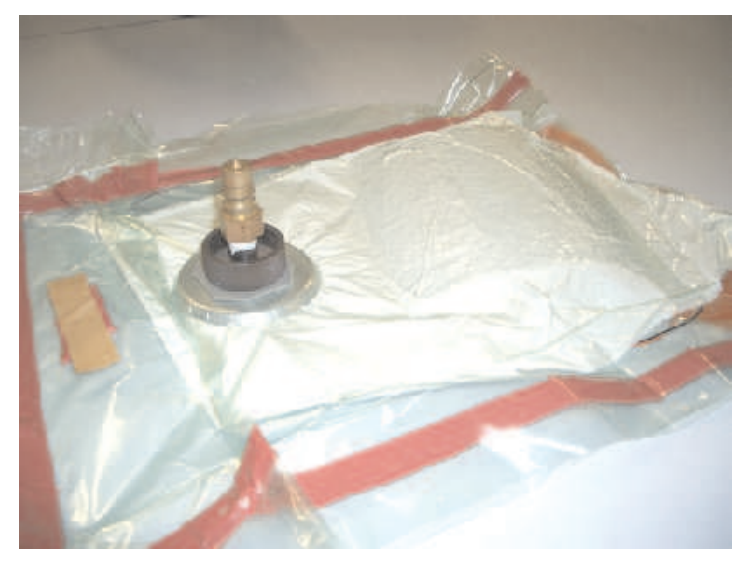

Figure 2-5: Vacuum bag used to cure the adhesive.

Figure 2-6 shows the MFC patch bonded to the laminate after the adhesive cured. The overflow of epoxy can be clearly seen and results in a odd looking bond. The bondline thickness also looks to thick. 


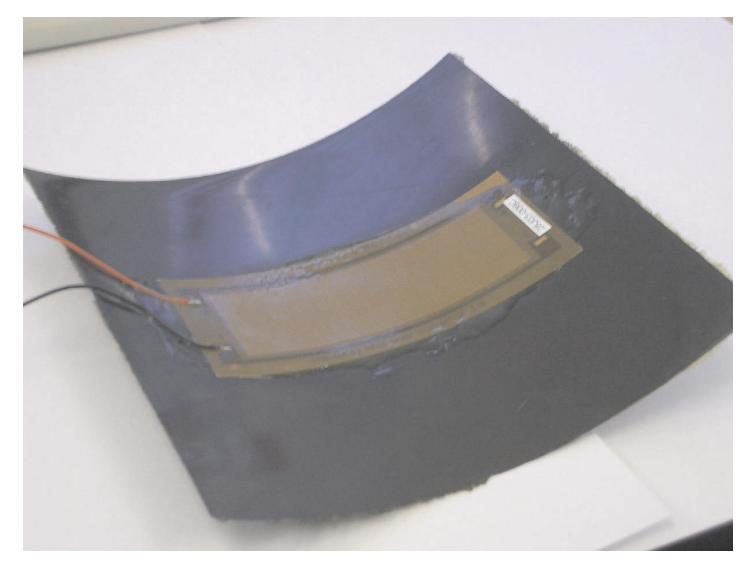

Figure 2-6: MFC patch bonded to the CFRP laminate.

Immediately after the cure a problem was detected. Although it was still possible to manually snap the plate to the other state, it required much more effort. Additionally, the plate did no remain in the alternative state for long but rather snapped back to its original configuration. Figure 2-7 illustrates this: as an external force is applied (green) there is an opposing spring-like force (red) that develops and prevents the laminate from snapping through. The magnitude of this spring-like force is significant. The laminate also became much thicker and stiffer when compared to laminates produced at the same time but without patches.

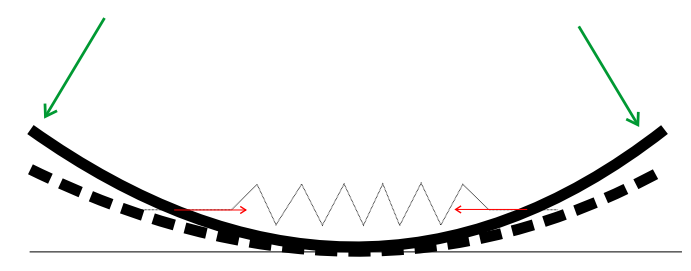

Figure 2-7: Spring effect.

Nevertheless the patch was tested and was actuated by a $1500 \mathrm{~V}$ DC power supply. As expected, little or no movement was seen. In another attempt, two MFC patches were bonded using the exact same procedure described above. The idea was to double the actuation force keeping the same underlying bi-stable 
structure, Figure 2-8.

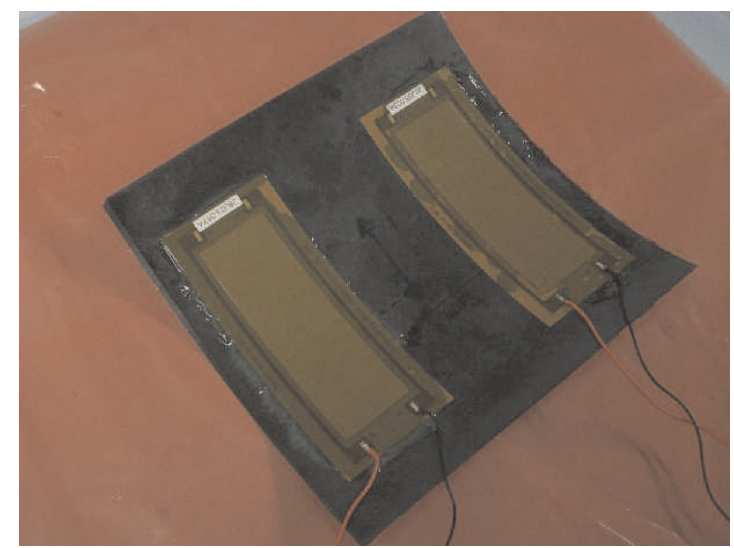

Figure 2-8: Two MFCs bonded to the laminate.

Again, the results were very clear once the adhesive layer was cured. The stiffness of the laminate increased even more and it was even more difficult to snap. By the end of these first experimental investigations several questions were unanswered:

1. What is the appropriate actuator size?

2. What is its effect on the laminate's stiffness?

3. How powerful does the actuator need to be?

4. Can the MFC be used to trigger snap-through in both ways?

To answer these questions a reliable FE analysis model had to be developed. This is the topic of the next chapter. 


\section{Chapter 3}

\section{Finite Element Simulations}

\subsection{Introduction and scope}

After the initial experiments that lead to unexpected results, it was decided to develop a simulation based on finite element (FE) analysis. Finite element modelling was used for several purposes. First, to reproduce the cured shapes of the asymmetrical laminates. This is not a new approach for this problem as FE predictions of asymmetrical laminates' shapes are documented for example in reference $[15]$. The cure of $\left[0^{\circ} / 90^{\circ}\right],\left[0^{\circ} / 45^{\circ}\right],\left[45^{\circ} /-45^{\circ}\right]$ square laminate were simulated and their shapes and snap-through behavior was compared to experimental data. This first task was useful to gain insight on the snap-through phenomenon. It was also necessary to confirm the analysis procedures and simplifying assumptions typical of FE analysis (i.e. boundary conditions, applied loads and the material properties). The second purpose of the FE analysis was to simulate the combined laminate/actuator system. The model should be helpful in predicting the changes in the laminate's stiffness due to the presence of the actuator. Having accomplished this, the model should also help predict the voltage required to induce the snap-through effect of the laminates. Again, a square $\left[0^{\circ} / 90^{\circ}\right]$ laminate with a MFC actuator bonded to it was modelled. This configuration was chosen because of available experimental data not only in literature, [10], but also in the tests performed during this project. Finally, a large number 
of models were created in order to chose the best laminate/MFC configuration. The parameters for this design process were:

1. Stacking sequence;

2. Laminate size;

3. Laminate thickness;

4. Actuator size;

5. Actuator orientation.

In the following sections these analysis and methods will be described in detail and the results will be presented and discussed.

\subsection{Modelling the curvature development}

\subsubsection{Theory}

The first task in the modelling effort was to accurately predict the cured shapes and snap-through phenomenon of the asymmetrical laminates. For that purpose, a square laminate plate with side length of $150 \mathrm{~mm}$ was modelled. The plates's geometry and boundary conditions are depicted in Figure 3-1. The central node was clamped. Although the plates' nominal length was $150 \mathrm{~mm}$, is was necessary to include some geometric imperfections into the FE model. The sketch is not a perfect square but rather a rectangle with side lengths of $149 \mathrm{~mm}$ by $151 \mathrm{~mm}$. This is considered to be acceptable as the manufactured plates will also include imperfections in its dimensions and due to fibre misalignments. Using perfectly square plates in the FE model will make the analysis converge to unstable saddle shapes instead of stable cylindrical ones. The reason why this happens is still not clear. However, a hypothesis was formulated that this is related with the fact that the FEM developed does not handle the inertia forces. A good argument in favour of this hypothesis is the fact that this only happens in an implicit static 


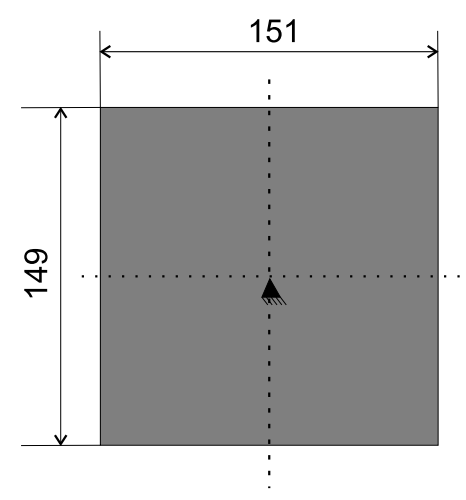

Figure 3-1: FE model boundary conditions

analysis (i.e. using Abaqus/Standard, for example). If instead of an implicit method an explicit method or a implicit direct-integration dynamic method is used to predict the cured shapes, the perfectly square plate will converge into a cylinder. In an explicit or direct-integration dynamic method, Abaqus solves the dynamic equilibrium equation in which the inertia effects are considered. An Abaqus/Explicit model was created that verified this. The main disadvantage of explicit models is the associated computational cost. Although the effort associated to a time step is very small, it is usually necessary to have thousands of time steps before an analysis is complete. In this particular case this increases the total run time from a couple of minutes to several hours or even days using a PC. The implicit direct-integration dynamic method solves the dynamic equilibrium equations for dynamic quantities at time $t+\Delta t$ based not only on values at $t$, but also on these same quantities at $t+\Delta t$. But because they are implicit, nonlinear equations must still be solved [21]. The total run time is shorter than in explicit models but still too long to be useful for design purposes. Thus, an explanation for the problem was, in principle, found. Although a way was found to make perfectly square plates converge into a cylinder instead of into a saddle, the traditional method of including a geometric imperfection was adopted anyway. The reason for this is the time it takes to run an explicit analysis compared to an implicit one and the accurate results that the implicit method provides regardless of the geometric imperfections introduced. In every model, nonlinear 
geometry was considered.

\subsubsection{Model description}

Two materials were used for the initial tests and, consequently for the analysis: the AS4-8552 and T800-977-2 carbon fibre prepreg. The mechanical properties of these two prepregs used in the models are listed in table 3.1 SI units were used in all the models.

\begin{tabular}{lll}
\hline Property & Value $(\mathrm{AS} 4-8552)$ & Value $(\mathrm{T} 800-2020)$ \\
\hline$E_{1}$ & $135 \mathrm{GPa}$ & $294 \mathrm{GPa}$ \\
$E_{2}$ & $9.5 \mathrm{GPa}$ & $9.5 \mathrm{GPa}$ \\
$\nu_{12}$ & 0.3 & 0.3 \\
$G_{12}$ & $5 \mathrm{GPa}$ & $5 \mathrm{GPa}$ \\
$G_{13}$ & $7.17 \mathrm{GPa}$ & $7.17 \mathrm{GPa}$ \\
$G_{23}$ & $3.97 \mathrm{GPa}$ & $3.97 \mathrm{GPa}$ \\
$\alpha_{1}$ & $-2 \times 10^{-8} /{ }^{\circ} \mathrm{C}$ & $-2 \times 10^{-8} /{ }^{\circ} \mathrm{C}$ \\
$\alpha_{2}$ & $-3 \times 10^{-5} /{ }^{\circ} \mathrm{C}$ & $-2.25 \times 10^{-5} /{ }^{\circ} \mathrm{C}$ \\
$t_{p l y}$ & $0.255 \mathrm{~mm}$ & $0.180 \mathrm{~mm}$ \\
\hline
\end{tabular}

Table 3.1: Mechanical properties of the AS4-8552 and the T800-977-2 pre-pregs used in the FE models

Although the T800 fibre is much stiffer then the AS4 one, the pre-preg ply thickness is roughly $60 \%$ of the AS4 one. Since the snap-through phenomenon is achieved by applying a bending moment, it is the flexural stiffness that plays a central role. The bending stiffness matrix is computed as: $[D]=\frac{1}{3} \sum_{k=1}^{2}[\bar{Q}]^{k}\left(z_{k}^{3}-z_{k-1}^{3}\right)$ The cubic dependence of the ply thickness is notorious. Hence, a $60 \%$ change in ply thickness will have a significant effect in the laminate's bending stiffness. Thus, the T800 material was used in the second set of experiments and in the following FE models unless otherwise specified in the text.

General purpose composite shell elements were used (type S4R). The meshes have approximately 900 elements. The analysis was divided into two different steps as shown in Figure 3-2. An initial temperature field of $180^{\circ} \mathrm{C}$ was imposed to the elements before starting the analysis. This represents the cure cycle's max- 
imum temperature which is taken as the stress-free temperature as well. Step one is a simple $*$ STATIC step where large deformation theory was used (NLGEOM) to calculate the plate's deformation due to a temperature change of $\Delta T=160^{\circ} \mathrm{C}$.

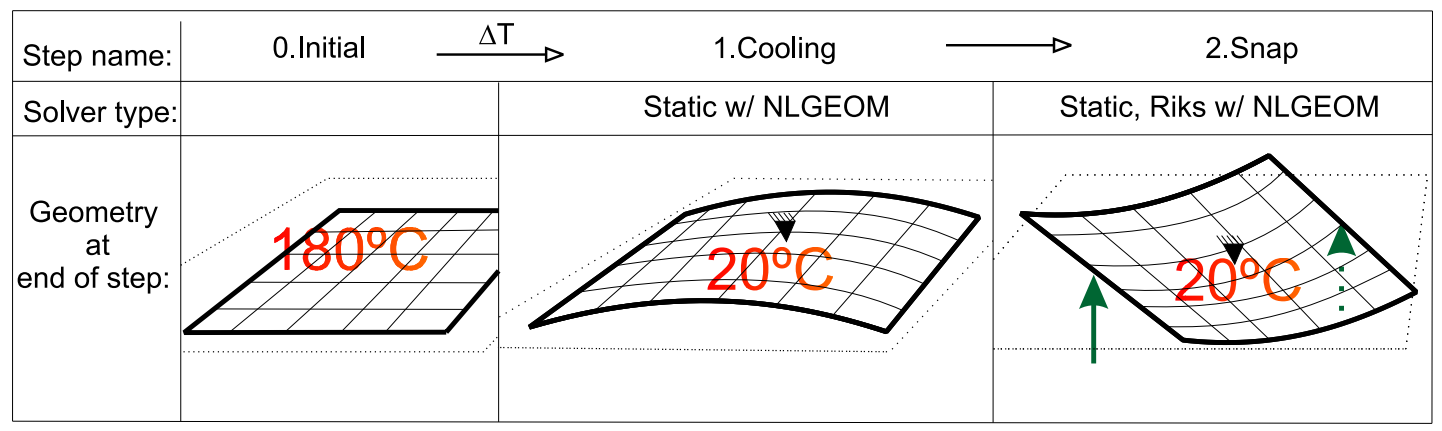

Figure 3-2: Representation of the analysis steps used

Figure 3-3 represents the plate at the end of this first step together with the undeformed mesh.

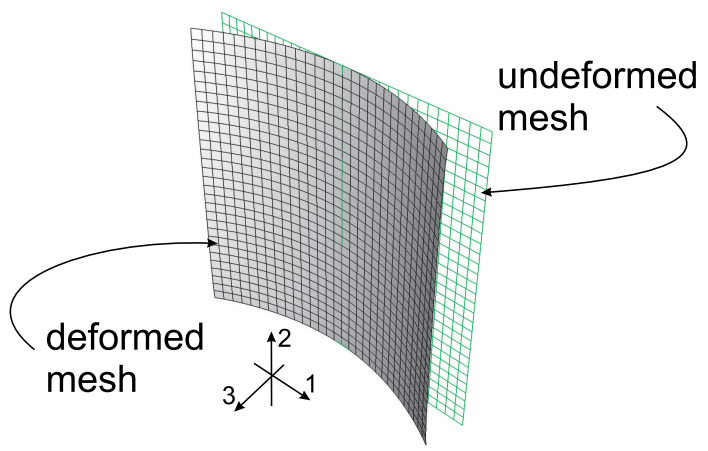

Figure 3-3: FE plot of the deformed plate at the beginning of the snap-through step. Scale factor $=1$

This displacement field shown in Figure 3-3 is qualitatively in good agreement with that observed in real plates. The curvatures were calculated as part of the output (*OUTPUT FIELD, SE) and compared to those measured in the real plates. The procedure to measure the curvature was taken from reference [10] and consists of tracing the contour of the laminate onto a white paper. 


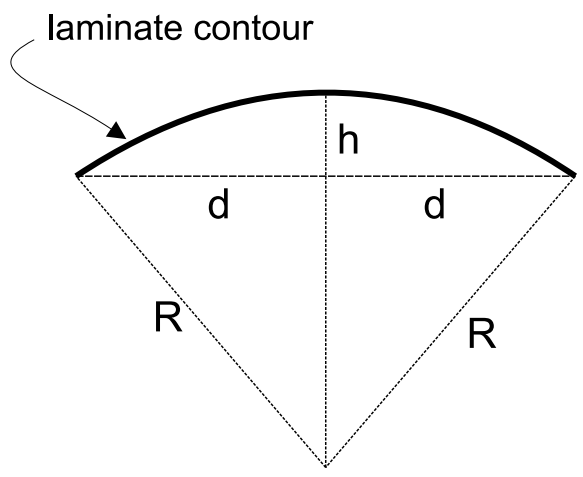

Figure 3-4: Definition of parameters used to calculate the curvature

The geometric parameters described in Figure 3-4 were measured and the curvatures were calculated using the equations (3.1)

$$
\begin{gathered}
R=\frac{\sin \left(\tan ^{-1}\left(\frac{d}{h}\right)\right) \sqrt{d^{2}+h^{2}}}{\sin \left(\pi-2 \tan ^{-1}\left(\frac{d}{h}\right)\right)} \\
\kappa=\frac{1}{R}
\end{gathered}
$$

The curvature directions and the way they are defined is shown in Figure 3-5.

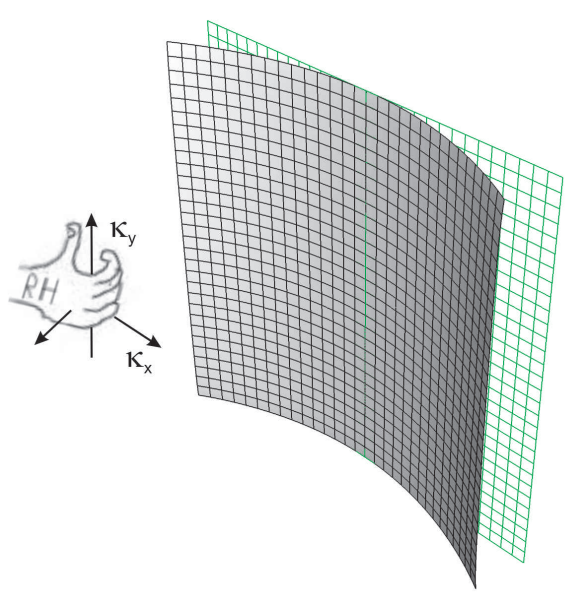

Figure 3-5: Definition of principal curvatures directions 
Figure 3-6 shows the Abaqus output plot for the surface curvatures of $\left[0^{\circ} / 90^{\circ}\right]$, $\left[45^{\circ} /-45\right]$ and $\left[0^{\circ} / 45^{\circ}\right]$ square $150 \times 150 \mathrm{~mm}$ laminates.
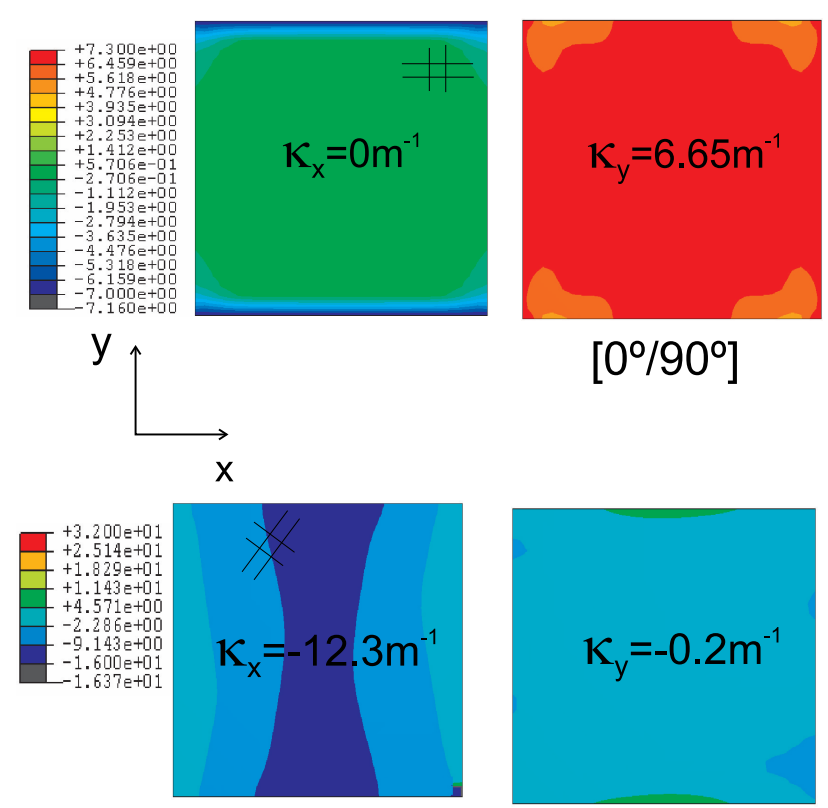

$\left[-45^{\circ} / 45^{\circ}\right]$
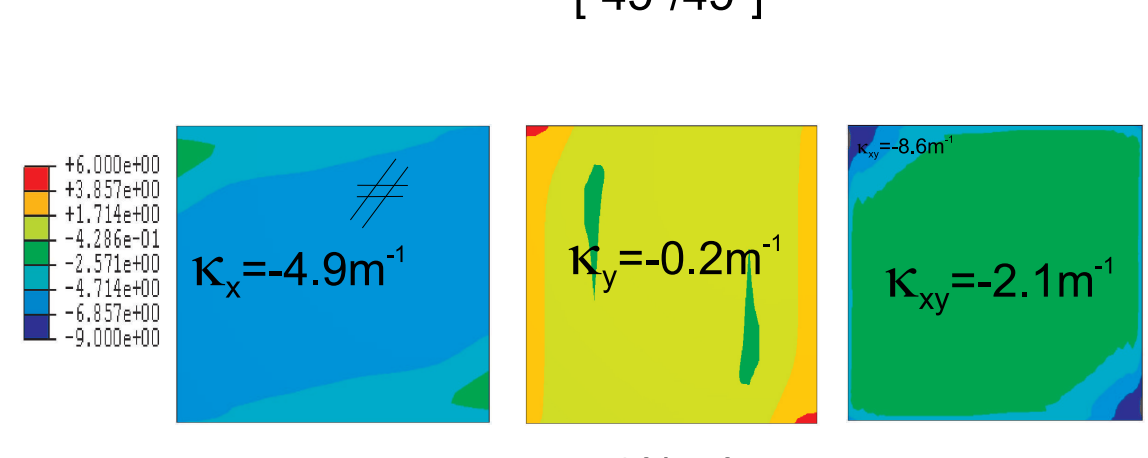

$\left[0^{\circ} / 45^{\circ}\right]$
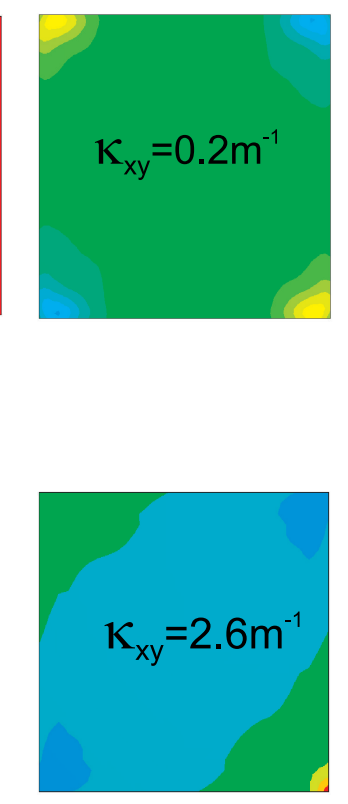

$\left[0^{\circ} / 90^{\circ}\right]$
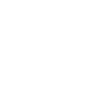

Figure 3-6: FE contour plots of the three principle curvatures for the three different lay-ups 
These plots show that, as expected, the distribution of curvatures is affected by the plates' boundaries. The middle section has a relatively constant curvature and this can be compared to measurements in real plates.Figure 3-7 pictures a qualitatively comparison between shapes obtained in the FE models and the ones observed in the manufactured laminates.

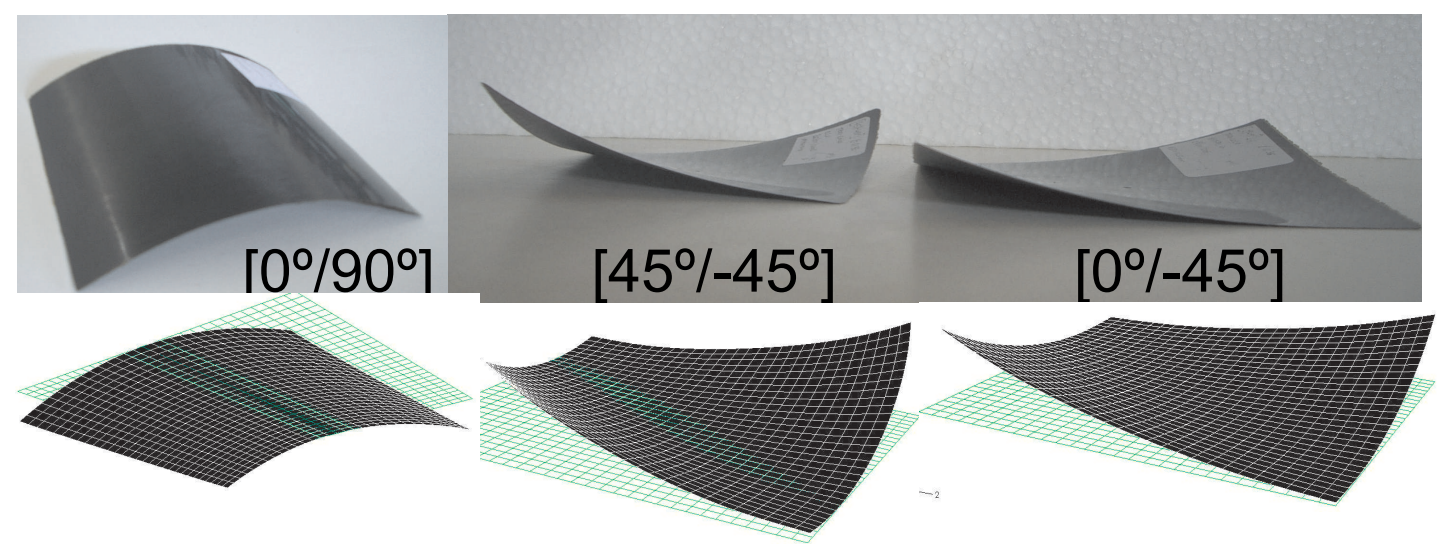

Figure 3-7: Comparison between FE shapes and those of the manufactured laminates.

\begin{tabular}{cccc}
\hline & Measured $(1 / m)$ & Finite Element $(1 / m)$ & Error $(\%)$ \\
\hline$\kappa_{y}$ & 6.51 & 6.65 & 2.1 \\
\hline
\end{tabular}

Table 3.2: Comparison between measured curvature and curvature obtained with FE

For the $\left[45^{\circ} /-45^{\circ}\right]$ laminates a different set of boundary conditions had to be used, Figure 3-8. Clamping the middle node was not enough to prevent the laminate to converge into an unstable shape regardless of the geometric imperfection used. Again, the explicit version of this model converged effortlessly into the stable shape without the need for geometric imperfections and with only the middle node clamped. 


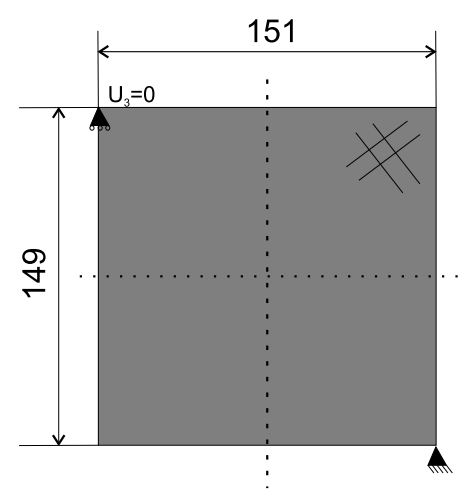

Figure 3-8: Boundary conditions used on the $\left[45^{\circ} /-45^{\circ}\right]_{T}$ laminate models

The curvature measurements were made after the plates were dried and dissicated. 


\subsubsection{Moisture effects and stress relaxation.}

Composite materials absorb moisture from the environment where they are immersed (air, water or any other fluid). Moisture absorption creates a stress field not unlike the one created by thermal stresses (see chapter 1.3). In this particular application the effect of the hygroscopic stress field is to relax the existing residual stress field and thus reduce the plates' curvature. This reduction in curvature, and consequently in the peak snap-through load, was included in the FE model. Abaqus does not include this effect in its constitutive models. In order to overcome this limitation, a modification of the thermal expansion coefficients is required to account for hygroscopic effects. Using Voigt notation to represent the several tensors, the hygrothermoelastic constitutive equations are developed assuming the effective strain is the superposition of the three strains acting on ply $k$ :

$$
\{\varepsilon\}^{k}=\left\{\varepsilon^{\sigma}\right\}^{k}+\left\{\varepsilon^{T}\right\}^{k}+\left\{\varepsilon^{H}\right\}^{k}
$$

where:

$\left\{\varepsilon^{\sigma}\right\},\left\{\varepsilon^{T}\right\},\left\{\varepsilon^{H}\right\}$ are the mechanical, thermal and hygroscopic strains.

Assuming plane stress conditions and neglecting the mechanical strains:

$$
\begin{gathered}
\{\varepsilon\}^{k}=\{\alpha\}^{k} \Delta T+\{\beta\}^{k} \Delta M= \\
=\left(\{\alpha\}^{k}+\{\beta\}^{k} \frac{\Delta M}{\Delta T}\right) \Delta T=\left\{\alpha^{*}\right\}^{k} \Delta T
\end{gathered}
$$

where:

$\{\alpha\}^{k}$ are the coefficients of thermal expansion in the ply coordinate system.

$\{\beta\}^{k}$ are the coefficients of moisture expansion in the ply coordinate system. 
$\left\{\alpha^{*}\right\}^{k}$ are the equivalent moisture expansion coefficients accounting for the effects of both thermal and hygroscopic residual strains.

$\Delta T$ is the applied temperature field.

$\Delta M$ is the percent weight gained through moisture absorption.

Assuming that $\Delta T<0$ and $\Delta M>0$ to force a coherent behaviour, the components of the $\alpha^{*}$ vector are:

$$
\left\{\begin{array}{c}
\alpha_{1}^{*} \\
\alpha_{2}^{*} \\
0
\end{array}\right\}^{k}=\left\{\begin{array}{c}
\alpha_{1} \\
\alpha_{2} \\
0
\end{array}\right\}^{k}+\left\{\begin{array}{c}
\beta_{1} \\
\beta_{2} \\
0
\end{array}\right\}^{k} \frac{\Delta M}{\Delta T}
$$

Typical values for $\beta$ is 0.0 in the fibre direction and $0.005 \frac{1}{\% M}$ in the transverse direction [22]. The percent weight gain is defined as

$$
\Delta M=\frac{\text { Weight of moist material-Weight of dry material }}{\text { Weight of dry material }} \times 100
$$

The maximum moisture content, $M_{m}$ or $\Delta M$, varies with relative humidity of the environment, the nature of the fluid, the matrix material and geometry. Thinner laminates reach a higher maximum moisture content faster than thicker ones. Springer [23] identifies the relation between maximum moisture content and relative humidity of the air, $\phi$, as:

$$
M_{m}=a \phi^{b}
$$

where $a$ and $b$ are constants to be determined experimentally. Springer [23] specifies the parameters $a$ and $b$ for three different materials exposed to humid air

Thus, assuming a relative humidity of $40 \%$ the time required for a composite material to attain $99.9 \%$ of its maximum possible moisture content is 


\begin{tabular}{lll}
\hline & $a$ & $b$ \\
\hline $\mathrm{T} 300 / 1034$ & 0.017 & 1 \\
$\mathrm{AS} / 3501-5$ & 0.018 & 1 \\
$\mathrm{~T} 300 / 5208$ & 0.015 & 1 \\
\hline
\end{tabular}

Table 3.3: Typical values for $a$ and $b$ parameters

$$
t_{m}=\frac{0.67 s^{2}}{D_{x}}
$$

where $s$ is the thickness of the laminate when it is exposed on two sides to the same environment and $D_{x}$ is the diffusity of the material in the direction normal to the surface. From reference [23]:

$$
D_{x}^{a v g}=c^{-\exp }-\left(\frac{d}{T}\right)
$$

Here, again, $c$ and $d$ are constants that depend on the material and must be determined experimentally and $T$ is the temperature in Kelvin. Experimental values for $c$ and $d$ are taken again from [23] .

\begin{tabular}{lll}
\hline & $c$ & $d$ \\
\hline T300/1034 & 0.83 & 5219 \\
AS/3501-5 & 6.51 & 5722 \\
T300/5208 & 0.58 & 5113 \\
\hline
\end{tabular}

Table 3.4: Typical values for $c$ and $d$ parameters

This data is combined into a single table with that of table 3.3 to calculate the maximum moisture content and the time required to reach equilibrium for the three different materials.

\begin{tabular}{lll}
\hline & $t($ days $)$ & $M_{m}$ \\
\hline T300/1034 & 66 & 0.68 \\
AS/3501-5 & 47 & 0.72 \\
T300/5208 & 70 & 0.6 \\
\hline
\end{tabular}

Table 3.5: Maximum moisture content and time to reach it for three different materials

Table 3.5 shows that the maximum moisture content does not vary too much. 
but the time it takes to reach equilibrium is significantly different. For the analysis purposes, and because there is no available data relative to the material a value of, $M_{m}=0.5$ was chosen. The $\alpha^{*}$ vector is

$$
\left\{\begin{array}{c}
2 \times 10^{-8} /{ }^{\circ} \mathrm{C} \\
2.25 \times 10^{-5} /{ }^{\circ} \mathrm{C} \\
2.25 \times 10^{-5} /{ }^{\circ} \mathrm{C}
\end{array}\right\}-\left\{\begin{array}{c}
0 \\
0.005 \\
0
\end{array}\right\} \frac{0.4}{160}=\left\{\begin{array}{c}
2 \times 10^{-8} /{ }^{\circ} \mathrm{C} \\
6.85 \times 10^{-6} /{ }^{\circ} \mathrm{C} \\
2.25 \times 10^{-5} /{ }^{\circ} \mathrm{C}
\end{array}\right\}
$$

With this data inserted into the FE model the change in curvature due to moisture absorption can be determined by calculating the curvature of the moist material. The following table lists those values for the $\left[0^{\circ} / 90^{\circ}\right] 150 \mathrm{~mm} \times 150 \mathrm{~mm}$ laminate.

\begin{tabular}{lll}
\hline & Dry & Moist \\
\hline$\kappa_{1}\left(m^{-1}\right)$ & 0 & 0 \\
$\kappa_{2}\left(m^{-1}\right)$ & 6.65 & 2.06 \\
$\kappa_{12}\left(m^{-1}\right)$ & \pm 0.02 & \pm 0.05 \\
\hline
\end{tabular}

Table 3.6: Effect of moisture content on the curvature.

The true measurement of moisture effect will become clearer in the next section where the snap-through loads are calculated.

\subsubsection{Discussion of results}

The actual thickness of the plates was measured and feedback to the model. Considering the uncertainties in the laminate's thickness, the relative thickness of each ply and in the material properties, these results were considered fairly acceptable. It was concluded that this procedure was accurate enough to simulate curvatures due to the curing cycle. To simulate the curvature development of $\left[45^{\circ} /-45^{\circ}\right]_{T}$ laminates it is necessary to use different boundary conditions that somehow force the plate into the stable shape. To overcome this limitation and to verify how that stable shape looks like and explicit model or implicit dynamic model should be run first. The approach used to include the moisture effects was also considered acceptable. A sensitivity study could have been made in order to 
better fit the results. However the FE models were developed with the purpose of delivering blind predictions with only little or no feedback from experimental data and access the method's accuracy for design purposes. A parametric study would not be helpful because its conclusions would be dependent on parameters that are different from plate to plate (p.e. individual ply thickness, true moisture content, measured material properties).

\subsection{Modelling the snap-through event}

\subsubsection{Theory}

As described in chapter one some asymmetrical laminates will, depending on the lay-up and geometry, exhibit what is known as snap-through behaviour. The objective of this second analysis step is to determine the load maximum (critical load) by analyzing the equilibrium path in the load displacement curve. This information was then compared with experimental data and used to evaluate the energy requirements and select a proper piezoelectric actuator. All in all it was used as a design tool. Snap-through is a buckling mechanism. Usually, eigenvalue analysis is used to predict buckling behaviour of "stiff" structures. This procedure is not suitable if large geometry changes occur prior to buckling as is the case in snap-through phenomenons. Fully non-linear transient analysis could be used to tackle this limitation either by adding inertia forces or viscous stabilizing ones. Both methods tend to obscure the structures behaviour by respectively creating oscillations in the post-buckling response and by artificially amplifying the viscous effects. The traditional Newton-Raphson method is also not suitable to study post-buckling or snap-through behaviour as it does not converge when a load maximum is reached (Figure 3-9).

Thus, an algorithm is needed that increases and decreases the load in varying increment sizes in response to the structure equilibrium requirements. The Riks method uses an algorithm in which the applied loads are adapted automatically, but the solution must be solved for loads and displacements simultaneously. To 


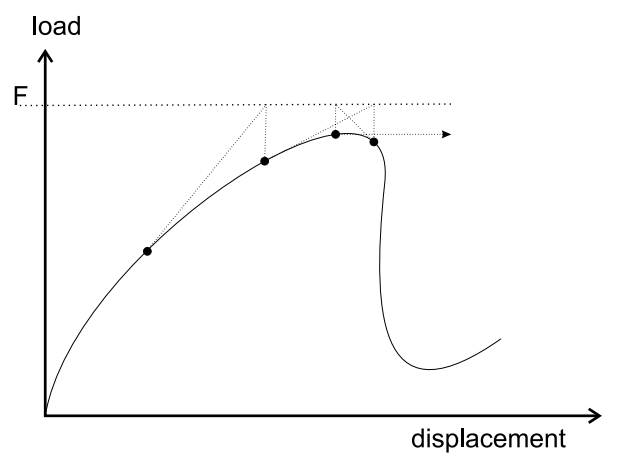

Figure 3-9: Solution failure if load maximum is reached

measure the progress of the solution the arc-length " $\Delta l$ ", which is the norm of the change in displacements and load is chosen.

$$
\Delta l^{2}=\sum_{N}\left(\Delta u^{N}\right)^{2}+(\lambda \Delta F)^{2}
$$

where $\mathrm{F}$ represents a loading parameter and $\lambda$ is a scaling factor called "load proportionality factor" (LPF).

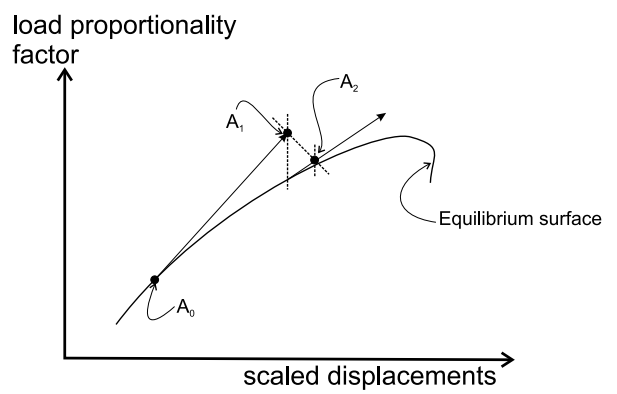

Figure 3-10: The arc length method implemented in Abaqus

This algorithm must be included in an iterative Newton-Raphson scheme (Figure 3-10). A form of this method is available in Abaqus and is activated by adding the RIKS parameter on the $*$ STATIC option. The method is named after Edward Riks, who first introduced the concept in the early 70's. The method works well if the equilibrium path in the load displacement space is smooth and does not branch. 
The magnitude of the force that the user inputs is irrelevant as the Riks algorithm automatically increases or decreases it by multiplying it by the load proportionality factor. If the Riks step is a continuation of a previous history, any loads that exist at the beginning of the step and are not redefined are treated as "dead" loads with constant magnitude. A load whose magnitude is defined in the Riks step is referred to as a "reference" load. All prescribed loads are ramped from the initial (dead load) value to the reference values specified. The loading during a Riks step is always proportional.The current load magnitude, $P_{\text {total }}$, is defined by:

$$
P_{\text {total }}=P_{0}+\lambda\left(P_{\text {ref }}-P_{0}\right)
$$

where $P_{0}$ is the "dead load," $P_{r e f}$ is the reference load vector, and $\lambda$ is the "load proportionality factor" (LPF). The load proportionality factor is found as part of the solution, [21]. The user can limit the value of the LPF as a stopping conditions.

\subsubsection{Model description}

Recalling Figure 3-2, the snap-through step naturally followed the curvature development step. The elements definition and meshes are therefore the same. Again, the purpose of this step was to understand the buckling mechanism and calculate the critical loads. The piezoelectric actuators were not yet considered at this stage. The use of piezoelectric elements is also not allowed in a Riks step. They were modelled in a different way as will be shown in a later section. Figure 3-11 represents the FE plots of the two stable states. 

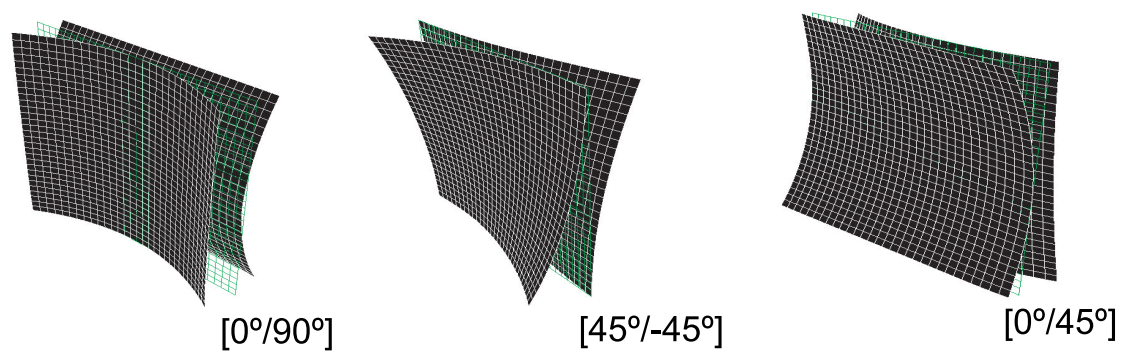

Figure 3-11: FE plots of the two stables states for the three different laminates

The force required to produce snap through can be monitored in the clamped node. A plot of this force versus step increment (arc length in the case of a Riks procedure) is shown in Figure 3-12.
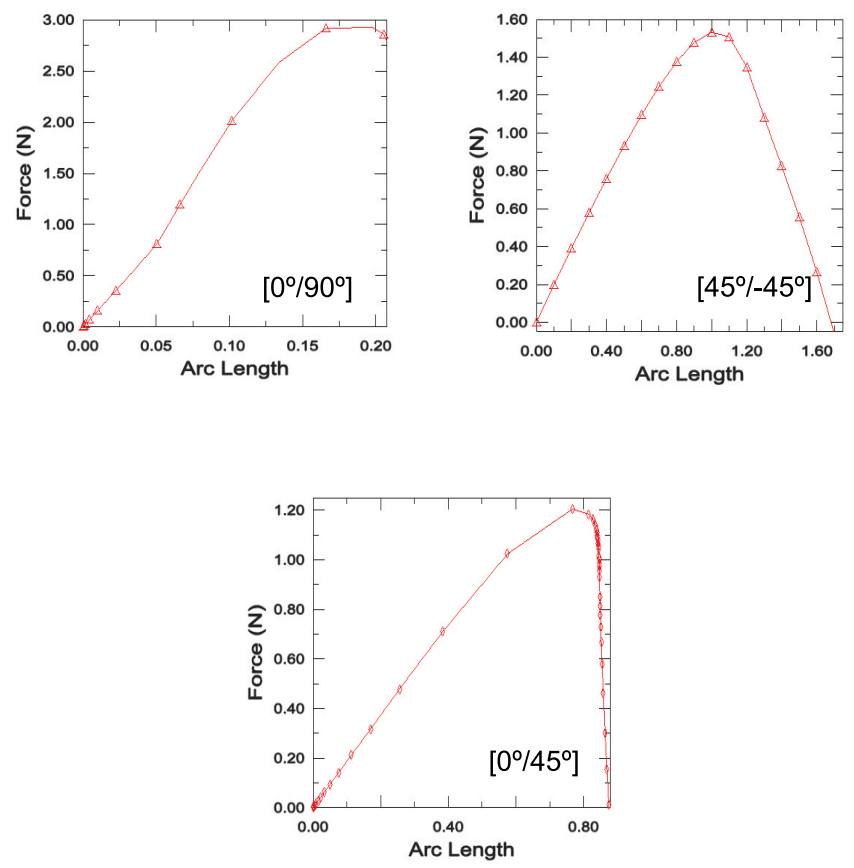

Figure 3-12: Evolution of the applied load with the step increment

Figure 3-2 depicts the loading applied to the FE model during this step. Two concentrated forces were applied to the middle of the edges. The force increases linearly until it reaches a maximum (critical load). This is the required force to induce transition. After this point the snap-through buckling will occur and the 
force can be removed. This is an important conclusion that will be used in the next step of the modelling process.

Potter et. al [5] provide experimental measurements of the load-displacement curve of the snap-through of a $150 \mathrm{~mm} \times 150 \mathrm{~mm}$ square $\left[0^{\circ} / 90^{\circ}\right]$ laminate. (Figure 3-13). The material used was the AS4 fibre. The load was applied in the middle of the plate which was supported on a rigid table.

The displacement measured is the displacement of this point. The simulation's
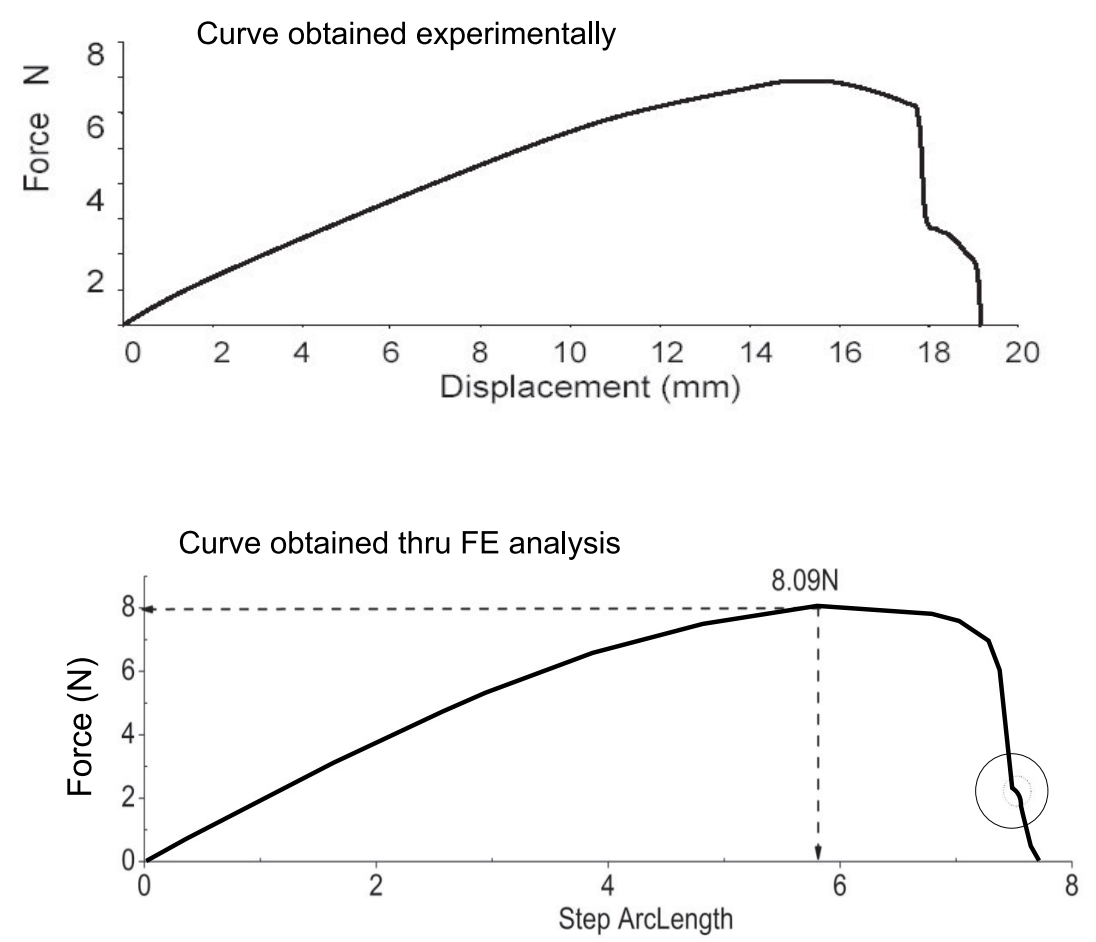

Figure 3-13: Measured force versus displacement. Taken from [5]

results are in good agreement with the experimental results. In fact, the analysis was able to capture the nonlinearity in the unloading portion of the plot. This corresponds to a point where part of the plate buckles while the other remains unchanged. Thus, this method is adequate to simulate the snap-through effect both qualitatively and quantitatively. Figure 3-14 shows the same experimental curve now plotted against load displacement curves obtained with FE. The displacement assumed for the FE model curves is the mean displacement of the 
points where the force is being applied. It is affected by the free-edge boundary conditions which could explain why the displacements decrease slightly in the unloading portion of the curve. The difference between a dry laminate and a moistened laminate at equilibrium in a $40 \%$ relative humidity is also notorious.

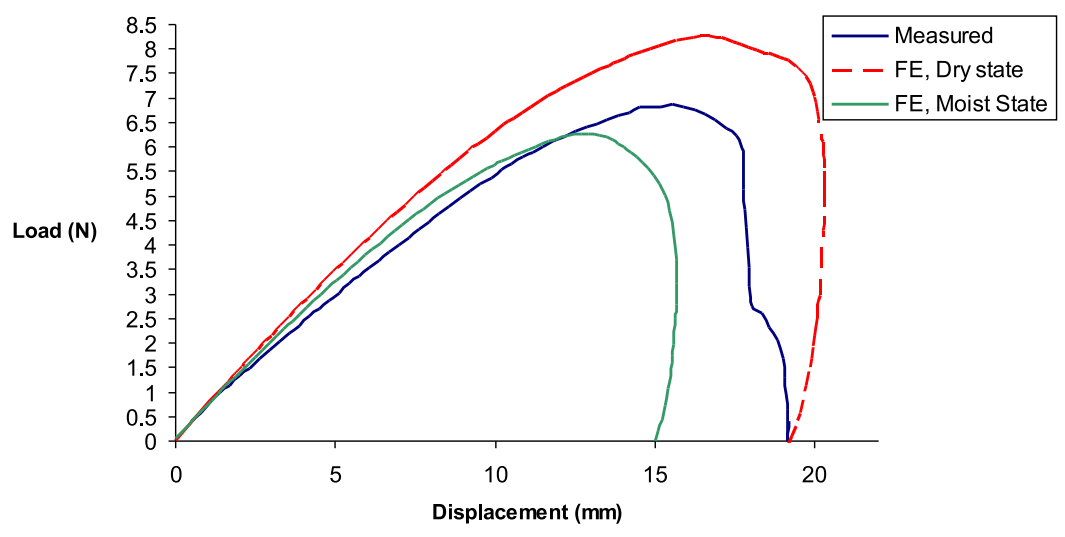

Figure 3-14: Measured force [5] versus displacement.

A small parametric study was done involving variations in the plate's length and stacking sequence. Using the stacking sequence $\left[0^{\circ} / 90^{\circ}\right]_{T}$ three other square models with nominal lengths of $200 \mathrm{~mm}, 250 \mathrm{~mm}$ and $300 \mathrm{~mm}$ were analyzed together with a $\left[0^{\circ} /-45^{\circ}\right]$. The critical force was measured in real plates and compared to the ones determined in the FE models (Table 3.7).

\begin{tabular}{lccc}
\hline & FE (N) & Measurement(N) & Error (\%) \\
\hline $150 \mathrm{~mm},[0 / 90]$, AS4 & 8.1 & 7.9 & 2.2 \\
$150 \mathrm{~mm},[0 / 90], \mathrm{T} 800$ & 2.9 & 2.4 & 20.4 \\
$200 \mathrm{~mm},[0 / 90], \mathrm{T} 800$ & 2.3 & 2.3 & 2.8 \\
$300 \mathrm{~mm},[0 / 90], \mathrm{T} 800$ & 3.0 & 3.1 & 2.3 \\
$120 \mathrm{~mm},[0 / 45], \mathrm{T} 800$ & 1.2 & 1.9 & 37.3 \\
\hline
\end{tabular}

Table 3.7: Comparison of measured versus FE calculated critical loads

A very simple curve polynomial curve fit was done and is show in figure 315. This is useful to predict the snap-through forces of slightly shorter or longer plates. Assuming the force is applied at the same points, this second degree approximation can be considered reasonable. 


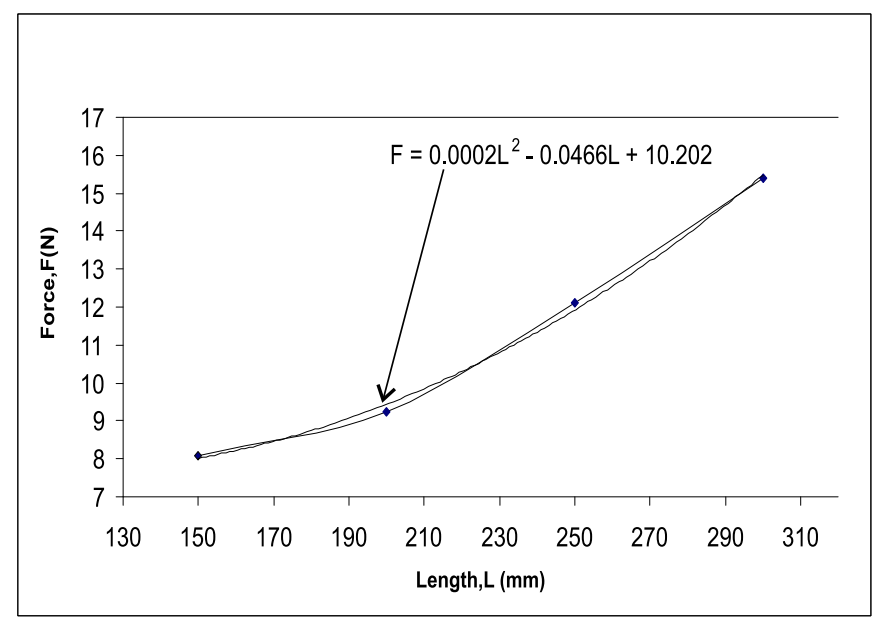

Figure 3-15: Maximum force versus plate length plot. Polynomial fit allows to extrapolate for shorter or longer plates

As expected the required snap-through forces increases as the plates get larger. Finally, the influence of the moisture content was analyzed. Using the procedure developed in the previous section, the FE model was changed to reflect the hygroscopic effects. The critical load was calculated for a $\left[0^{\circ} / 90^{\circ}\right], 150 \mathrm{~mm} \times 150$ mm AS4 laminate. The following table compares both measured and FE results

\begin{tabular}{llll}
\hline & Dry & Moist & \%Decrease \\
\hline Measured & $7.9 \mathrm{~N}$ & $4.73 \mathrm{~N}$ & $67 \%$ \\
FE analysis & $8.09 \mathrm{~N}$ & $4.38 \mathrm{~N}$ & $84 \%$ \\
Error(\%) & $2.4 \%$ & $7.49 \%$ & - \\
\hline
\end{tabular}

Table 3.8: Effect of moisture content of the critical force

\subsubsection{Discussion of results}

Given the good correlation between FE and crude experimental measurements, the procedure described above was considered adequate to determine the snapthrough loads of simple bi-stable laminates. The effect was both qualitatively and quantitatively well captured. This data is relevant for the next step in the analysis procedure where the actuator patch was included. While the Riks method is very useful to search for the critical load and to capture the entire load 
history during the buckling part analysis it is not strictly necessary to use it to induce snap-through. In principle, it can be done by simply applying a load that is sufficiently close the critical one in a simple $*$ STATIC, NLGEOM step. The inclusion of hygroscopic effects is crucial for the true evaluation of the bi-stable laminates' performance and should not be neglected. Once again, the method described in this work was considered adequate when compared to available experimental data. 


\subsection{Modelling the piezoelectric actuator}

\subsubsection{Theory}

The next step into the modelling process is to include the MFC patch and its influence into the system's stiffness together with its actuation effect. After the plates are cured, the actuators are bonded to one of its surfaces. The bonding procedure is described in Chapter 2 This means that during the cure, the plates are allowed to assume its equilibrium shapes freely. This is different than having the actuators bonded to it before the cure and actually co-curing them with the prepreg (this is also not recommended as the MFC'c maximum operating temperature is $150^{\circ} \mathrm{C}$ and the maximum curing temperature is $180^{\circ} \mathrm{C}$ ). The MFC's nominal thickness is roughly $0.3 \mathrm{~mm}$. This is slightly less than the two ply T800 laminate which is $0.36 \mathrm{~mm}$ thick. Considering what was demonstrated in section 3.2 regarding the influence of the laminate's thickness in the final curvature and snap-through characteristics, it can be concluded that it is necessary to simulate the bonding process after the laminate has cooled down and developed its curvature freely, simulating the change on the laminate's curvature and stiffness. Schultz [11] suggests a way to deal with this problem: a frictionless contact constraint between the laminate's and the actuator's surfaces is established during the curing step. This, together with a no-separation condition, allows the actuator to "slip" during this step thus not interfering with the development of the shape. Next, the contact constraint is changed to "rough" contact herewith attaching the MFC to the laminate (Figure 3-16).

This procedure was implemented in an Abaqus model. An intermediate *Static, General step had to be created to introduce the change in contact properties (*Model change). This model change function is not available in a *Static, Riks analysis. This solution, although theoretically correct, leads to many problems during analysis because of the complex contact constraint. In the first increments of the curing step, the patch had a tendency to slip out of position thus compromising the subsequent steps of the analysis 

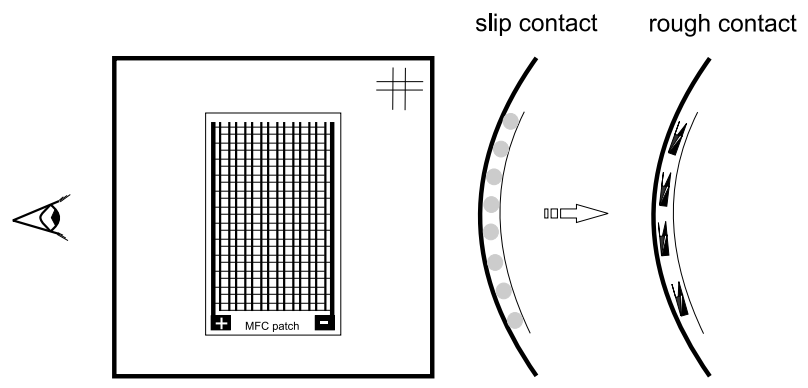

Figure 3-16: Schematics of the solution proposed by Schultz

An alternative method to solve the problem of virtually bonding the actuator to the laminate was developed and implemented. This method uses temperature dependent elastic properties for the MFC. The key is to realize that one can impose a temperature field to the laminate and the MFC model independently. The stiffness effects of the patch during cure are postponed until room temperature is reached (see Figure 3-17).

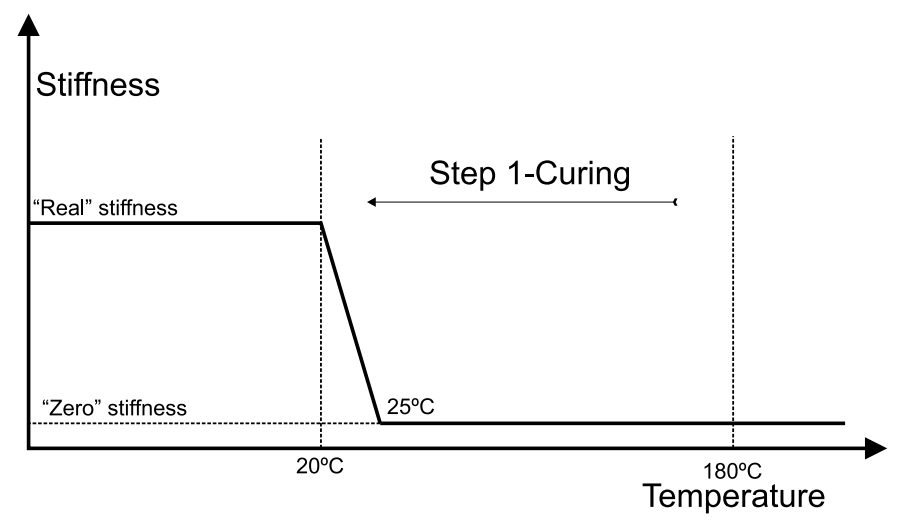

Figure 3-17: Variation of the MFC's elastic properties with temperature

The initial temperature of $180^{\circ} \mathrm{C}$ is applied to the laminate and the patch. The patch remains relatively stress-free because of the very low stiffness values and null thermal expansion coefficients. When room temperature is reached (at about $25^{\circ} \mathrm{C}$ ) the stress field in the patch increases significantly because of the sudden increase in stiffness to its real values. The thermal expansion coefficients remains unchanged. The redistribution of stress in the laminate/actuator system 
causes a slight change in curvature and shape of the laminate. This can easily be seen in figure $3-18$.

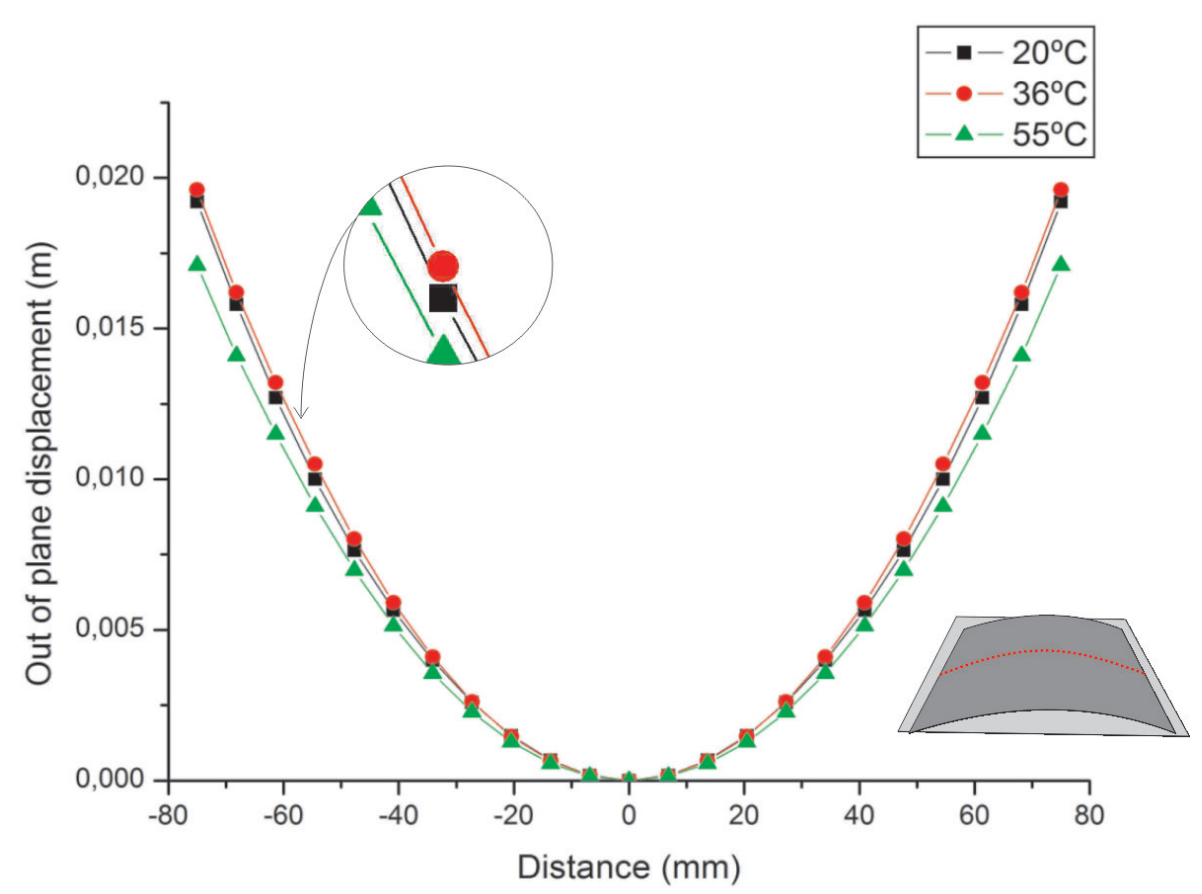

Figure 3-18: Development of curvature during cool down.

In this plot the final phases of the cool down process can be observed through the out of plane displacements of the middle of the plate. This is shown as a dashed red line in the inset schematics. As the stiffness of the patch starts to increase, the laminate must readjust its curvature. Although the temperature is decreasing, the laminate is actually loosing some of its curvature. 


\subsubsection{Model description}

The models used for this study were the same as the ones used for the study of the curvature development and the snap-through force. To simulate the MFC patch, shell elements were used and only the active area of the patch was represented. The patch was placed in the centre of the laminate and the two surfaces were separated by $0.338 \mathrm{~mm}$ to account for the thickness of both laminate and MFC.

$$
\frac{1}{2} t_{M F C}+\frac{1}{2} t_{l a m}=\frac{0.3}{2}+0.188=0.338 m m
$$

The elastic properties of the MFC patch were taken from the manufacturer's literature to be:

\begin{tabular}{ll}
\hline Property & Value \\
\hline$E_{1}$ & $30.34 \mathrm{GPa}$ \\
$E_{2}$ & $15.86 \mathrm{GPa}$ \\
$\nu_{12}$ & 0.31 \\
$G_{12}$ & $5.52 \mathrm{GPa}$ \\
$\alpha_{1}$ & $0.75 \times 10^{-6}$ \\
\hline
\end{tabular}

Table 3.9: Mechanical properties of the MFC

At "high" temperatures $\left(T>25^{\circ} \mathrm{C}\right)$ these were reduced to:

\begin{tabular}{ll}
\hline Property & Value \\
\hline$E_{1}$ & $10 \mathrm{~Pa}$ \\
$E_{2}$ & $10 \mathrm{~Pa}$ \\
$\nu_{12}$ & 0.001 \\
$G_{12}$ & $10 \mathrm{~Pa}$ \\
$\alpha_{1}$ & 0 \\
\hline
\end{tabular}

Table 3.10: Artificial mechanical properties of the MFC

Nonzero values were introduced to avoid numerical instabilities. This approach was considered acceptable as the stress field present in the MFC during cool down has an order of magnitude of $10^{-4} \mathrm{~Pa}$. The values of $\alpha$ do not represent the material thermal expansion coefficient but rather the free-strain per volt values that will be used later to recreate the actuation effect. The patch was connected to the laminate through a $*$ TIE constraint. This constraints rigidly 
connects the nodes on the master surface (the laminate) to the ones on the slave surface (the MFC patch). The finite element mesh is shown in figure 3-19.
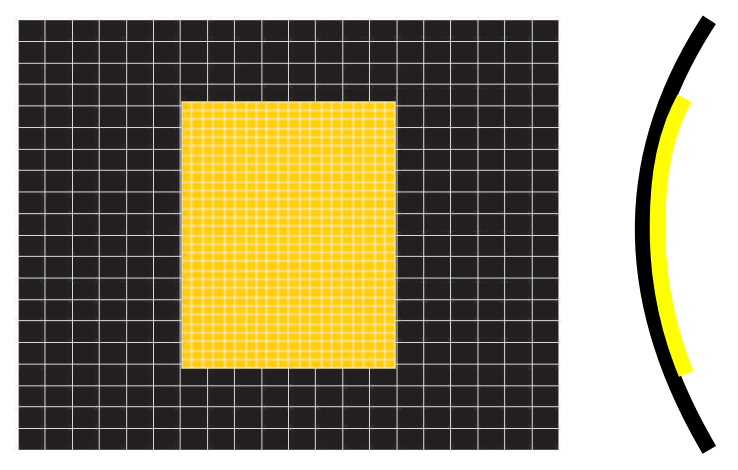

Figure 3-19: FE mesh of the laminate and the active area of MFC patch

\subsubsection{Modelling the actuation effect}

The last step of the modelling is to recreate the actuation force and use the results to design a working system. As described in chapter 1.4 the MFC is a composite piezoelectric actuator made of piezoelectric fibres encased in an interdigited electrode pattern (IDE). When the IDE is energized with a DC voltage, the fibers expand or contract depending on whether the polarity is positive or negative. This creates a in-plane strain that is transmitted to the adhesive layer and consequently to the laminate. The relation between applied voltage and strain is, for modelling purposes, assumed to be linear. The proportionality factor is called the free-strain per volt. This value, given by the manufacture of the $\mathrm{MFC}$, is in the range $0.75-0.9 \mathrm{ppm} / \mathrm{V}$ or $0.75-0.9 \mu \varepsilon / V$. If this value is used as the MFC's CTE in the fibres' direction (the material 1-direction) one can use the thermal expansion effect to simulate the piezoelectric effect simply by applying a temperature field. There is a one-to-one relation between applied temperature difference $(\Delta T)$ and the real applied voltage $(\Delta V)$ to the patch. Using the method described above to predict the stiffness change of the system and using the free-strain per volt value as the MFC's CTE one can gain insight 
into the required voltage to produce snap-through. The Riks method can be used again in the second step of the analysis as there are neither piezoelectric elements nor model changes used. To better control the analysis process a limit LPF should be set to 1 and the temperature field applied in this step must be such that the difference between it and the "dead load" equals desired applied temperature/voltage.

For example, considering that an MFC 8528 is being bonded to a $\left[0^{\circ} / 90^{\circ}\right]_{T}$ square $150 \mathrm{~mm} \times 150 \mathrm{~mm}$ AS4 laminate to test if it is able to produce snapthrough. The first analysis step in the curing step. The initial temperature must be set to, for example $10180^{\circ} \mathrm{C}$. In the curing step a temperature difference of $-160^{\circ} \mathrm{C}$ must applied to both the laminate and the patch. Thus, the final temperature is $10020^{\circ} \mathrm{C}$ (Figure $3-20$ ). This is a *STATIC step with nonlinear

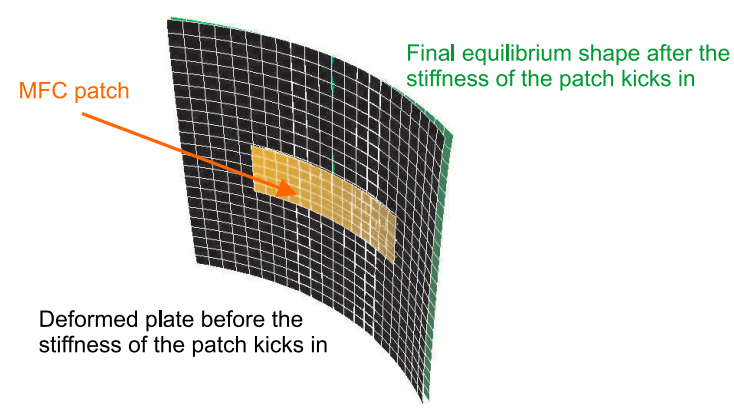

Figure 3-20: FE mesh of the laminate and the active area of MFC patch after the curing step

geometric deformations. The definition of the material properties must be shifted accordingly. The second analysis step is a Riks step. A temperature field of $8520^{\circ}$ $\mathrm{C}$ is applied exclusively to the MFC patch thus creating a temperature difference of $1500^{\circ} \mathrm{C}$ at the end of the step. The MFC's maximum operating voltage is 1500 Volts. In the Riks parameters the maximum LPF is set to 1. After the analysis runs, it becomes clear that this patch is not sufficiently powerful to promote snap-through. The edges of the plate moved as little as $3 \mathrm{~mm}$ in the out of plane direction (Figure 3-21). This type of analysis was done for a large number of combination between MFC patch sizes, orientation, laminate lay-up and size. 


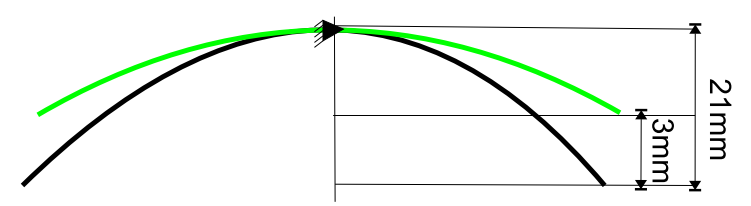

Figure 3-21: Schematics of the insufficient actuation power

\subsubsection{Discussion of results}

To evaluate the possibility of using MFC actuators to trigger the snap-through several combinations of material thickness, actuator size and number were modelled. Moisture effects were also considered. Figure 3-22 lists the different combinations modelled.

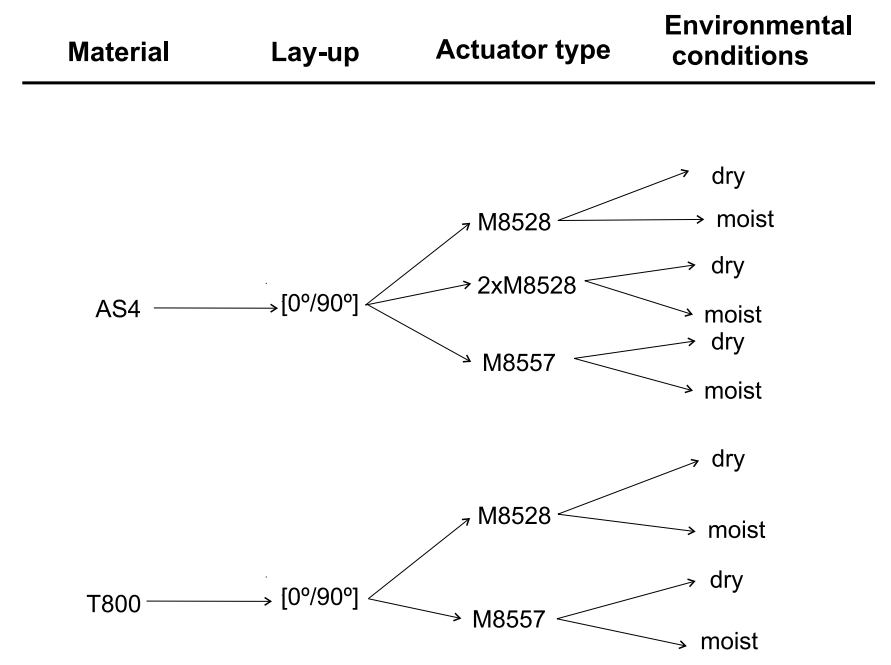

Figure 3-22: Design tree of the FE models analyzed

Both dried and moistened conditions were analyzed separately. The goal was to verify whether a given combination would work better or worse given a specified moisture content. While intuition tells that a moistened plate would be easier to snap because the snap-through loads are considerably lower than in a dried one, such a plate would also have a reduced curvature and thus be more sensitive to the change in curvature due to the MFC. The MFC patch can have a more significant effect on the laminate's bi-stability to the extent of even disrupting it 
completely. This was the case of the first set of experiments where the presence of the MFC patch and the "thick" adhesive layer turned a bi-stable laminate into a meta-stable one (Chapter 2). Based on the FE results of these models a "winning combination" was chosen as the one most likely to produce a working morphing plate. There were considerable simplifying assumptions introduced into the models (neglecting the adhesive layer and assuming a linear behaviour of the MFC are some of the critical ones). Considering also the manufacturing and the material properties' uncertainties the fact that a combination worked well in the FE model was no guarantee that it would work in the real plate. The criteria used to judge the "winning combination" were three-fold:

- Preference should be give to a laminate similar to the one used one published work.

- Curvature of the laminate after bonding the MFC patch should not be greatly reduced.

- The required snap-through voltage should be around or below $1500 \mathrm{~V}$.

In order to accept a possible candidate, complete snap-through had to occur. This means that the LPF curve had to peak and drop to zero as shown in figure $3-23$. 


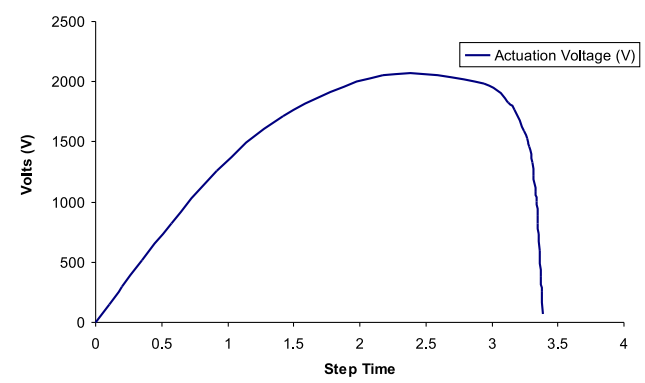

Figure 3-23: Typical LPF plot for a successful snap-through

In other cases the load curve looked like the one in Figure 3-24. This happened in the T800, M8557 and for most of the moistened laminate plates, i.e. in the cases where the bending stiffness is reduced.

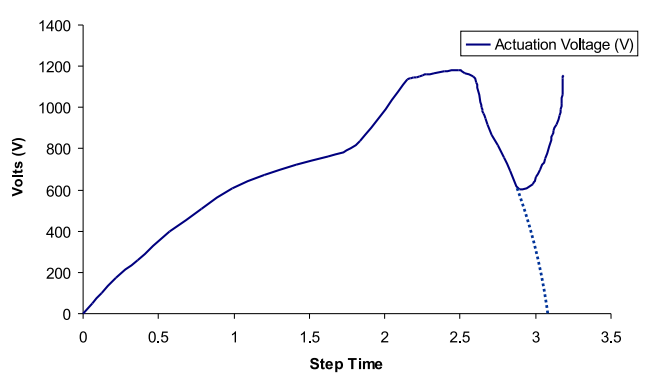

Figure 3-24: LPF curve for the T800 fibre with M8557 actuator 
These plots can have different interpretations. In the first portion of the curve the MFC is clearly driving the laminate. After the critical load is reached, it is the laminate that drives the patch as is typical for a snap-through. However, at around $600 \mathrm{~V}$ both the systems appear to reach an equilibrium point. Here, an inversion occurs and, again, the MFC starts driving the laminate. The FE code is unable to reach a solution at the second peak. It could be that a secondary bifurcation is occurring. A secondary bifurcation has been seen in previous models (see section 3.3.2) and observed experimentally.

There are conflicting effects at work when a patch is bonded to the laminate. If the laminate is large (larger than $200 \mathrm{~mm}$ for example) even the largest MFC commercially available will not be powerful enough to induce snap-through. But, if the laminate's size is reduced to bellow $150 \mathrm{~mm}$ the presence of the bonded patch will disrupt its bi-stability or bring to the verge of instability. It is also possible that a combination will work smoothly with a dried laminate and not work at all with a moistened one. An equilibrium compromise between these two competing effects must be found. This can be readily understood in Figure 3-25.

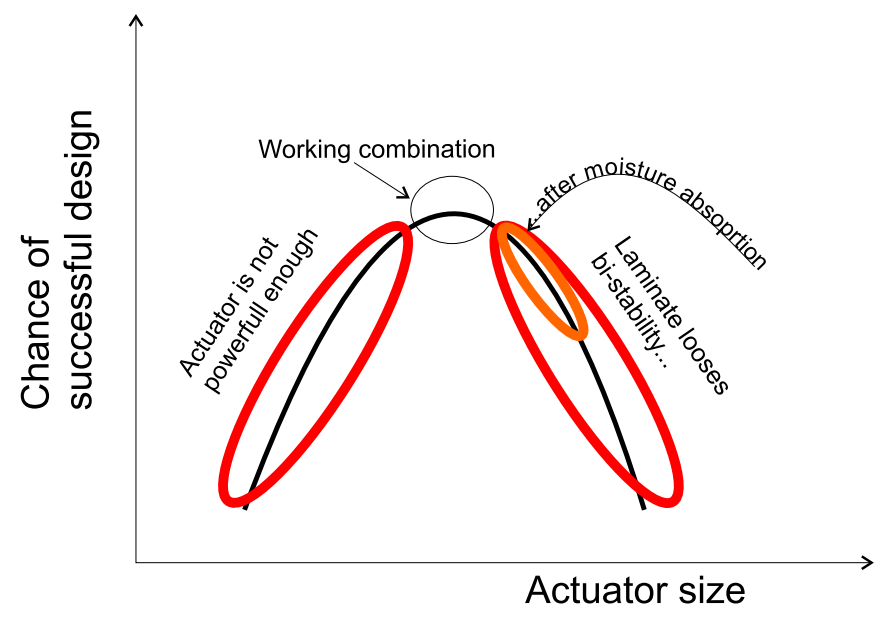

Figure 3-25: Design curve of MFC actuated bi-stables plates

For a given laminate size there is range of MFC sizes that will not produce enough actuation force to trigger snap-through. However, slightly larger ones will work on a dried laminate but not after is has absorbed moisture. Even larger 
ones will completely destroy the bi-stability by affecting the laminate's bending stiffness. Somewhere in the middle between small and large there is an optimum size that will not significantly affect the curvature and still be powerful enough to produce snap-through.

The first model, AS4 $\left[0^{\circ} / 90^{\circ}\right]_{T}$ M8528, did not suffer from loss of bi-stability in both the dry and the moistened plate. There was complete snap-through which means that the patch did not influence too much the laminate's stiffness. However the predicted snap-through voltage is $2052 \mathrm{~V}$ for both of them. With two patches, complete snap-through also occurs but at a significantly higher voltage of 2700 V. The moistened model did not converge into a cylindrical shape despite the geometric imperfections. It was assumed that the two patches would probably destroy the laminate's curvature. The larger MFC, the M8557 patch, looked more promising as the predicted activation voltage was $2000 \mathrm{~V}$ for the dry condition, but dropped to $1509 \mathrm{~V}$ in a moistened laminate. Branching was found as part of the solution for this particular case but the LPF dropped to zero (Figure 3-26)

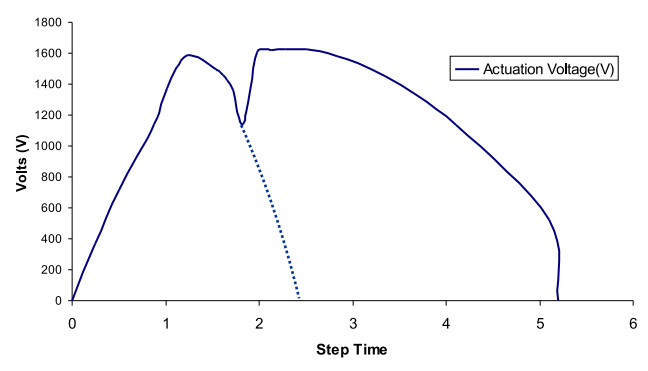

Figure 3-26: LPF plot for the moistened AS4 fibre laminate with an M8557 actuator

This means that the patch did not destroy bi-stability and was probably the right size. Using thinner prepreg, like the T800 fibre also looked promising as the peak voltage was $1950 \mathrm{~V}$ but dropped to less than $300 \mathrm{~V}$ after moisture effects were considered but branching also occured. It is important to note that the simulation of the actuation was based on a proportionality factor (free strain per volt) of $0.9 \mu \varepsilon / V$. As explained in chapter 1.4 the voltage/strain curve is very 
nonlinear. Using this first order approximation for the actuator underestimates the real applied strain. Because a higher order approximation is impossible to do with this FE approach other models were developed in which the proportionality factor was increased to $1.5 \mu \varepsilon / V$. With this new value, the peak load dropped to 1100 Volts. Figure 3-27 shows the evolution of the strain field in the laminate during the curing stage, and during the actuation stage. The order or magnitude for the principal stress in the actuation zone is $40 \mathrm{MPa}$ which is in accordance with the data specified by the MFC manufacturer. It's presence can be clearly seen by the strain distribution.
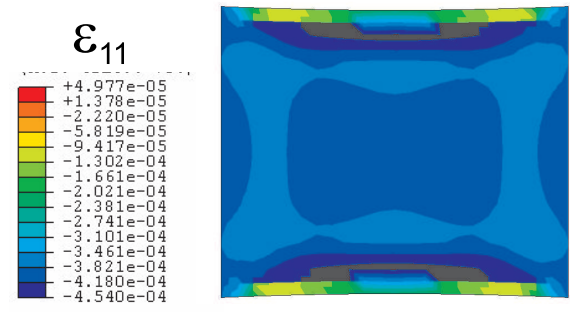

After cure, before bonding the actuator

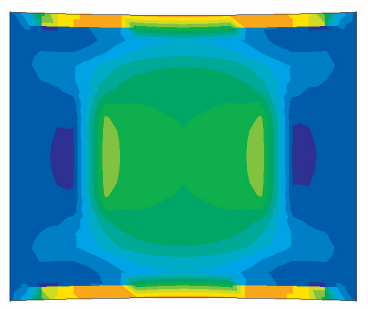

After cure, after bonding the actuator

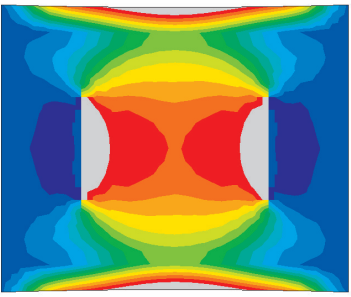

In-plane strain caused by the actuator

Figure 3-27: Contour plots of the strain field caused by the MFC 


\subsection{Additional FE Models}

\subsubsection{Rectangular $\left[0^{\circ} / 90^{\circ}\right]$ slab}

If a large rectangular slab with a width to length ratio of, for example, 1:10 is laminated with a $\left[0^{\circ} / 90^{\circ}\right]$ stacking sequence, another interesting bi-stable structure is produced. Nonlinear FE was used to study the cured shape, 3-31
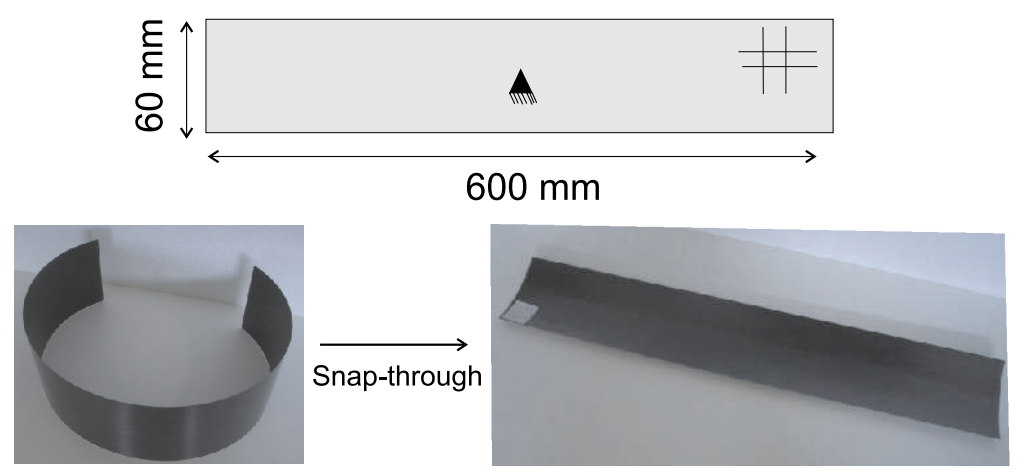

Figure 3-28: Rectangular asymmetrical laminate. Pictures of the two stable states and the FE model.

The particular aspect of this laminate is that one of its shapes is mostly a flat rectangular slab with little curvature in its longitudinal direction. It could be used as a deployable boom where the curled shape would function as a stowed configuration and the flat as a deployed one. It is difficult to analyze this geometry because of the very large displacements that the edges of the plate suffer and because of the complex snap-through that occurs. When the applied load reaches 0.4 Newton which represent roughly the shape shown in figure the code is unable to continue.

The load increments decrease until they reach zero and the program stops. Many different boundary conditions and load combinations were used to trigger snap-through but without success. An explicit analysis will be needed to overcome this difficulty. 

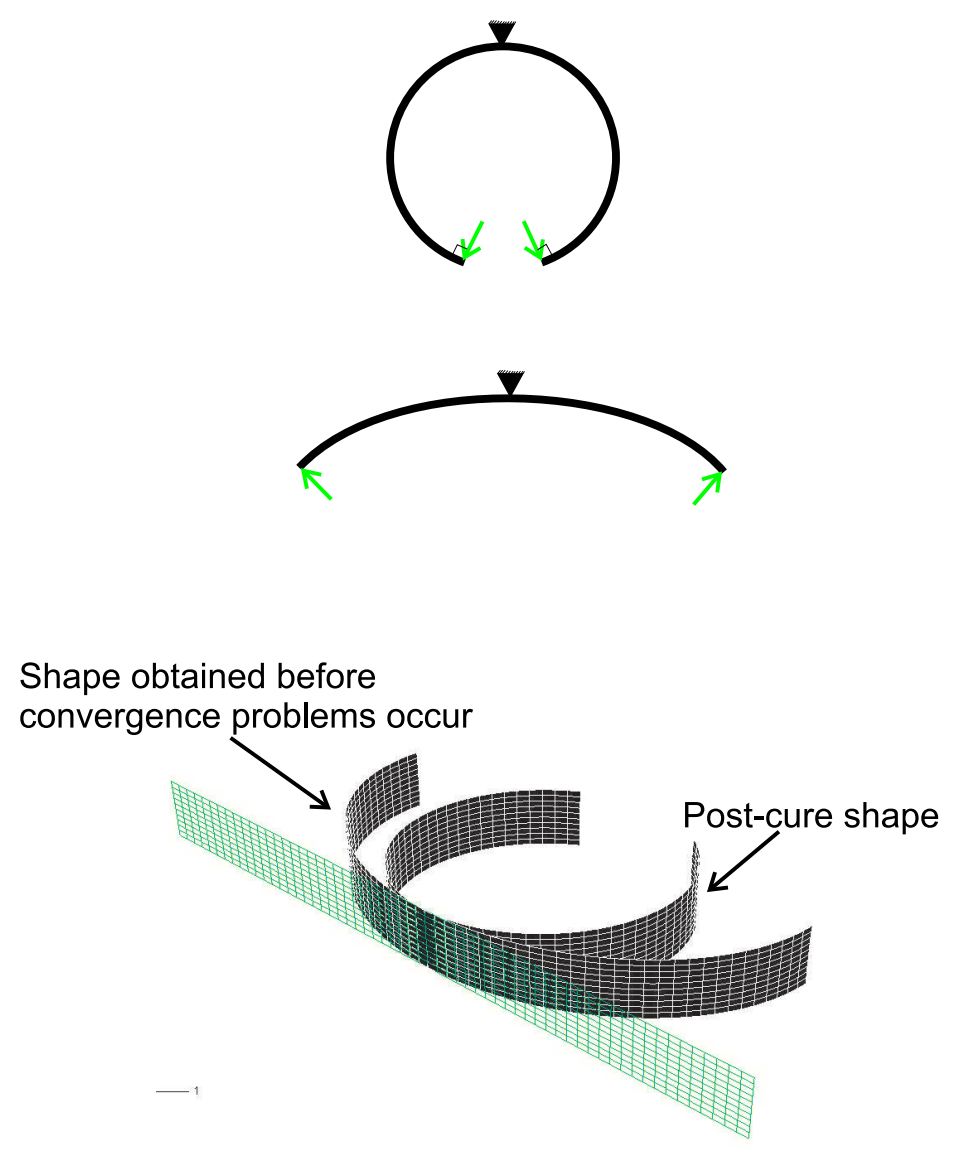

Figure 3-29: Schematics of the two stable states.

\subsubsection{Combined $\left[0^{\circ} / 90^{\circ}\right]+\left[0^{\circ} / 45^{\circ}\right]$ laminate}

This laminate is made stacking a $90^{\circ}$ ply and a $45^{\circ}$ ply side by side but over a $0^{\circ}$ ply. This laminate was manufactured with the single purpose of verifying that complex layups could be modelled accurately by FE. The results were very encouraging. It was possible to correlate the two table shapes with those obtained with $\mathrm{FE}$ analysis. Interesting about this laminate is that the $\left[0^{\circ} / 90^{\circ}\right]$ cell remains mostly flat in both states while allowing the $\left[0^{\circ} / 45^{\circ}\right]$ cell to assume both states almost freely. 


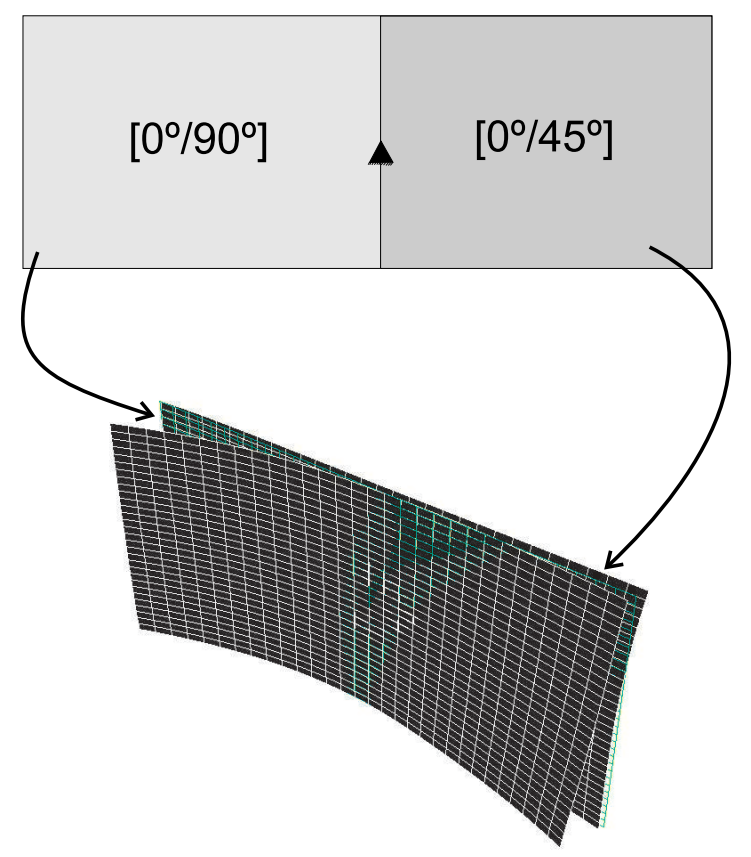

Figure 3-30: The mixed laminate before and after snap-through.

\subsubsection{Chess board laminate}

This laminate is actually made of four $\left[0^{\circ} / 90^{\circ}\right]$ cells each rotated by $90^{\circ}$ with regard to the neighboring cells. The manufacturing process of this laminate is very difficult. 


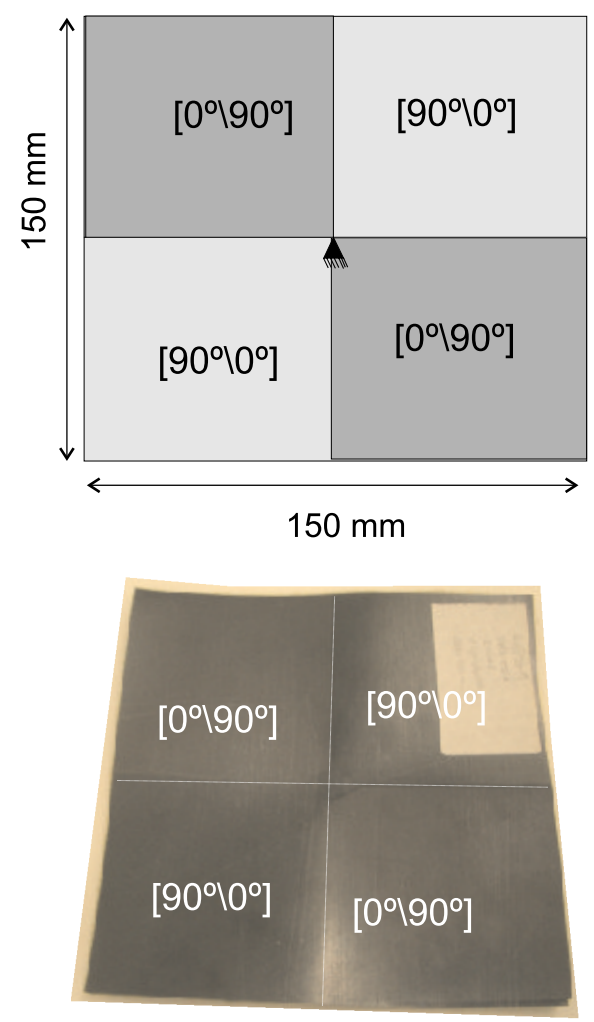

Figure 3-31: Rectangular asymmetrical laminate. Pictures of the two stable states and the FE model.

Modelling the cured shape of this laminate was only possible with an explicit code. Implicit methods showed many convergence problems. Figure 3-32 shows the three principal curvatures of the cured shapes. 


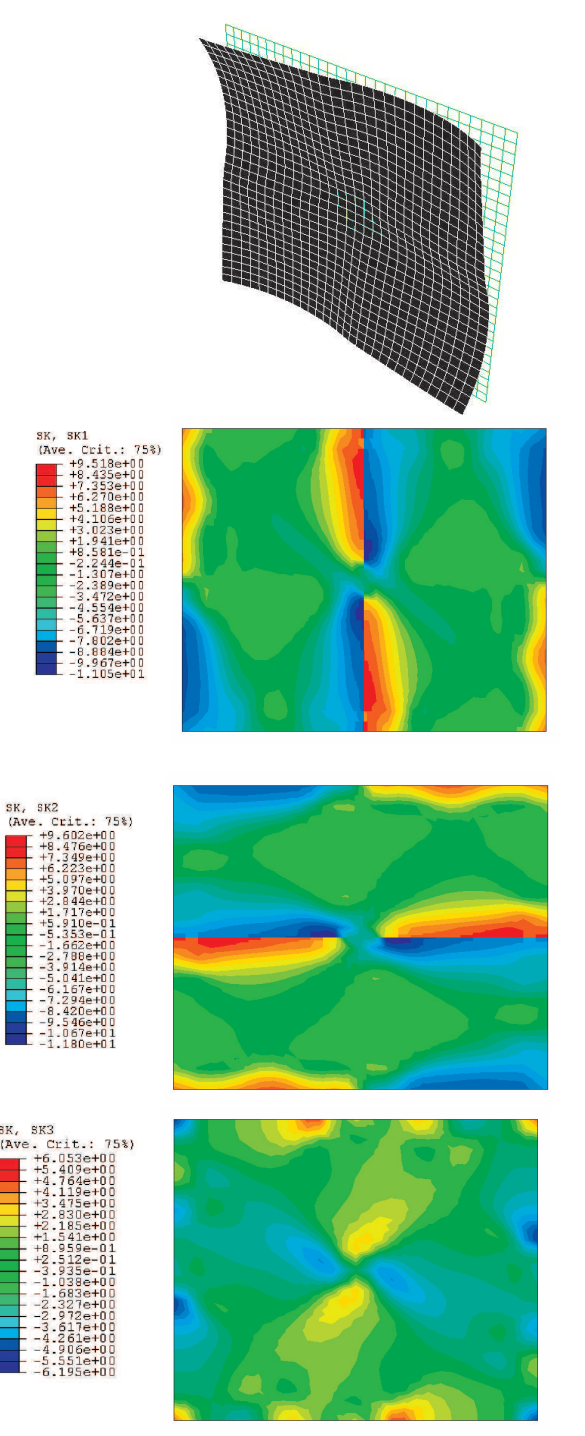

Figure 3-32: Chess board laminate curvatures.

There are severe discontinuities at the cells' borders but the overall shape is interesting. The laminate has two very similar stable shapes. It is possible to repeat this four-cell pattern as many times as needed in order to produce a larger plate with many stable shapes. The difference in reflection indexes of fibre and matrix makes the laminate look like a chess board with dark black and greyish cells. 


\subsubsection{Laminate with two MFC's}

To establish what would happen when two MFC were bonded to each side of the laminate, another FE model was created. The goal was to verify what happens to the stiffness of the laminate when both MFC's are added to it, Figure 3-33.

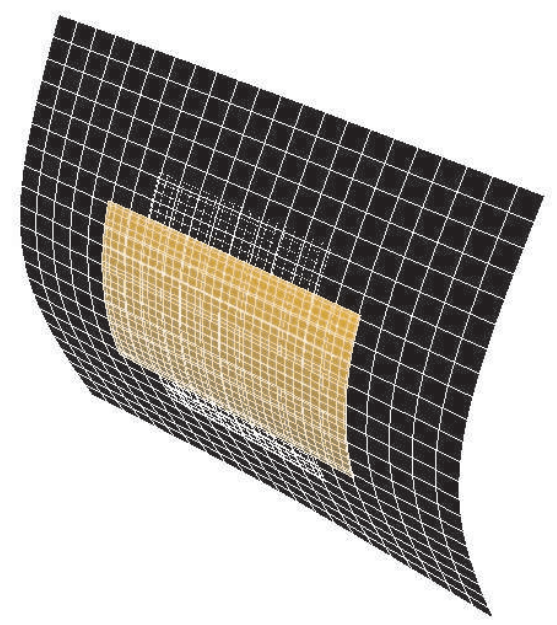

Figure 3-33: Laminate with two MFC bonded to each side.

The analysis program was also unable to find a solution for the post-cure shape using implicit methods. This probably means that the patches have an overwhelming effect on the laminate's stiffness. An explicit model should be develop to verify this. Nevertheless, it is an indication that bonding two patches may not be a reasonable solution.

\subsection{Conclusions}

The development of these FE models allowed to gain some insight on the behaviour the the laminate with a thick patch bonded to its surface. The data obtained in this analysis was unavailable in the literature survey, although there is considerable work done in the prediction of post-cure shapes of unsymmetrical laminates. It is, however, true, that the fact that one is unable to visualize the 
two or multiple stable shapes without a nonlinear step in between, is a significant limitation that analytical models based on Rayleigh-Ritz methods do not have. The computational costs of both approaches are, of course, not comparable. Nevertheless the FE approach is much more versatile for design purposes as it allows the investigation of complex layups and three dimensional geometries. Inclusion of piezoelectric actuators is also very simple and does not add much to the computational costs.

Based on these results, it was decided to bond an M8557 MFC actuator to a square $150 \mathrm{~mm} \times 1500 \mathrm{~mm}$ laminate. Details of this process and the experimental results are discussed in the following chapter. A very important aspect that was not considered in these first models is the adhesive layer between the patch and the laminate and the way the it is cured (position and temperature). This turned out to be a critical success factor that required some additional modelling effort also described in the following Chapter. 


\section{Chapter 4}

\section{Experimental results}

As mentioned before a much thinner pre-preg $(0.13 \mathrm{~mm})$ was used in the second set of experiments. This time a larger MFC patch was acquired to replace the smaller, rectangular ones. The bi-stable plates were manufactured in the same way described in chapter 2 . This time however, besides the $\left[0^{\circ} / 90^{\circ}\right]$ laminates, additional stacking sequences and geometries were produced in order to increase the number of different combinations to validate the FE models.

\begin{tabular}{ccc}
\hline Material & Size & Stacking sequence \\
\hline T800-977-2 & $100 \mathrm{~mm} \times 100 \mathrm{~mm}$ & {$\left[0^{\circ} / 90^{\circ}\right]$} \\
T800-977-2 & $150 \mathrm{~mm} \times 150 \mathrm{~mm}$ & {$\left[0^{\circ} / 90^{\circ}\right]$} \\
T800-977-2 & $200 \mathrm{~mm} \times 200 \mathrm{~mm}$ & {$\left[0^{\circ} / 90^{\circ}\right]$} \\
T800-977-2 & $250 \mathrm{~mm} \times 250 \mathrm{~mm}$ & {$\left[0^{\circ} / 90^{\circ}\right]$} \\
T800-977-2 & $300 \mathrm{~mm} \times 300 \mathrm{~mm}$ & {$\left[0^{\circ} / 90^{\circ}\right]$} \\
T800-977-2 & $150 \mathrm{~mm} \times 150 \mathrm{~mm}$ & {$\left[0^{\circ} / 45^{\circ}\right]$} \\
T800-977-2 & $150 \mathrm{~mm} \times 150 \mathrm{~mm}$ & {$\left[45^{\circ} /-45^{\circ}\right]$} \\
E-Glass-977-2 & $150 \mathrm{~mm} \times 150 \mathrm{~mm}$ & {$\left[0^{\circ} / 90^{\circ}\right]$} \\
E-Glass-977-2 & $150 \mathrm{~mm} \times 150 \mathrm{~mm}$ & {$\left[0^{\circ} / 0^{\circ} / 90^{\circ} / 90^{\circ}\right]$} \\
\hline
\end{tabular}

Table 4.1: Summary of the plates manufactured in the second experimental campaign.

Measuring the critical load was the next step in the experimental programme. A tensile test machine used with displacement control could be used to measure not only the critical load but also to capture the unloading portion of the loaddisplacement curve. Since the expected loads are very low, a small load cell is needed in order to have a reasonable resolution. As an alternative to this, and 
because only the critical loads are of interest, a much simpler method was used instead. A small hole was drilled in the center of the laminates and a container full of sand was hung from it through a wire, Figure $4-1$. The force was increased by adding sand to the container until snap-through occurred.

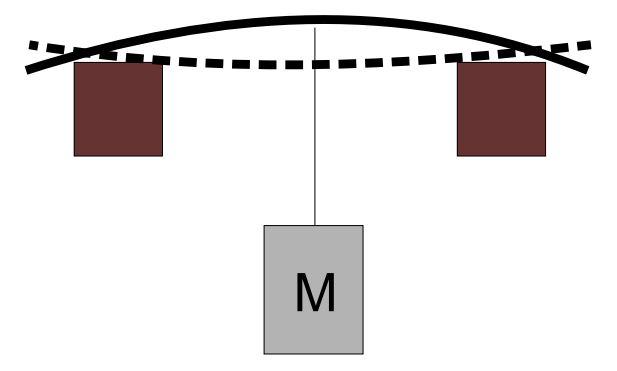

Figure 4-1: Measurement of the critical loads.

The container was weighted and the critical force was registered. The results are listed in table 4 .

\begin{tabular}{cccc}
\hline Material & Size & Stacking sequence & Critical Force (N) \\
\hline AS4-8552 & $150 \mathrm{~mm} \times 150 \mathrm{~mm}$ & {$\left[0^{\circ} / 90^{\circ}\right]$} & 7.9 \\
T800-977-2 & $150 \mathrm{~mm} \times 150 \mathrm{~mm}$ & {$\left[0^{\circ} / 90^{\circ}\right]$} & 2.4 \\
T800-977-2 & $200 \mathrm{~mm} \times 200 \mathrm{~mm}$ & {$\left[0^{\circ} / 90^{\circ}\right]$} & 2.3 \\
T800-977-2 & $300 \mathrm{~mm} \times 300 \mathrm{~mm}$ & {$\left[0^{\circ} / 90^{\circ}\right]$} & 3.1 \\
T800-977-2 & $150 \mathrm{~mm} \times 150 \mathrm{~mm}$ & {$\left[0^{\circ} / 45^{\circ}\right]$} & 1.9 \\
\hline
\end{tabular}

Table 4.2: Summary of the measured critical loads.

The adhesive layer was not included in the FE models and because of the initial results described in Chapter 2, special attention was paid to it in this second round of experiments. To minimize costs, a low cost replacement for the MFC patch was used. It should have approximately the same thickness and Young modulus. A plexiglass sheet was cut to the size of MFC 8557 patch and bonded to the laminate with different adhesives and different procedures.

1. $3 \mathrm{M}$ DP460 low viscosity adhesive cured in vacuum at $60 \mathrm{C}$

2. $3 \mathrm{M}$ DP460 adhesive cured in a vacuum at $60 \mathrm{C}$ in the second stable state

3. Film adhesive cured at $60 \mathrm{C}$ 
The 3M DP460 epoxy adhesive has a lower viscosity than the Araldite Rapid and does not cure at room temperature. There is more time to position the patch and the bondline thickness is reduced as well. Ultimate control of bondline thickness can be achieved by using film adhesive. The test performed with plexiglass showed that the most promising combinations was number 2. Figure 4-2 shows the laminate with the actuator bonded to it. If the resin is allowed to cure in the $\mathbf{A}$ state, the stress field in the resin will work in the opposite direction to the actuation load, i.e. it will tend to keep the laminate in the $\mathbf{A}$ state. If, on the other hand, it is cured in the $\mathbf{B}$ state it can be manually snapped back to the $\mathbf{A}$ state and the stress field in the resin will be favorable to the actuation load. Of course, there is a reduction in curvature which, in some cases, may even influence the bi-stable behaviour.

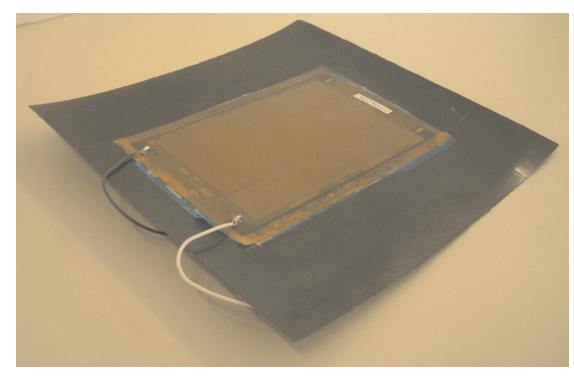

Laminate in the A state

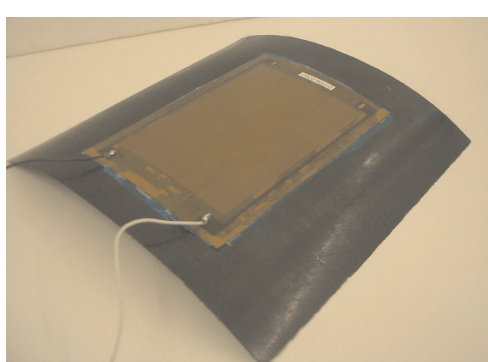

Laminate in the $\mathbf{B}$ state

Figure 4-2: Morphing plate in both states

The area where the patch was bonded was taped of from the rest of the laminate to reduce the amount of adhesive and the bond layer thickness. The morphing plate was tested at different voltage levels. Snap-through was achieved with as little as $390 \mathrm{~V}$ in the moistened conditions. Several effects need to be taken into account:

1. The MFC is a capacitor with very high resistance. The lower the voltage the longer it takes for it to reach its maximum force (for that voltage level).

2. It is difficult to evaluate the true moisture content of the laminate. As time 
passes it becomes increasingly easier to snap the laminate. After about three months the laminate loses bi-stability and must be dried again.

3. The MFC voltage/strain behaviour shows hysteresis. This means it is history dependent and it is difficult to predict the actual strain that is to be expected for a given voltage level. 


\section{Chapter 5}

\section{Conclusions}

The morphing concept based on multi-stable composite laminates looks promising. The main advantages of morphing structures based on multi-stable laminates are that it is possible to have one single structural component with two or more different geometric shapes, performing differently but with no need of a constant actuation power being provided. Their load carrying capability is indicated by the snap-through load type (bending moment, point force, in-plane strain, etc) and intensity. It is difficult to find a limit for the different combinations of asymmetrical stacking sequence, material types and geometries that result in multi-stable structures.

It has been shown that non-linear FEA is capable of predicting with accuracy not only the curvatures developed during the curing of these laminates but also the snap-through loads and alternative stable shapes. A numerical problem arises when perfectly square laminates or complex lay-ups like the chess-board laminate are analyzed. In this case, either geometric imperfections or dynamical methods should be used. There are clues that the laminate undergoes a thermal buckling process in the initial temperature difference increments. The existence of negative eigenvalues of the stiffness matrix are indications of just that. Eigenvalue buckling analysis with a thermal load were performed to try to find the different shapes but without success.

Different actuator technologies can be used to trigger snap-through of multi- 
stable laminates. A summary of the requirements for such an actuator is listed:

1. Powerful enough to reach the snap-through load of the underlying structure.

2. Low power consumption and easy to activate.

3. Reliable (i.e. the relation between input signal and output result should be well established).

4. Not influence the behavior of the structure it is actuating on.

5. Damage tolerant

This work has shown how simple approximations can yield good results in terms of recreating the presence and actuation force of an MFC actuator patch. The models have been used to design and test a working morphing structure and good correlation with experimental results has been obtained. The source for discrepancies has been identified. Long term behavior of multi-stable laminates has also been addressed by successfully including the hygro-thermal-elastic effects into the FE models. Other forms of actuation that satisfy most, if not all, of the above mentioned requirements and that can be modelled with relative ease are SMA wires. It was shown that it is possible to predict the necessary pull force that an SMA wire must exert to trigger snap-through. Preliminary tests already showed that it is possible to use SMA to trigger bidirectional snap-through.

The MFC patch is a step forward towards the increase of performance over traditional waffer type PZT actuators. By using the fibres' $d_{33}$ mode of activation it is possible to attain blocking stresses of $40 \mathrm{MPa}$. The forces proved to be enough to induce snap-through of a square $150 \mathrm{~mm}$ x150 $\mathrm{mm}\left[0^{\circ} / 90^{\circ}\right]$ laminate. It was shown that the size and thickness of the patch as well as the way it is bonded to the structure has a large influence on the laminate stiffness and buckling behaviour. This influence can be either prejudicial or beneficial. It the system is well designed the stiffness reduction will be beneficial and will reduce the force requirements on the MFC. It will eventually be able to activate the snap-through. If not, the laminate will become meta-stable with the MFC and 
the adhesive layer forcing it to reset itself to the original curved shape. The FE models also suggest that bonding an additional MFC to the other side of the laminate would not be a feasible solution for bi-directional snap-through. SMA wires appear to be much more effective for this purpose. Past research has already demonstrated that SMA wires can trigger snap-through. Preliminary experiments with a $\left[+45^{\circ} /-45^{\circ}\right]$ laminate and two wires activated by a timing circuit has produced an autonomous morphing laminate that can be snapped both ways. 
5. CONCLUSIONS 


\section{Chapter 6}

\section{Future Work}

There are still a lot of unanswered questions regarding the curvature development and bi-stability behaviour of asymmetrical composite laminates. The thermal buckling clue is one that should be pursuited. It should be possible to use nonlinear FE based eigenvalue buckling analysis to predict the several different stable and unstable shapes. As mentioned above, the number of different combinations that can be used to produce multi-stable laminates is overwhelming. Many of such combinations can yield interesting shapes and applications. Further investigations of these combinations is required and a simple procedure should be derived to characterize and analyze them. It is foreseeable that these asymmetrical laminates will be integrated into symmetrical structures or interface with traditional materials. Initial experiments allowed to conclude that in some case this interface can inhibit the snap-through behaviour. The problem of interfacing with flat surfaces has not yet been addressed and is crucial if industrial applications are sought for this technology. Perhaps the most ambitious task that this project was unable to solve was that of embedding the actuator into the structure. Hollow piezoelectric fibres, as discussed in Section 2 look like good candidates as they solve many of the issues that embedding the actuators arise, specifically how to activate them. The question subsists of whether they are powerful enough to provided the required strain, provided they can be effectively coated in the inside, embedded into a carbon epoxy pre-preg, co-cured with it and activated using the 
carbon fibres as electrodes. Reliability issues would then have to be considered as the piezo fibres would probably act as delamination initiators and reduce the laminate's damage tolerance. Developments in metallurgy promise to provide researchers with very high temperature (VHT) SMA alloys. These VHT alloys have a transformation temperature in the $150^{\circ} \mathrm{C}$ to $200^{\circ} \mathrm{C}$ range. This means that, in principle thin wires could also embedded in the pre-preg and co-cured at $180^{\circ}$ with it without the need of retaining assemblies. The problem of electrical contact between the wires and the carbon fibres still needs to e addressed. 


\section{Bibliography}

[1] R.W. Wlezien, G.C. Horner, A. M. S. P. M. S. R. S. J. S., "The Aircraft Morphing Program," 39th Structures, Structural Dynamics and Materials Conference and Exhibit, edited by AIAA, AIAA, 1998.

[2] Jha, A. K. and Kudva, J. N., "Morphing Aircraft Concepts, Classifications, and Challenges," Industrial and Commercial Applications of Smart Structures Technologies, 2004.

[3] Cannon, D. B. B. J., "Piezoceramic Hollow Fiber Active Composites," Composites Science and Technology, Vol. 64, 2004, pp. 245-261.

[4] R. Brett Williams, Daniel J. Inman, M. R. S. and Hyer, M. W., "Nonlinear Tensile and Shear Behavior of Macro Fiber Composite Actuators," Journal of composite materials, Vol. 38, 2004, pp. 855-869.

[5] Kevin Potter, Paul Weaver, A. A. S. S. S., "Phenomena In The SnapThrough Bifurcation Of Unsymmetric Composite Plates," .

[6] Lu, K.-J. and Kota, S., "Design of Compliant Mechanisms for Morphing Structural Shapes," Journal of intelligent material systems and structures, Vol. 14, 2003, pp. 379-391.

[7] Ramrakhyani, D., G. L. M. F. and Bharti, S., "Aircraft Structural Morphing Using Tendon Actuated Compliant Cellular Trusses," AIAA, 2004.

[8] Straub, F. K., "A Feasibility Study of Using Smart Materials for Rotor Control," Smart Materials and Structures, Vol. 5, 1996, pp. 1-10. 
[9] F.K. Straub, H.T. Ago, V. A. D. D., "Development of a Piezoelectric Actuator for Trailing Edge Flap Control of Full Scale Rotor Blades," Smart Materials and Structures, Vol. 10, 2001, pp. 25-34.

[10] Schultz, M. R., Use of piezoelectric actuators to effect snap-through behavior of unsymmetric composite laminates, Ph.D. thesis, Faculty of the Virginia Polytechnic Institute and State University, 2003.

[11] Schultz, M. R., "A Morphing Concept Based on Unsymmetric Composite Laminates and Piezoceramic MFC Actuators," 2004.

[12] Marie-Laure Dano, M. W. H., "SMA-Induced Snap-Through of Unsymmetric .Ber-Reinforced Composite Laminates," International Journal of Solids and Structures, Vol. 40, 2003, pp. 5949-5972.

[13] W. Hufenbach, M. Gude, L. K., "Design of Multistable Composites for Application in Adaptive Structures," Composites Science and Technology, 2002, pp. 2201-2207.

[14] Hufenbach, W. and Gude, M., "Analysis and Optimisation of Multistable Composites under Residual Stresses," Composite Structures, Vol. 55, 2002, pp. 319-327.

[15] Dano, M.-L. and Hyer, M. W., "Thermally-induced deformation behavior of unsymmetric laminates," lnternational Journal of Solids Structures, Vol. 35, 1998, pp. 2101-2120.

[16] M. Schlecht, K. Schulte, M. W. H., "Advanced Calculation of the RoomTemperature Shapes of Thin Unsymmetric Composite Laminates," Composite Structures, Vol. 32, 1995, pp. 627-633.

[17] Kevin Potter, Marco Gigliotti, M. R. W., "Development of Curvature During the Cure of AS4/8552 [0/90] Unsymmetric Composite Plates," Composites Science and Technology, Vol. 63, 2003, pp. 187-197. 
[18] Kevin Potter, Marco Gigliotti, M. R. W., "Loss of Bifurcation and Multiple Shapes of Thin [0/90] Unsymmetric Composite Plates Subject to Thermal Stress," Composites Science and Technology, Vol. 64, 2004, pp. 109-128.

[19] Jonathan Scholey, G. W., Novel piezo-composite for morphing structures, Master's thesis, University of Bristol, 2004.

[20] Christopher Niezrecki, Diann Brei, S. B. and Moskalik, A., "Piezoelectric Actuation: State of the Art," The Shock and Vibration Digest, Vol. 33, 2001, pp. 269-280.

[21] Abaqus, Abaqus 6.4 User's Manuals, 2004.

[22] Herakovich, C. T., Mechanics of fibrous composites, John Wiley and Sons, inc, 1998.

[23] Springer, G. S., Environmental Effects on Composite Materials, Technomic Publishing Company, 1981. 